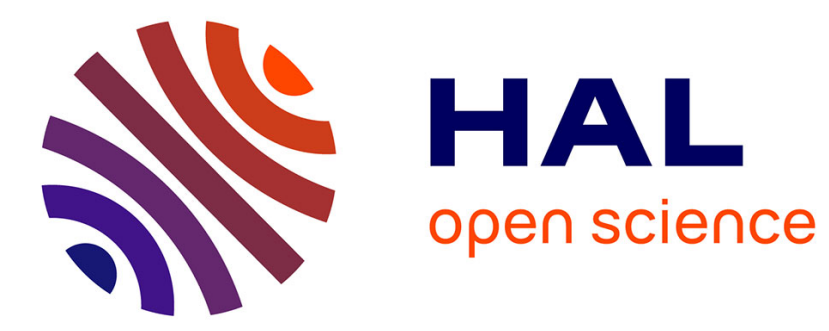

\title{
Le monde peut-il nourrir tout le monde?
}

Mohamed Ag Bendech, Francis Akindès, Gérard Azoulay, Georges Courade, Francis Delpeuch, Michel Griffon, Bernard Hubert, John Igué, Henri

Josserand, Xavier Leverve, et al.

\section{- To cite this version:}

Bernard Hubert (Dir.). Le monde peut-il nourrir tout le monde?: Sécuriser l'alimentation de la planète. pp.161, 2006. hal-02824716

\section{HAL Id: hal-02824716 https://hal.inrae.fr/hal-02824716}

Submitted on 6 Jun 2020

HAL is a multi-disciplinary open access archive for the deposit and dissemination of scientific research documents, whether they are published or not. The documents may come from teaching and research institutions in France or abroad, or from public or private research centers.
L'archive ouverte pluridisciplinaire HAL, est destinée au dépôt et à la diffusion de documents scientifiques de niveau recherche, publiés ou non, émanant des établissements d'enseignement et de recherche français ou étrangers, des laboratoires publics ou privés. 


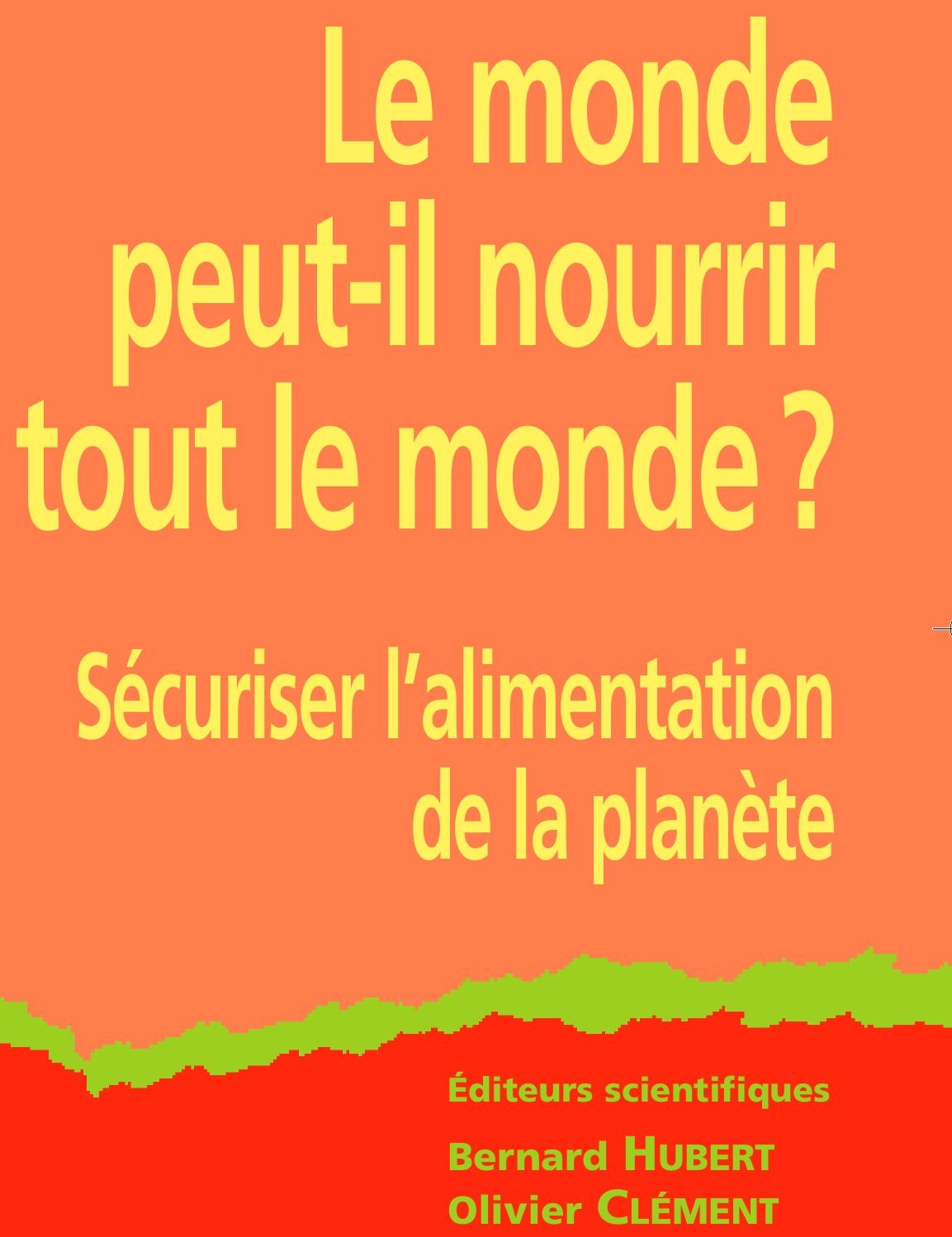

Quxe

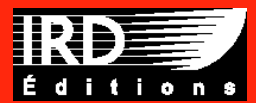




\section{Le monde peut-il nourrir tout le monde?}

Sécuriser l'alimentation de la planète 


\section{Le monde peut-il nourrir tout le monde? \\ Sécuriser l'alimentation de la planète}

Éditeurs scientifiques

Bernard HUBERT Olivier CLÉMENT

Institut de recherche pour le développement

Éditions Quæ 
Préparation éditoriale

Yolande Cavallazzi

Mise en page

Bill Production

Correction

Corinne Lavagne

Coordination, fabrication

Catherine Plasse

Maquette de couverture

Maquette intérieure

Aline Lugand - Gris Souris

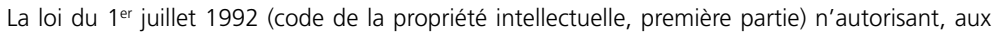
termes des alinéas 2 et 3 de l'article L. 122-5, d'une part, que les « copies ou reproductions strictement réservées à l'usage du copiste et non destinées à une utilisation collective » et, d'autre part, que les analyses et les courtes citations dans le but d'exemple ou d'illustration, " toute représentation ou reproduction intégrale ou partielle faite sans le consentement de l'auteur ou de ses ayants droit ou ayants cause, est illicite » (alinéa $1^{\text {er }}$ de l'article L. 122-4).

Cette représentation ou reproduction, par quelque procédé que ce soit, constituerait donc une contrefaçon passible des peines prévues au titre III de la loi précitée.

○ IRD, Éditions Quæ, 2006

ISBN IRD : 2-7099-1590-1

ISBN Quæ 10 : 2-7592-0008-6

ISBN Quæ 13 : 978-2-7592-0008-5 


\section{Sommaire}

Liste des auteurs . . . . . . . . . . . . . . . . . 7

Allocution d'ouverture $\ldots \ldots \ldots \ldots \ldots \ldots \ldots \ldots \ldots \ldots$

Marion GUILLOU

Introduction

Sécuriser l'alimentation de la planète . . . . . . . . . . . . 11

Bernard HUBERT

Partie 1

Comprendre les besoins alimentaires $\ldots \ldots \ldots \ldots \ldots 23$

Nourrir... le corps humain et le corps social . . . . . . . . . . . 25 José MUCHNIK

Qualité des aliments, qualité de l'alimentation ......... 43 Xavier LEVERVE

Qualifier la nutrition, les savoirs et les régulations . . . . . . . 57 Francis AKINDĖS

Partie 2

Instaurer des droits à se nourrir $\ldots \ldots \ldots \ldots \ldots \ldots 6$

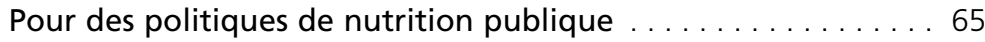
Francis DELPEUCH

L'Ifpri et sa contribution à la recherche et à l'action dans le domaine des politiques alimentaires et nutritionnelles . . . 77 Marie T. RUEL

Des politiques de nutrition

Responsabilités des politiques et des chercheurs .

Mohamed AG BENDECH 
Partie 3

Concevoir une nouvelle cohérence

des politiques agricoles et alimentaires

Politiques alimentaires et agricoles en Afrique subsaharienne

Le possible et le nécessaire

Georges COURADE

Insécurité alimentaire dans le monde

Implications pour les pays européens

Henri JOSSERAND

Le difficile chemin des politiques

de sécurité alimentaire en Afrique

John IGUÉ

Partie 4

Repenser la mondialisation

Les agricultures du Sud et les responsabilités européennes . . 125 Michel GRIFFON

Pour une sécurité alimentaire durable des pays les plus pauvres

Quelques enjeux

Gérard AZOULAY

Allocutions de clôture

Jean-François GIRARD

Benoît LESAFFRE

Bertrand HERVIEU

Table des mots-clés

Liste des sigles 


\section{Liste des auteurs}

Mohamed Ag Bendech, nutritionniste

responsable de l'organisation Helen Keller International,

Ouagadougou, Burkina Faso.

Francis Akindès, sociologue

Professeur à l'université de Bouaké, Côte d'Ivoire.

Gérard Azoulay, économiste

maître de conférence à l'université Paris-Sud.

Georges Courade, économiste

IRD, université de Paris-1.

Francis Delpeuch, nutritionniste

IRD, directeur de I'UR 106 « Nutrition, Alimentation, Sociétés », Montpellier.

Michel Griffon, agronome et économiste

Cirad, conseiller Développement durable.

Bernard Hubert, écologue

Inra, directeur scientifique adjoint.

John Igué, géographe

Professeur à l'université nationale du Bénin.

Henri Josserand, économiste

FAO, chef du Système mondial d'information et d'alerte rapide (Smiar).

Xavier Leverve, nutritionniste

Professeur à l'université Joseph-Fourier, Grenoble,

directeur scientifique NHSA, Inra, Paris.

José Muchnik, anthropologue

Inra (SAD/UMR Innovation Montpellier),

directeur de recherche, directeur du GIS Syal.

Marie T. Ruel, nutritionniste

Ifpri, Washington, D.C. 


\section{Allocution d'ouverture}

\section{Marion GUILLOU}

Directrice générale de l'Inra'

Paris, 15 octobre 2003

"Le monde peut-il nourrir le monde ? » est une question substantielle et immanente, et pour tenter d'y répondre, il faut privilégier les échanges et les débats. L'objectif est de mieux nous comprendre, de mieux cerner les enjeux et mieux définir ensemble des voies pour avancer.

Notre position doit associer modestie et engagement.

La question est ambitieuse, mais ne doit pas faire oublier la modestie nécessaire selon moi face à l'immensité de la tâche, à la diversité des acteurs impliqués et à la complexité du sujet.

Modestie face à la situation de la malnutrition dans le monde. Sans rappeler les chiffres, je ne crains pas d'affirmer que malgré des progrès considérables, les populations connaissant l'angoisse de la faim sont encore beaucoup trop nombreuses, aussi bien dans les pays du Nord que dans ceux du Sud.

Modestie face aux enjeux à l'œuvre. Au-delà du bien-être, du mode de vie, des maladies des populations et des individus, sont impliquées aussi des questions lourdes, mondiales, à horizon large comme l'accès aux ressources intellectuelles, génétiques, technologiques, la gestion locale et globale des écosystèmes cultivés qui permettraient à tous de se développer, localement et librement.

Modestie de la science face aux solutions qu'elle peut contribuer à élaborer. Les travaux des organismes de recherche, les innova- 
tions qu'ils orientent ne peuvent être élaborés de façon isolée, déconnectée des enjeux locaux et des conditions de faisabilité. La recherche en soi, et loin de tout, ne serait pas utile pour répondre à une telle question. En revanche, et à égalité de dignité, nous souhaitons apporter notre pierre, comme ressource ouverte et accessible à tous, à la production de connaissance, à l'appui à l'expertise et à la contribution à l'innovation.

Modestie, enfin, quant à notre position d'Européens dans un débat mondial, que nous souhaitons multipolaire. L'Europe peut s'efforcer de comprendre, d'être vigilante sur ses objectifs, ouverte et respectueuse sur ses orientations. Mais elle ne pourra proposer des ressources, des biens collectifs accessibles, que si ces ressources sont utiles aux pays connaissant des pénuries et que ceux-ci le souhaitent. Gardons-nous des leçons faciles, des solutions miracle et d'une fausse générosité. Nous sommes devant une nécessité collective.

Mais la modestie n'empêche pas l'engagement et l'action volontaire. Les objectifs d'un organisme de recherche finalisé dédié à l'agriculture, à l'alimentation et à l'environnement sont ambitieux. Nous en sommes, en tout cas, convaincus. Je n'en citerai que quelques-uns : s'efforcer de montrer la voie vers une gestion équitable des droits de propriété intellectuelle, gérer au mieux et de façon accessible à tous les ressources génétiques de nos territoires, ouvrir nos ressources et nos méthodes à ceux qui le souhaitent, contribuer par nos nouveaux savoirs et savoir-faire à la sélection de variétés végétales et de races animales diverses, à la fois rentables, productives et respectueuses des environnements locaux, appuyer la définition de pratiques agricoles ou alimentaires, nouvelles, aptes à atteindre à la fois et simultanément des objectifs qualitatifs et quantitatifs.

Les nouveaux enjeux scientifiques serviront à l'élaboration de nouvelles réponses à des questions anciennes. La compréhension du génome et de son expression dans un environnement permettra de mieux expliquer les relations entre la plante et son environnement. Elle ouvrira de nouvelles perspectives à la fois sur la sélection génétique et sur l'élaboration de nouvelles pratiques adaptées à des territoires de plus en plus spécifiques. La gestion, approfondie et mieux outillée, des écosystèmes cultivés devrait 
éclairer d'un jour nouveau les pratiques agronomiques dans une perspective de développement durable. Enfin, la connaissance et la compréhension accrue des facteurs de virulence des pathogènes ou de la plasticité du génome bactérien nous donneront de nouvelles capacités dans la détection précoce et la réponse à des questions sanitaires émergentes.

Les textes rassemblés dans cet ouvrage éclaireront et compléteront de nombreux aspects de ces problématiques. Nous examinerons alternativement l'importance des systèmes localisés dans une vision durable de l'alimentation, la nécessité de cohérence dans les politiques agricoles et alimentaires, la place cruciale d'acteurs majeurs que sont les politiques, les producteurs et les scientifiques, et enfin l'objectif commun de régulation de la mondialisation et d'équilibre des pouvoirs que nous poursuivons chacun à notre niveau.

Puissent ces textes contribuer à répondre à cette question commune, passionnante et dérangeante ! 


\section{Introduction}

\section{Sécuriser I'alimentation de la planète}

\section{Bernard HUBERT}

Écologue

La sécurité alimentaire est comprise aujourd'hui comme le droit imprescriptible de la personne humaine à se nourrir (Sommets mondiaux de l'alimentation, Rome, 1996 et 2002). Elle renvoie non seulement aux besoins alimentaires, seule dimension jusquelà considérée, mais également aux droits de l'homme à se nourrir, comme l'un des droits fondamentaux. Dans un contexte de mondialisation et d'internationalisation des échanges, la vieille question économique des relations entre production et distribution des richesses se pose ainsi à des échelles spatiales plus englobantes et à des échelles temporelles plus réduites. Elle se double, en outre, de questionnements propres aux sociétés modernes organisées autour de la technologie, sur la distribution-allocation des risques, et l'attention portée à la gestion des ressources naturelles renouvelables, terrestres comme océaniques, mobilisées dans les activités agricoles, aquacoles, forestières et halieutiques. Nous n'avons pas souhaité mettre en avant ici les seules questions relatives à la production, qui n'en sont pas moins présentes, car le challenge sera bien de nourrir correctement 8 à 9 milliards d'êtres humains en 2050 ! Or, dans les pays industrialisés, l'ensemble des surfaces cultivables est, pour l'essentiel, déjà mis en valeur et des augmentations de productivité qui reposeraient sur une plus grande utilisation de certains intrants (énergie, engrais, 
produits phytosanitaires, mécanisation, etc.) provoqueraient des atteintes à l'environnement et des risques alimentaires, vite considérés comme inacceptables. La mise en culture de vastes zones potentiellement productives dans certains pays en transition ou en développement ne pourrait se réaliser sur la base des mêmes modèles techniques sans rencontrer également très vite des limites à la fois écologiques et sociales, dont les prémices se font déjà sentir.

Ainsi, l'existence des « poches » de pauvreté extrême comme l'émergence brutale de crises sanitaires ou les risques de surexploitation des ressources halieutiques et la diffusion médiatique en temps réel de ces situations posent de manière impérative la question du rôle des États et des autres institutions dans la régulation d'un processus économique qui prend une dimension internationale.

Paradoxalement, ces enjeux ne touchent pas seulement les populations urbaines, car il est reconnu aujourd'hui que les trois quarts des « mal nourris » de la Planète sont des ruraux et des producteurs agricoles ! La sous-alimentation chronique en énergie, qui les touche particulièrement, apparaît ainsi avant tout comme le résultat d'une organisation inadéquate du système économique et politique sur lequel reposent, au niveau local, la production et la répartition des produits alimentaires et, au niveau international, la régulation des échanges. Elle touche bien sûr majoritairement les pays en développement (PED) et les pays les moins avancés (PMA), mais les grandes puissances agricoles et agro-alimentaires sont également confrontées au phénomène de malnutrition (estimé à $10 \%$ de la population d'Europe et d'Amérique du Nord). Ce qui confirme que la question alimentaire est devenue autant affaire d'accès à une alimentation en quantité suffisante, de qualité et équilibrée, que de production.

Afin d'éclairer ces questions et commencer à leur donner des éléments de réponse, l'Inra, le Cirad et l'IRD ont organisé un colloque, «Le monde peut-il nourrir le monde? Sécuriser l'alimentation de la planète », le 15 octobre 2003 au Palais de la Découverte à Paris ${ }^{\mathbf{1}}$. 
Il s'agit pour la recherche de contribuer à anticiper les aggravations que l'on peut redouter du fait des évolutions démographiques, des incertitudes climatiques, de l'urbanisation mal contrôlée, de la concentration des productions dans les zones littorales, des migrations de population, des mutations économiques et des modes de vie ainsi que des transitions nutritionnelles qu'elles induisent.

Si la responsabilité politique est clairement identifiée, celle des scientifiques l'est également. Elle l'est par les attentes qui sont exprimées vis-à-vis de la technologie, mais aussi par les craintes qui découlent de l'avancée de celle-ci. Elle l'est également du fait de l'attitude normative de recherches qui s'inscrivent délibérément dans une perspective d'intégration des aspects productifs, économiques et environnementaux, tout en ayant à prendre en considération de nouvelles exigences en termes d'équité sociale. La recherche est ainsi appelée à intervenir dans des processus dynamiques, et non plus en situation d'équilibre, dans lesquels s'enchevêtrent des pas de temps aussi différents que ceux de l'action, de l'intergénérationnel et des processus biophysiques et économiques aux échelles locales et planétaire.

Ce colloque était structuré autour de quatre thèmes organisés en deux sessions d'une demi-journée chacune : "Lalimentation : un bien public ? » et " Pour une nouvelle cohérence des politiques agricoles et des politiques alimentaires $»$. Le présent ouvrage reprend le découpage initial et vise à mettre à la disposition du public les textes de ces interventions ainsi que les exposés de discutants (F. Akindès, M. Ag Bendech et J. Igué) venus spécialement pour le colloque et invités à réagir à chaud à l'issue de chaque couple de présentations. La première partie vise ainsi à donner un cadrage général tant des aspects culturels, sociaux (J. Muchnik) et nutritionnels (X. Leverve) de l'alimentation, que des principaux problèmes rencontrés et de quelques pistes pour commencer à y répondre (F. Delpeuch et $\mathrm{M}$. Ruel). La seconde partie fait le lien entre les politiques agricoles et alimentaires (G. Courade), en désignant les effets ( $\mathrm{H}$. Josserand) et les responsabilités au niveau global entre pays du Nord et du Sud (M. Griffon), compte tenu des accords internationaux existants (G. Azoulay). Le lecteur trouvera en fin d'ouvrage une table des principaux mots-clés qui pourra le guider dans ses propres recherches. 


\section{Développer une approche en termes de systèmes alimentaires}

Les textes et réflexions présentés dans cet ouvrage ouvriront, espérons-le, de nouvelles pistes de recherche qui permettront de rapprocher des sphères actuellement disjointes comme celles de la production, de l'alimentation et de la consommation. Ils proposent également de réarticuler des domaines scientifiques - c'està-dire des dispositifs de recherche et des cultures scientifiques actuellement disjoints dans leurs objets comme dans leurs formes de structuration disciplinaire. Agronomie de la production, sciences des aliments, économie des circuits marchands, analyse du comportement des consommateurs, étude des risques alimentaires, étude des politiques publiques doivent se sentir mobilisées pour mieux comprendre l'organisation des filières agro-alimentaires, c'est-à-dire du dispositif de production-transformation-commercialisation, devenu de plus en plus opaque, créant une distance croissante entre le producteur et le consommateur.

Dans les pays industrialisés, cette disjonction entre la production et la consommation est à l'origine de peurs alimentaires, qui introduisent ainsi les questions liées à l'émergence de nouveaux risques. Ces peurs se révèlent à la suite d'une succession de crises sanitaires, d'autant plus brutales et remarquées que le niveau de risques s'était considérablement atténué depuis plusieurs années $\mathrm{du}$ fait de progrès sanitaires significatifs en termes d'alimentation. En plus de risques avérés d'altération des ressources naturelles, les pratiques de l'agriculture intensive ont entraîné une saturation quantitative de certains marchés mais, en même temps, un appauvrissement « qualitatif »du contenu de notre régime. L'essentiel des productions agricoles (céréales, produits animaux, fruits et légumes) est obtenu dans des conditions de production très intensive, ce qui s'est traduit par de forts excédents et donc une baisse régulière des prix agricoles. Cette situation a permis à l'industrie alimentaire de se développer en transformant les produits à partir de matières premières disponibles en masse, avec segmentation en produits de base et produits intermédiaires pour faciliter l'innovation par combinaison des mélanges de ces composés. La part des aliments formulés aujourd'hui est estimée à un tiers des aliments consommés en Europe et plus de la moitié aux USA. 
Une grande partie des aliments transformés provient d'un nombre réduit d'espèces sélectionnées pour leur haute productivité. C'est ainsi qu'une dizaine d'espèces cultivées assurent plus de $75 \%$ de notre alimentation, alors que le développement des échanges nous permet de nous rendre compte de l'infinie richesse des espèces consommables par l'humanité. Parallèlement, pour des besoins de diversification dans un marché très concurrentiel, l'industrie a développé des produits nouveaux formulés et aromatisés attractifs pour le plaisir des consommateurs mais parfois de faible densité nutritionnelle. Cette sélection agricole, alliée à l'évolution des pratiques industrielles de l'agro-alimentaire, a contribué à l'appauvrissement en certains composés essentiels de notre régime. Dans ce contexte, la production halieutique est restée la dernière source sauvage de production alimentaire pour l'homme avec des particularités dans la composition nutritionnelle et dans la diversité des espèces (plus de 500 espèces consommées en France) qui en font une source de protéines animales d'intérêt pour l'homme.

Le domaine de l'alimentation est au cœur de graves problèmes de santé publique : nous avons rappelé ci-dessus la sous-alimentation chronique en énergie qui touche un grand nombre de ruraux de par le monde, mais il faut compter également avec les carences en micronutriments, qui affectent 2 à 3 milliards de personnes, et avec la surnutrition, qui en touche un milliard, entraînant obésité, maladies cardio et cérébro-vasculaires, hypertension artérielle, diabète de type II, certains cancers, etc. Leur poids sur la santé est considérable. La mobilisation sociale, l'éducation et la formation permanente du public restent indispensables mais ne sont pas suffisantes. La recherche, qui a davantage porté son attention sur les produits et les aliments, doit s'attacher à l'étude des régimes alimentaires dans leur ensemble.

La question alimentaire que le monde devra résoudre dans les années à venir relève donc de registres distincts que je propose de regrouper dans la notion de système alimentaire :

- éradiquer la faim, avec une population mondiale qui devrait presque doubler, en exploitant avec précaution le rôle nourricier de la planète, de ses milieux tant terrestres qu'aquatiques ;

- réconcilier les citoyens avec leur alimentation, c'est-à-dire principalement avec leur agriculture ;

- replacer l'alimentation dans la participation au bien-être et à la santé des consommateurs. 
Elle s'inscrit ainsi dans la problématique du développement durable, qui se veut réflexive par rapport aux effets et conséquences du type de mondialisation qui s'est engagé depuis deux décennies. Celle-ci attire l'attention sur les risques que le développement des uns se nourrisse du sous-développement des autres ; elle vise à surmonter la fracture entre le Nord et le Sud et à mieux intégrer les processus économiques, sociaux et écologiques au service de la satisfaction des besoins des populations, sans nier les différences considérables existant d'un pays à l'autre. Le développement durable cristallise ainsi de nos jours les débats au Nord comme au Sud. Il porte avec lui la prise de conscience des impacts à l'échelle de la Planète non seulement des actions menées au Sud ou au Nord, mais également des interactions entre différentes parties du Globe. Ces dernières sont désormais liées entre elles de façon objective par une interdépendance à laquelle il manque de trouver son répondant en termes de solidarité assumée et de gouvernance. Le Sommet mondial de Johannesburg de 2002 a été une parfaite illustration tant du besoin que de l'absence d'une réponse à la hauteur. C'est pourquoi les établissements de recherche impliqués dans ce colloque, ainsi que d'autres engagés dans la production de connaissances sur la gestion du monde vivant, visent à favoriser la mobilisation conjointe de chercheurs de différentes disciplines dans des programmes coordonnés afin de contribuer aux enjeux de la sécurité des systèmes alimentaires mondiaux.

\section{De la sécurité à la sécurisation des systèmes alimentaires}

\section{Systèmes alimentaires, qualité et sécurité de l'alimentation}

La prise en compte de nouveaux risques ainsi que des crises récentes ont modifié le paysage économique de la qualité et de la sécurité des aliments (GODARD et Hubert, 2002). Des produits agroalimentaires sont soupçonnés de porter en eux des facteurs de risque cachés pour les consommateurs (OGM, farines animales, résidus de produits phytosanitaires ou boues d'épandage d'origine agricole ou urbaine, etc.). En outre, les consommateurs 
et les opérateurs commerciaux commencent à être attentifs aux conditions environnementales et sociales de production des denrées et des matières premières à partir desquelles sont élaborés des produits de consommation, qu'elles proviennent de pays du Nord ou de pays du Sud. Enfin, une meilleure maîtrise des conditions d'approvisionnement en biens alimentaires, qualitativement comme quantitativement, est revendiquée par les consommateurs des deux hémisphères à la recherche d'une sécurisation de leur alimentation. Tout cela ne va pas sans instrumentalisation stratégique des peurs et craintes et de ce que les économistes appellent les situations d'asymétrie d'information, si bien que les craintes pour la sécurité ne sont pas en proportion exacte des dangers tels qu'ils peuvent être appréhendés par l'évaluation scientifique. Sont en jeu tout à la fois l'évaluation experte des menaces et des risques, et les procédures qui peuvent permettre de rétablir une confiance entamée dans les garanties offertes sous contrôle public ou privé.

Définir les enjeux en termes de sécurisation, et pas seulement de sécurité, c'est privilégier l'analyse des processus permettant de gérer durablement les approvisionnements et d'en assurer la sécurité d'une façon jugée fiable par différentes parties prenantes. Cela touche à plusieurs dimensions :

- la sécurisation de la qualité des ressources naturelles et des milieux productifs terrestres (eau, fertilité, diversité génétique et spécifique, diversité des écosystèmes et des paysages) et marins, des écosystèmes et des zones sensibles d'intérêt halieutique ${ }^{2}$ (préservation des zones humides face à la multiplication des usages à caractère plus agressif ou destructeur : agriculture intensive, constructions immobilières, industrie...);

- la sécurisation foncière (garantir une emprise agricole suffisante face à l'urbanisation et la désertification) ;

- la sécurisation des ressources (eau, matériel génétique, intrants et équipements agricoles, droits d'accès, d'usage, de contrôle, de propriété, d'initiative sur les ressources, mais également connaissances et savoir-faire);

2 Contrairement à la production agricole où la contribution technologique sur la productivité est prépondérante, la production marine est majoritairement d'origine halieutique et donc dépendante de l'état des écosystèmes. 
- la pérennité de l'accès aux marchés (accès, transports, réseaux et filières) ;

- la stabilité des pratiques de consommation.

Ces questions rejoignent ainsi à la fois les problématiques de gouvernance locale et de gouvernance des filières ${ }^{3}$.

En effet, pour mieux apprécier la complémentarité entre ces deux approches, on peut dire (HUBERT et CASABIANCA, 2003) que celle en termes de sécurité alimentaire est associée à une entrée verticale et par le " haut », privilégiant l'étude des grandes filières agro-alimentaires, le rôle régulateur des politiques agricoles et des marchés internationaux ainsi que les processus de recomposition des grandes firmes internationales tant en amont qu'en aval des filières. Lapproche en termes de sécurisation alimentaire est associée à une entrée par le « bas » et horizontale. Elle privilégie l'analyse des dynamiques territoriales, le rôle des organisations socioprofessionnelles, l'émergence des réseaux locaux d'innovation autour des savoir-faire techniques, de la spécification des produits, de pratiques commerciales ou de règles financières. Ces deux approches sont bien complémentaires en ce sens qu'il est difficile d'analyser par le « bas » le développement local ou l'évolution des agricultures familiales sans tenir compte de l'influence des processus de mondialisation et d'internationalisation des échanges. Et réciproquement, l'analyse macro-économique et les outils de modélisation de la production et des échanges alimentaires devront affiner le plus possible la prise en compte du comportement et des stratégies des acteurs sociaux et des variables locales de la conception de leurs modèles.

\section{Systèmes alimentaires pour le bien-être et la santé des consommateurs}

À côté des problèmes de disponibilité et d'accès aux ressources alimentaires, on assiste dans beaucoup de pays industrialisés à des surconsommations associées à un mode de vie souvent séden-

3 Qui, ainsi que le souligne I'Ifpri (International Food Policy Research Institute), sont de plus en plus l'objet d'initiatives locales et de pratiques décentralisées, d'une part, et de réglementations et législations à caractère national et international, d'autre part. 
taire pouvant affecter directement la santé des consommateurs. Le régime alimentaire peut alors être la cause de désordres divers incluant certains cancers, les maladies cardio-vasculaires ou les déficiences du système immunitaire. Par ailleurs, les progrès réalisés dans la nutrition ont permis de mieux préciser les besoins des différentes catégories de population en fonction de leur âge et de leur mode de vie, ainsi que le rôle essentiel joué par certaines catégories d'aliments dans notre régime (poissons pour les acides gras poly-insaturés à longue chaîne, fruits et légumes pour les fibres...).

Après une période d'intensification agricole et d'industrialisation de produits de masse, les attentes actuelles des consommateurs tendent à orienter le futur sur des perspectives durables et raisonnables d'une alimentation diversifiée mais de qualité, respectueuse de l'environnement et du bien-être animal mais offrant toujours plus de services et de santé.

Les actions d'éducation, de formation et de recherche sur le rôle fonctionnel de l'aliment peuvent contribuer à orienter les consommateurs vers des choix alimentaires mieux adaptés à leur besoin, donc à améliorer leur état nutritionnel.

\section{Systèmes alimentaires et modes d'intervention économique et politique}

Le contraste est saisissant avec les tendances passées qui privilégiaient une production indifférenciée de masse, le morcellement du processus de production, et la dispersion des séquences productives entre des lieux géographiques distants, en fonction de divers avantages comparatifs. Du fait du brassage des produits et des composants au sein de processus industriels complexes alimentés par de vastes mouvements de transports de marchandises le long de circuits marchands longs qui accentuent la disjonction entre échange et production, ce modèle d'organisation de la production entraînait un haut niveau d'entropie de l'information sur les conditions de production à chaque stade : en cas de problèmes, il devenait impossible de remonter la trace pour un coût non prohibitif, de même qu'il était impossible de donner des informations précises au consommateur, si ce n'est de lui certifier que les processus finaux de transformation industrielle étaient « sûrs ». 
Les enjeux de la sécurisation contribuent également à remettre en cause certaines règles actuelles du commerce international. Il en va ainsi de la distinction entre produits et procédés : à l'exception possible du «Protocole sur la bio-sécurité » concernant le commerce international des OGM, lorsqu'il sera ratifié, seuls les risques attachés aux produits constituent un motif légitime clairement reconnu pour justifier des mesures de restriction au commerce de la part d'un État importateur. Les nouveaux enjeux de la qualité sous l'égide du développement durable remettent en cause le bien-fondé de cette distinction. Pour le moins, elles requièrent l'introduction de procédures de traçabilité au sein des filières et des circuits commerciaux, de façon à pouvoir aisément localiser les facteurs de risque pour la santé et l'environnement présents dans le produit final mis à disposition. Cette sécurisation de l'information sur la qualité qui intègre toute la filière jusqu'au produit final peut s'obtenir de deux façons très différentes :

- d'un côté, il s'agirait de préserver une production industrielle de masse en établissant des procédures de qualification qui reconstitueraient, dans une logique proche des analyses de cycles de vie, une filière d'information sur la qualité de façon parallèle aux filières de transformation et de production, afin d'être en mesure de dresser un profil sanitaire et environnemental intégral pour chaque marchandise. Cette stratégie appellerait une organisation d'un type nouveau qui reste encore à inventer au sein de chacune des filières, même s'il existe des embryons de cela dans telle ou telle filière qui a déjà été éprouvée par une crise ;

- de l'autre côté, il faudrait envisager un raccourcissement des chaînes d'approvisionnement et des circuits d'échange, et préserver la spécialisation des productions. Il s'agirait de redimensionner et reconsidérer les filières de production à l'aune de la fiabilité de l'information qu'elles peuvent assurer aux consommateurs finaux sur la qualité intégrale des produits qui traversent ces filières. Pour la filière halieutique, il s'agirait tout autant de préserver la diversité des espèces et des populations que d'assurer un minimum d'authenticité et de traçabilité, souvent difficile à mettre en œuvre compte tenu des habitats concernés, variables dans le temps et dans l'espace. 


\section{Systèmes alimentaires et modèles de développement}

Dans le même temps, il convient de se demander comment les pays en développement, en particulier les moins compétitifs, pourraient rester insérés dans le marché mondial, face aux nouvelles exigences de sécurité et de qualité imposées par certains pays du Nord, dont la France. N'y a-t-il pas là de formidables obstacles à l'accroissement de leurs débouchés commerciaux et une nouvelle source d'amplification de la fracture Nord-Sud que les stratégies de développement durable visent à résorber ?

Le cas des produits aquacoles est différent car la demande en produits de la mer est supérieure à l'offre au niveau mondial pour les espèces nobles ; celles-ci sont donc exportées et constituent pour les PED une source de devises non négligeable. En même temps, elle entraîne une pression de pêche excessive et un détournement de certaines matières premières de haute qualité, réservant à la population locale l'accès surtout aux poissons pélagiques, certes de haute densité nutritionnelle mais de conservation plus difficile.

Plus généralement, il est essentiel de s'interroger sur les moyens d'accroître le niveau de qualité environnementale et de sécurité alimentaire des produits obtenus dans les pays en développement. La recherche de la compétitivité ne risque-t-elle pas de se faire au détriment de la gestion des ressources naturelles (eau, sols, fertilité, forêts) ? Les réservoirs de productivité et les marges de progrès technique sont-ils les mêmes que ceux mobilisés dans les modèles occidentaux ? Les formes collectives de solidarité et d'agriculture ne doivent-elles pas procéder des cultures locales ? Il faut pour cela mieux comprendre, pays par pays, produit par produit, quels sont les enjeux réels de développement et de débouchés, aider les pouvoirs publics à promouvoir des politiques agricoles et environnementales efficaces (afin de remplacer le pilotage de la modernisation de l'agriculture et de l'agro-alimentaire par des « projets» qui ne sont de toute façon plus financés par les bailleurs de fonds), à maîtriser des outils de modélisation pour les politiques économiques (simulation et prospective) et des outils de dialogue permettant des approches négociées de la décision. Il faut étudier les moyens d'éviter que la baisse des coûts unitaires par produits (obtenue sur les transports et les rendements) ne se 
fasse au détriment irréversible des producteurs, du fait d'une plus grande volatilité des prix internationaux. Comme en France, il s'agirait de jouer sur l'amélioration et la stabilité de la qualité des produits, en assurant davantage leur protection par des labels ou des appellations. Des accords de qualité passés entre producteurs, consommateurs et opérateurs de l'interprofession iraient également dans ce sens. Enfin, il est manifeste que la réflexion sur la réorientation des politiques agricoles des pays industrialisés doit prendre en compte l'objectif de ne pas provoquer l'effondrement des systèmes productifs dans les pays moins favorisés, ce qui exclut une logique de guerre des prix sur le marché mondial à partir d'une stratégie agressive de subventions publiques.

Par ailleurs, ces questions de sécurité et de qualité sont à replacer dans un contexte de désengagement de l'État, de nouvelles répartitions de compétences entre les différents niveaux territoriaux au profit des instances locales, et ce d'autant plus que ces évolutions favoriseraient la ré-émergence d'anciennes formes de pouvoir local qui ne sont pas toujours les plus porteuses de dynamiques de développement. Les choix publics décentralisés jouant un rôle important dans la gestion de l'environnement et des ressources naturelles renouvelables, des recherches spécifiques devraient être engagées sur les méthodes d'appui aux collectivités territoriales, dont le rôle sera encore plus décisif que par le passé.

Le lecteur trouvera dans les pages qui suivent les premiers éléments de réponse à ce qui, pour l'instant, constitue surtout un agenda de recherches. Celles-ci restent encore largement à développer.

\section{Références bibliographiques}

Godard O., Hubert B., 2002 - Le développement durable et la recherche scientifique à l'Inra. Paris, Inra Éditions, coll. Bilans et perspectives, $58 \mathrm{p}$.

Hubert B., CASABianca F., 2003 - « Entre mondialisation et dynamiques localisées, quelle sécurisation pour des systèmes alimentaires durables ? ». In : Productions agricoles et développement durable, Inra Mensuel n $116: 10-13$. 
Partie 1

Comprendre les besoins

alimentaires 



\section{Nourrir... \\ le corps humain \\ et le corps social}

\section{José MUCHNIK}

Anthropologue

«Et l'aliment d'un homme ou d'une femme

Est un compendium de compendiums

Et ce qui les attire et les unit

Est une cime et une fleur. "

(Walt Whitman, Chant de moi-même)

\section{Introduction : Qualitas... AEqualitas...}

Parler de qualité des aliments, du goût ou de choix des consommateurs semble utopique et parfois provocateur pour des populations qui n'arrivent pas à satisfaire leurs besoins alimentaires de base. Lors d'un cours récent à l'université de La Plata en Argentine, des élèves ont réagi non sans raison aux analyses que je présentais, par rapport à un pays exportateur d'aliments (viande, poisson, soja, maïs...), mais dont 30 à $40 \%$ de la population est passée audessous du seuil de pauvreté. Réaction analogue d'une collègue sénégalaise partenaire du projet de recherche Alisa ${ }^{1}$, qui s'interro-

1 Alisa : "Alimentation, savoir-faire et innovations agro-alimentaires en Afrique de l'Ouest », projet de recherche soutenu par la Commission européenne (1996-2002). 
geait sur la pertinence dans leur contexte de la notion de «style alimentaire $» \ldots$ « Peut-on dire qu'on a un style quand on n'a pas le choix ? " me demanda-t-elle. C'est bien le double défi qu'affrontent de nombreux pays du Sud : sans que la question de l'accessibilité de la nourriture ne soit résolue pour une partie importante de la population, ils doivent répondre aux nouvelles contraintes et enjeux autour de la qualité des aliments, tant pour la consommation interne que pour leurs échanges internationaux. Il est donc important d'affirmer un postulat de départ : la qualité des aliments et de l'alimentation n'est pas un luxe mais un droit auquel toutes les personnes devraient avoir accès.

Un premier partage grossier pourrait alors être fait entre les sociétés confrontées au "paradoxe de l'abondance » et les sociétés soumises au « défi de la rareté ».

Selon Claude Fischler (2003), dans les sociétés où l'obésité et les maladies cardio-vasculaires deviennent endémiques, « les dispositifs sociaux et culturels qui adoucissent les rigueurs de la vie et de l'environnement ont été poussés à un niveau de perfectionnement tel qu'aujourd'hui les phénotypes sont sollicités d'une manière radicalement nouvelle, devant laquelle ils sont mal adaptés... Pour simplifier on peut dire que nous vivons au milieu de l'abondance alimentaire avec un organisme adapté à la pénurie ». Une partie significative de la population aurait donc du mal à gérer son alimentation dans cette situation d'abondance.

Pour les sociétés soumises au défi de la rareté, le premier problème de qualité qui est posé est celui de la quantité. Effectivement, audessous d'un certain seuil, que la nourriture soit accessible en quantité suffisante devient le principal défi de la qualité de l'alimentation. Cette deuxième situation est bien plus grave et concerne des cas très divers, depuis des pays avec des conditions bioclimatiques très adverses et un déficit chronique d'approvisionnement alimentaire jusqu'à des pays relativement favorisés par la nature et avec des productions agro-alimentaires théoriquement suffisantes pour nourrir leurs populations. Par exemple, au Brésil ou en Argentine nous trouvons en même temps la société confrontée au « paradoxe de l'abondance » et la société soumise au « défi de la rareté ».

Alors de quoi parle-t-on quand nous parlons de qualité des aliments et de l'alimentation ? S'interroger sur la « qualité » (qualis) 
de quelque chose signifie s'interroger sur " quelle est la chose ", « quelle est sa nature ». Quand nous nous interrogeons sur la qualité d'un être humain, nous ne nous interrogeons pas sur son poids, ni sur la couleur de sa peau... mais sur les éléments significatifs qui caractérisent cet être humain : est-il bon ou mauvais ? intelligent ou stupide ?... Il n'y a pas une « qualité en soi ». Elle se constitue "en relation avec », la qualité a besoin d'un point d'appui extérieur pour s'interroger sur sa nature, il en est ainsi pour la qualité d'une musique, d'une maison ou d'un gâteau... Si nous nous interrogeons sur la qualité des aliments et de l'alimentation, je reprendrai volontiers la formule simple mais fort significative de LÉVI-Strauss (1964) : « Ils doivent être bons à manger et bons à penser. " Cette formule a la « qualité » de tenir compte en même temps de l'aliment et des hommes qui s'interrogent sur la nature de celui-ci.

Cette communication apporte des réflexions pour repenser et se représenter les problèmes posés dans un contexte en rapide évolution. Nous aborderons alors les questions suivantes :

- l'alimentation... construction du corps humain et du corps social ;

- les dimensions de la qualité ;

- le retour du local... et la qualification de la qualité ;

- les liens au local et les organisations agro-alimentaires.

\section{L'alimentation, un enjeu de société et un objet sociobiologique}

\section{Un tout indissociable... La force de la bouche}

Dans l'approche du fait alimentaire, nous ne pouvons ni isoler le biologique du social, ni réaliser l'inverse. La composition et les caractéristiques des aliments, la santé du consommateur, son identité culturelle, la dynamique des territoires où il habite, l'évolution des productions et des producteurs agricoles... La force de la bouche est telle qu'elle peut même arriver à modifier les marchés ou à redessiner les paysages. En reprenant Marcel Mauss (1980), nous pouvons qualifier l'alimentation comme un " fait social total ", un fait qui met en branle l'ensemble des relations sociales. 
Figure 1.

Le fait alimentaire et les enjeux sociaux.

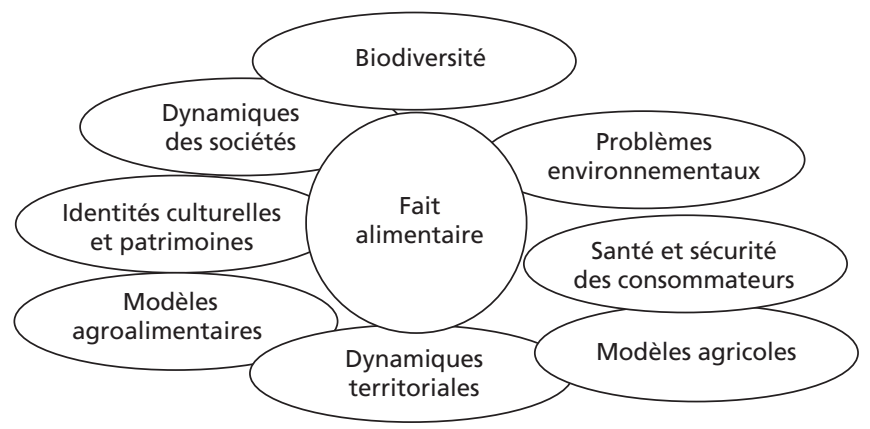

Cet éclairage gagne en intensité dans la période actuelle qui est aussi celle de la remise en cause du modèle de développement agricole basé sur la production de masse et la standardisation. Des nouveaux modèles de développement agricole commencent à se constituer, au Nord comme au Sud, pour tenir compte de nouvelles contraintes : qualité des aliments et sécurisation des consommateurs, bouleversement des sociétés rurales, reproduction des tissus sociaux, emplois, articulation rural/urbain, évolution du métier des agriculteurs, pluriactivité, problèmes environnementaux, biodiversité...

Le fait alimentaire se trouve alors au centre d'enjeux sociaux fondamentaux (fig. 1).

\section{Les contraintes démographiques et l'urbanisation}

D'ici 2025, la population mondiale va s'accroître de 100 millions de personnes par an, il faudra alors nourrir 8,5 milliards d'hommes. Nous ne pouvons pas envisager l'alimentation dans les pays du Sud sans tenir compte du processus accéléré d'urbanisation et de ses conséquences. Or la plupart de ces pays se voient confrontés à un double défi, la population rurale ne cesse d'augmenter en chiffres absolus, d'une part, et il y a une concentration relative croissante des populations dans les grandes villes, d'autre part.

Les comportements alimentaires urbains ont beaucoup évolué. Les sociétés ont toujours un langage alimentaire, mais ces langages se modifient. Au Bénin, au Sénégal et au Burkina Faso, la crise 
économique, en particulier la diminution du rôle de régulation de l'État et la dévaluation du franc CFA, a changé les comportements alimentaires en milieu urbain au cours de ces cinq dernières années. Elle a provoqué l'émergence de nouvelles pratiques alimentaires. Cela se reflète tant sur les produits et les plats consommés que sur la fréquence et les modalités de leur consommation (Alisa, 2003).

Au Sénégal par exemple, la sardinelle (yaboy) était traditionnellement peu consommée par les ménages urbains. Elle était transformée en keccax ${ }^{2}$ par les femmes des pêcheurs et stockée pour les périodes de soudure (hivernage). Actuellement, l'exportation des espèces nobles vers les pays européens prend de l'importance, tandis que la consommation de keccax augmente en ville, en substitution au poisson frais, notamment dans les ménages pauvres. Ces mêmes ménages utilisent également de plus en plus fréquemment la sardinelle en frais dans les préparations alimentaires (N'Doye, 2001).

Le développement de la restauration extérieure constitue un autre indicateur des adaptations aux nouvelles contraintes économiques. Lalimentation hors domicile a connu un essor considérable depuis la dévaluation du franc CFA en 1994, notamment dans les quartiers populaires, beaucoup de ménages n'ayant plus les moyens de réaliser deux préparations culinaires quotidiennes. Les enquêtes réalisées confirment la place croissante acquise par ce type de restauration pour les ménages qui évoluent dans une forte précarité. Le fait que les pauvres achètent une très grande partie de leur riz dans les gargotes signifie que le secteur de la restauration est intimement impliqué dans le passage à un régime alimentaire plus riche en riz.

Les recherches menées sur l'organisation alimentaire urbaine (Thuillier Cerdan, 1996) montrent la capacité des sociétés à développer des innovations et des stratégies de survie dans des contextes soumis à des changements rapides. Identifier et connâ̂tre ces évolutions est une tâche essentielle pour la recherche afin que les connaissances produites puissent contribuer à structurer

2 Keccax : au Sénégal, sardinelle braisée/salée/séchée/fumée, utilisée pour la préparation de sauces diverses. 
des politiques qui tiennent compte des dynamiques locales. « Les arbres ne poussent pas en tirant de la coupe mais en arrosant leurs racines » (BÂH HAMpÂTÉ, 1991). S'il s'agit de "nourrir le monde », les démarches volontaristes « top-down » sont certainement louables... mais elles ont montré leurs limites si elles ne s'articulent pas avec les dynamiques ascendantes " bottom-up " mises en place par les populations. Nourrir le monde implique également nourrir les tissus sociaux qui le constituent.

\section{Nourriture du corps social... La symbolique des aliments}

Un célèbre nutritionniste français a dit « on mange avant tout des symboles » (TREMOLIĖRES, 1968). Il est certain qu'au moment où les famines continuent de menacer dans les pays du Sud et où les questions de sécurité alimentaire hantent nos assiettes, parler de symbolique des aliments semble un peu provocant. Mais nous n'y pouvons rien si les aliments et les sociétés sont construits aussi symboliquement. Un drapeau, une croix, une couronne, un hymne... les symboles montrent, ils délimitent socialement des hommes qui se reconnaissent dans ce qui est montré et en même temps ils prescrivent des comportements sociaux. Comment décrire le goût du pain ou le sentiment que donne l'arôme d'une boulangerie un matin d'hiver ? Comment décrire le frémissement d'un Congolais quand il retrouve avec les siens sa boule de chikwangue ${ }^{3}$ ? Pour étudier la valeur symbolique des aliments, outre les recherches de terrain, je me suis appuyé sur l'étude de textes poétiques d'époques et de sociétés différentes (Muchnik, 2003). La poésie facilite l'accès à une connaissance plus sensible, «plus chaude » de la nourriture et de certaines faces cachées de l'assiette ; le rôle de lien social de la nourriture dans la construction des identités apparaît de manière sensible.

\section{... elle lie les individus à un lieu, à une communauté...}

La symbolique des aliments participe à la construction des identités individuelles et collectives, malgré la mobilité des hommes et 
la globalisation des enjeux socio-économiques, il faut toujours « être et se sentir de quelque part » pour agir et être reconnu. Individus et sociétés cherchent alors à reconstruire identités et appartenances. «Dis-moi ce que tu manges, je te dirai qui tu es »: les nourritures constituent des repères identificatoires essentiels dans ces processus, « bases sensibles et mémorielles sur lesquelles se construisent nos diverses façons d'habiter le monde suivant diverses "modalités" du rapport à soi et à autrui » (OrTigues, 1989)... Des appartenances tissées à base de mil ou de sorgho au Sénégal : "Sorgho tu fais les empires / et tu défais les peuples / jour de mariage, jour de baptême / de toi on fait le laakh ${ }^{4}$ / bol de bouillie pour le cultivateur / graine cuite de l'éleveur /... qui firent grandir tes fils ...»(Harouno, 2001). Ou d'autres mets en France : «Au temps jadis, des gelinottes / des pâtées, des filets mignons / des coqs fricassés en cocotte / avec du lard et des oignons / des langues tripes et rognons / je consommais en abondance / plats d'autrefois, mes compagnons / il n'en est plus un seul en France »(VIAN, 2003).

\section{... elle lie les individus entre eux...}

Car la nourriture est aussi partage, savoir ce qu'on mange est important mais savoir comment, avec qui on mange l'est aussi... Qui sont les convives, comment est composé le « convivium »... Un couscous au Maroc, une grillade (asado) en Argentine ou une paella en Espagne nourrissent les estomacs et les liens entre les gens... «Lamitié célèbre messe / dans le rituel de l'asado " (Gomez TejAdA, 1974).

\section{. elle lie, dans le temps, l'homme aux ancêtres, les morts aux vivants, le passé au présent}

« La nourriture est bien là, au milieu / elle scelle le Lien de Sang / cristallise la grande Famille et les Valeurs / lie les Aieux aux fiers Descendants... ». La nourriture est un fleuve qui parcourt le temps : « Nourriture hier / nourriture aujourd'hui / nourriture demain / nourriture toujours ! » (SADE YAOVI, 2001)... 
Nourriture de rites dans lesquels les individus en société se reconnaissent, sacrifices nécessaires pour que la vie continue... « Après le bel hivernage / sur la terrasse de la dune / derrière le dattier sauvage / loin de la tente / on sacrifia un gros Bélier blanc aux yeux bleu sombre... / la bergère pleura... » et puis « la bergère se remit en joie / la famille se réjouit / ...autour du Thé et du Méchoui / le matin, sur l'or de la dune / à midi, sous la tente commune / le soir, au joyeux clair de lune... » (Slaïmany, 2001).

\section{... elle marque le rythme festif}

Car la vie affective n'est pas comme la vie biologique une fonction continue. Comme des raisins à une grappe de la vigne, les hommes essayent d'arracher des instants au temps. Des instants significatifs, structurants des vies et des mémoires. Ainsi les fêtes ont toujours, de tous les temps, rythmé la vie des hommes, même aujourd'hui au troisième millénaire, même si les types de fêtes ont évolué. Et la nourriture n'a pas le choix, elle doit s'adapter au rythme festif. Nous constatons alors qu'il faut prendre les fêtes au sérieux et que le caractère symbolique se traduit aussi en efficacité économique. Ainsi, en France, des milliers d'artisans et d'industriels travaillent toute l'année pour fabriquer le champagne, la dinde, le foie gras, les huîtres... et autres délices qui s'écouleront en quelques jours lors de fêtes de Noël et du réveillon du 31 décembre.

\section{Les dimensions de la qualité}

Une fois le fait alimentaire posé comme un objet sociobiologique, nous pourrons mieux aborder les tensions constatées dans les approches de la qualité entre une approche « basée sur des caractéristiques scientifiquement objectivables, formalisées dans des critères clairement identifiés et mesurables » et une approche qui « met l'accent sur la multiplicité des attentes des consommateurs, leur caractère individuel, subjectif et souvent incommensurable scientifiquement »(CASABIANCA et VALCESChinI, 1996). Il faudrait donc commencer par analyser les différentes dimensions qui structurent la qualité des aliments. Chaque composante de la qualité mobilisera des valeurs, des représentations et des critères de jugement différents chez les consommateurs potentiels. 
Le problème pour le produit et le producteur pourrait être posé de manière très simple : être choisi par les consommateurs. Ceci implique au préalable deux conditions à remplir : que le produit soit accessible au consommateur et que celui-ci ait les moyens de l'acheter, d'y mettre le prix. Ces deux conditions remplies, commencent à jouer les préférences du consommateur. Qu'est-ce qui fait qu'il décidera d'acheter des carottes ou de la panela bio 20 à $30 \%$ plus cher que les produits standards, ou du poulet fermier au lieu du poulet « classe A » sensiblement moins cher ?

Nous représentons dans le schéma ci-après (fig. 2) diverses dimensions de la qualité. Elles sont mentionnées à titre indicatif et non exhaustif, d'ailleurs les diverses catégories explicitées sont imbriquées les unes dans les autres. Lanalyse des interactions entre la « composition » de la qualité et les critères de préférence mobilisés par les consommateurs est par ailleurs essentielle pour définir des stratégies commerciales et les signes de qualité à adresser au marché.

Figure 2.

Diverses dimensions qualitatives de la consommation.

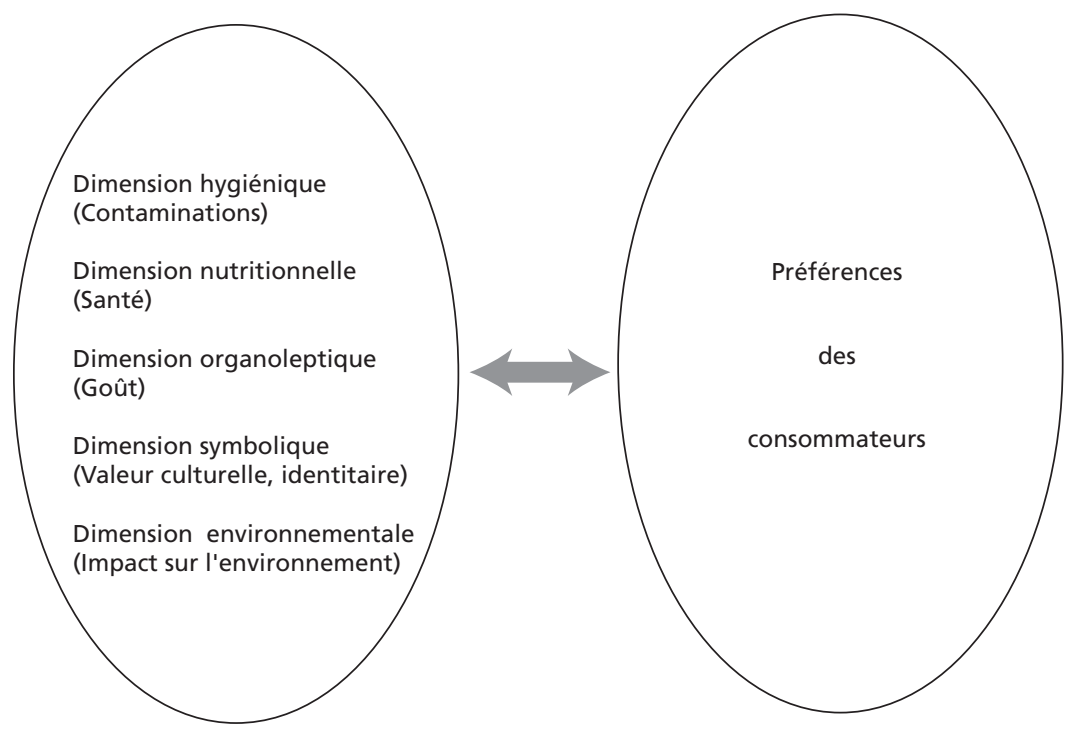

5 Panela : sucre roux de canne très consommé en Colombie, il se présente sous forme de pains compacts. 
Il est certain que le contexte rend les consommateurs plus sensibles à l'impact des aliments sur leur santé. Mais ceci n'est pas nouveau. Depuis toujours on a attribué des propriétés médicales aux aliments, ce que l'on peut constater dans les textes de médicine traditionnelle ou dans les récits des civilisations orales. Des études récentes menées en Colombie montrent que la décision des consommateurs de consommer de la panela bio est motivée en bonne partie par des préoccupations de santé associées à des considérations environnementales plutôt que par des différences dans le goût du produit, même si aucune étude ne prouve que celle-ci est plus bénéfique à la santé que la panela traditionnelle. Un raisonnement semblable pourrait être tenu dans le cas du miel, alicament traditionnel : la demande de miel biologique est en expansion permanente.

Dans d'autres cas comme le fromage de Cajamarca, le goût du produit fortement associé à son origine territoriale déterminera le choix des consommateurs (BOUCHER et GUEGAN, 2002). Les fraudes deviennent nombreuses et diverses : on ajoute par exemple de la farine de pomme de terre pour augmenter les « rendements » de fromages qui proviennent effectivement de cette région ou on fausse directement l'origine du produit. Ce n'est pas dans ce cas un critère de santé qui guide le choix des consommateurs, certains sont même conscients qu'ils prennent des risques, mais « c'est bon, on aime cela, et ça rappelle le pays ». Le cas du queijo de coalho $o^{6}$ au nord-est du Brésil est exemplaire à ce propos : on sait qu'il ne remplit pas toutes les normes sanitaires, les producteurs refusent de pasteuriser leur lait comme l'exigent les services de contrôle, et même les inspecteurs du service vétérinaire prennent des risques en achetant leur fromage chez un producteur réputé (pour le goût du produit, pas pour sa qualité hygiénique). Le risque zéro n'existe pas et des solutions qui tiennent compte de la qualité sanitaire et des références identitaires des produits sont parfois difficiles à trouver. Les débats concernant les réglementations sur la pasteurisation, ou non, du lait pour la fabrication de fromages l'illustrent parfaitement.

Quant à la dimension symbolique des aliments et de l'alimentation, il s'agit surtout de comprendre l'évolution des processus de 
symbolisation, car il s'agit de situations dynamiques en évolution rapide. La percée de la consommation du vin français au Japon n'est pas sans rapport avec de nouvelles constructions symboliques et de nouvelles distinctions sociales faites autour de ce produit. En Amérique latine, de nombreux produits méprisés autrefois comme des produits « paysans » ou « indiens » peuvent aujourd'hui retrouver des nouveaux débouchés auprès de certains consommateurs, le frango caipira (poulet paysan) au Brésil ou le quinoa (Chenopodium quinoa) au Pérou n'en sont que des exemples. Dans les pays européens, le pain blanc a été pendant longtemps synonyme de pureté, aujourd'hui il y a une évolution de préférences vers un pain plus coloré qui renvoie à la campagne, même quand il n'a pas grand-chose de campagnard. C'est d'ailleurs sur cette dimension symbolique que sont fondés aussi les faits économiques (Bourdieu, 1994). Les prix de marché sont souvent difficilement justifiables si l'on ne se réfère pas à la valeur symbolique des produits.

\section{Le retour du local... et la qualification de la qualité}

\section{Sur les liens au local}

Soulignons d'abord que nous ne délimitons pas le local pour séparer mais pour lier, pour articuler. Il ne s'agit pas de favoriser des « localismes », qui sont souvent préjudiciables sur le plan économique et dangereux sur le plan politique, il ne s'agit pas de lever des remparts, mais plutôt de jeter des passerelles pour que des produits spécifiés puissent traverser des frontières.

Ensuite une question paraît prioritaire : quels sont les liens au local ?

Dans le domaine agricole et agro-alimentaire ont toujours existé des zones reconnues pour l'élaboration de produits différenciés. En Europe, les jambons d'Extremadura en Espagne, les vins de Bordeaux en France ou les fromages de Reggiano en Italie font depuis longtemps partie du patrimoine de ces pays. De même, nous pourrions citer, en Amérique latine, la viande de la pampa argentine ou les cafés colombiens (MuCHNIK, 2002). Pour les pro- 
duits cités, les caractéristiques biophysiques et climatiques du lieu de production, "l'effet terroir », paraissent évidentes et constituent un des facteurs forts du lien au local.

Mais si on reprend dans une perspective historique des produits typiques comme la viande argentine, les vins de Bordeaux ou les spaghettis italiens, en passant par le queijo de coalho brésilien, le tempeh $^{7}$ indonésien ou l'akassa ${ }^{8}$ béninois... force est de constater que ces produits si "locaux », si "spécifiques » ont aussi été « localisés » un jour. Un jour les produits arrivèrent, un jour des savoirs se sont créés et transmis, un jour quelqu'un a appris à quelqu'un à élaborer ces aliments qui ont pris leur « carte de séjour » et des racines locales. Alors, les savoir-faire portés par certains acteurs sociaux, dans des contextes historiques particuliers, ont été un des facteurs clefs de cette localisation.

Dans d'autres cas, les liens au local changent de nature avec le temps. Ainsi, d'un lien qui passe par le terroir, on peut aller à un lien qui passe par l'image et la réputation d'un lieu, comme pour le célèbre cassoulet de Castelnaudary dont une partie des matières premières ne sont plus originaires du lieu de production. Ce sont la réputation, l'image du produit et le savoir-faire qui garantissent ce lien.

On pourrait citer des expériences relativement récentes qui montrent ce « retour du local » sur des produits pour lesquels nous aurions eu du mal à imaginer des « appellations d'origine » il y a quelques années. Par exemple, le success story du sel de Guérande en France, grâce à des paludiers qui ont lancé le défi il y a une vingtaine d'années de différencier la qualité du sel, en s'appuyant sur leur savoir, l'histoire et le patrimoine de cette région. Aujourd'hui, les $200 \mathrm{~g}$ de fleur de sel de Guérande se vendent à 4 euros : un métier, un lieu, un produit. Des expériences similaires sur le sel sont en cours de développement en Espagne et au Portugal.

Liens par le " terroir », par les savoir-faire, par l'image du produit. Ce sont des hommes socialement constitués, avec leurs institutions, leurs organisations collectives et leurs rêves individuels

7 Tempeh : en Indonésie, pâte à base de soja fermenté.

8 Akassa : au Bénin, pâte à base de maïs fermenté. 
qui portent ces liens. Le local n'est pas un attribut figé dans le temps, c'est le processus de localisation (ou délocalisation) qui nous intéresse, c'est-à-dire le processus qui conditionne l'enracinement (ou déracinement) d'un savoir-faire dans une société et un milieu biophysique donné, permettant ainsi de mieux comprendre sur la longue période les diverses modalités de constitution de ces " compétences localisées », de ces " traditions productives » territorialisées.

\section{La qualification de la qualité}

Comme nous l'avons déjà précisé, la qualité n'est pas une propriété intrinsèque aux produits, nous avons besoin d'un point d'appui extérieur pour nous interroger sur sa nature ; c'est l'acte de qualification qui est révélateur de la qualité des produits à travers les interactions entre les produits et les critères pour en juger : quels sont les critères de jugement de la qualité ? Comment décide-t-on de ces critères ? Quelles sont les personnes chargées de juger ? Comment certifie-t-on la qualité ou comment sanctionne-t-on, éventuellement, ceux qui ne remplissent pas les critères établis ? Nombreux sont les mécanismes utilisés en France pour « labelliser » les produits : AOC/IGP/Label rouge/Marques. Ces distinctions servent en même temps d'outil de marketing pour gagner la fidélité du consommateur et d'outil de protection contre la concurrence et les contrefaçons.

Dans les pays du Sud, nous retrouvons souvent des « labellisations tacites " basées sur la réputation du produit. L'explicitation, la codification de la qualité devraient permettre de mieux valoriser ces ressources, ce patrimoine. Mais en la matière il est difficile de donner des solutions prêtes à appliquer, car les processus de qualification de produits dépendent fortement des interactions avec les institutions bâties par les acteurs et leurs réseaux de relations.

Ainsi l'établissement d'une AOC ou d'autres appellations peut sanctionner/exclure ceux qui n'appartiennent pas à la zone d'origine délimitée ou ceux qui ne remplissent pas les normes techniques établies. La concertation entre acteurs pour produire des normes doit donc inclure les dispositifs de contrôle (qui contrôle? comment ?), les types de sanction et les modalités de leur application (fig. 3). Inutile de définir des normes si on n’a pas les 
Figure 3.

Une représentation de l'organisation de la qualification.

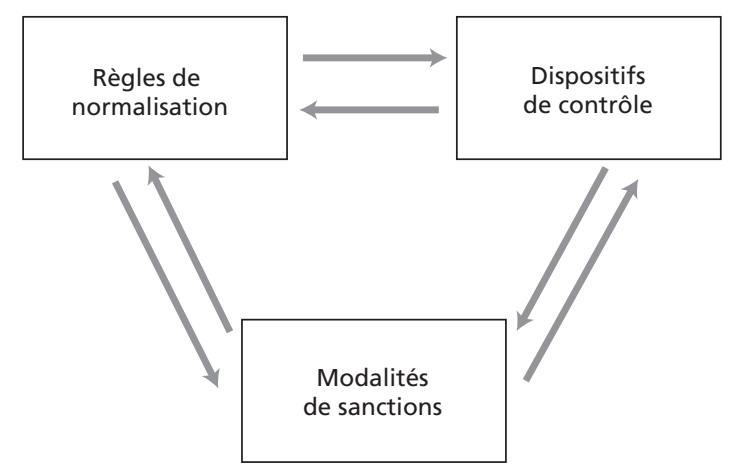

moyens de les appliquer. Dans de nombreuses situations observées dans les pays du Sud, vue la « fragilité » des dispositifs de contrôle et de sanction, il est légitime de se poser la question de la pertinence ou pas d'appliquer telle ou telle distinction du produit. Il serait intéressant de réfléchir dans ces cas à des dispositifs bottom-up, issus d'un vrai processus de concertation entre acteurs, peut-être plus longs à mettre en place, mais peut-être aussi plus efficaces. La constitution de cahiers de charges qui définissent les critères de qualité, la constitution de jurys pour appliquer ces critères, la définition de règles d'action collective permettant d'exclure ceux qui ne remplissent pas les conditions exigées peuvent constituer autant de catalyseurs pour développer des actions collectives et pour la mise en place de dispositifs institutionnels permettant d'aborder les diverses questions posées.

Chaque produit, chaque situation demande une analyse particulière. Le type de marché, les dispositifs institutionnels, les savoirs et les techniques mobilisées ainsi que les statuts des produits et des ressources conditionneront le processus de qualification. Il sera très différent de qualifier par exemple la production de légumes « bio » issue de l'agro-écologie, ou un fromage traditionnel destiné au marché local qui fait déjà partie du patrimoine gastronomique, ou un cacao spécifique qui transite par des filières plus longues avec des normes de qualité et des dispositifs de contrôle concertés au sein de filières internationales. Dans ce domaine, il est donc dangereux de copier des formules, nous pouvons par contre aider à bâtir un cadre d'action pour aborder cette problématique. 


\section{Les liens au local et les organisations agro-alimentaires... La redécouverte des Syal}

L'évolution profonde de l'agriculture devrait être accompagnée par une évolution conjointe des activités de transformation, distribution et restauration, plus respectueuse de l'environnement, plus attentive à la diversité et à la qualité de produits agricoles et alimentaires, plus soucieuse de dynamiques locales de développement et de nouveaux enjeux du monde rural. Les « systèmes agro-alimentaires localisés » renvoient à l'émergence de modèles de développement agro-alimentaire basés sur la mise en valeur des ressources locales (produits, savoirs, compétences, entreprises, institutions...); il n'est donc pas étonnant de constater un regain d'intérêt, tant au Nord qu'au Sud, pour ces formes d'organisation productive.

Nous avons défini les Syal, Systèmes agro-alimentaires localisés, comme « des organisations de production et de service (unités de production agricole, entreprises agro-alimentaires, entreprises commerciales, entreprises de restauration...) associées de par leurs caractéristiques et leur fonctionnement à un territoire spécifique. Le milieu, les produits, les hommes, leurs institutions, leur savoir-faire, leurs comportements alimentaires, leurs réseaux de relations se combinent dans un territoire pour produire une forme d'organisation agro-alimentaire à une échelle spatiale donnée »(CIRAD-SAR, 1996).

Qu'on dénomme aujourd'hui Syal ces formes de production ne doit pas nous tromper sur le fait qu'il s'agit bien d'un modèle agroalimentaire qu'il faut apprécier dans sa profondeur historique. On constate effectivement déjà dans des époques très anciennes une spécialisation spatiale dans certains types de transformations agro-alimentaires. La production d'huile d'olive dans la Méditerranée, déjà dans la période gréco-romaine, était fondée sur ce type de modèle : réseaux locaux d'unités de transformation basées sur un savoir-faire maîtrisé socialement et cumulé historiquement, développement de complémentarités horizontales avec d'autres entreprises (fabrication du matériel de pressage, fabrication des amphores en terre cuite pour le stockage et le transport), 
exportation du produit hors zone de production, réseaux de commercialisation basés sur des liens sociaux et ethniques, etc.

En Amérique latine, on pourrait citer de nombreux exemples à ce propos : les divers types de sucre roux de canne (panela, rapadura au Brésil, tapa de dulce en Amerique centrale, piloncillo au Mexique...), de nombreux fromages (queijo de coalho ou queijo serrano au Brésil, queso de Cajamarca au Pérou, queso de la Quebrada de Humahuaca ou de Tafi del valle en Argentine,....) et même des produits de consommation massive comme l'arepa ${ }^{9}$, la tortilla $^{\mathbf{1 0}}$ ou la farinha ${ }^{\mathbf{1 1}}$ ont souvent leur réputation associée à un lieu. Les produits d'exportation n'échappent pas à cette caractéristique. Il en va ainsi pour le cacao de Chuao au Venezuela ou le café de Cundinamarca en Colombie. Il s'agit bien de produits avec des qualités spécifiques, avec des compétences reconnues et construites dans la durée. Des exemples analogues pourraient être mentionnés dans d'autres pays du Sud.

Du point de vue scientifique, l'intérêt d'une approche en termes de Syal est de contribuer au décloisonnement des disciplines et des objets et de donner cohérence à une approche des phénomènes alimentaires qui puisse réunir le biologique, le social et le technique.

Quatre familles d'objets peuvent nous aider à formaliser cette représentation qui met l'accent sur les relations et les interactions entre des éléments considérés parfois de manière isolée (fig. 4) (Muchnik, de SAinte Marie, 2003).

Dans ce schéma, A, B, C et D représentent respectivement : (A) le rôle de réseaux d'acteurs qui tissent les différentes modalités de coordination entre les acteurs et les dispositifs institutionnels qui règlent et régulent les actions des acteurs impliqués ; (B) les processus locaux de qualification de produits, le contenu technique des normes à établir et les modalités sociales de leur mise en œuvre ; (C) les savoirs, les savoir-faire et la formation de compétences, la constitution et distribution de ces savoirs, leur transformation au cours du temps ainsi que les processus d'apprentissage

9 Arepa : au Venezuela et en Colombie, petits « pains » à base de farine de maïs. 10 Tortilla : au Mexique et en Amérique centrale, galette de maïs, cuite au préalable dans une solution alcaline.

11 Farinha : au Brésil, semoule de manioc. 
Figure 4.

Interactions entre les familles d'objets d'un Syal.

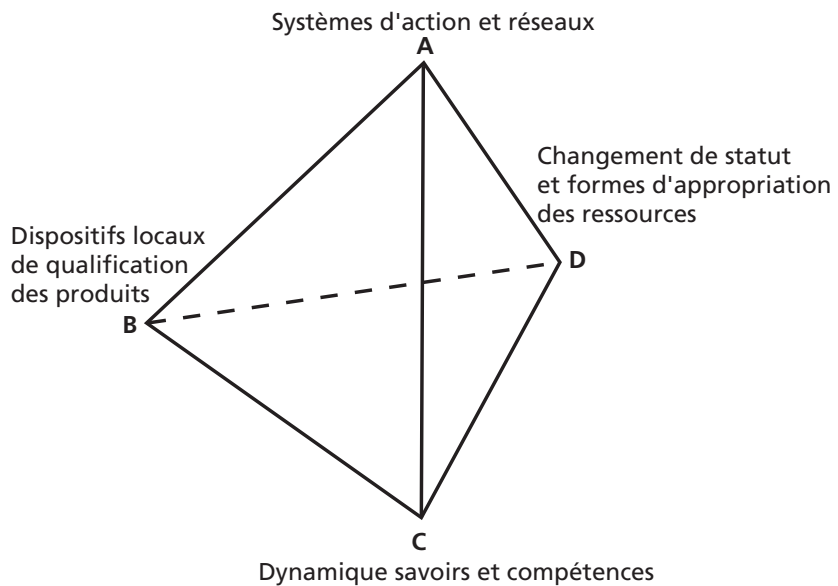

aux niveaux individuel et collectif ; (D) les processus de patrimonialisation des produits et des ressources (races d'animaux, variétés de plantes, savoir-faire, paysages...).

Lintérêt de la notion de Syal est de penser ces familles d'objets en étroite interaction. Précisons pour finir qu'il ne s'agit pas d'un « modèle », nous soulignons cela car on risque souvent de s'enfermer dans les notions que l'on utilise. Il s'agit simplement d'une manière de penser et de se représenter les phénomènes étudiés, représentation qui peut être utile à la lumière des contraintes actuelles.

\section{Références bibliographiques}

Alisa, 2003 - Synthèse des résultats, (coord. Muchnik J.). Montpellier, Cirad.

BÂH Hampâté H., 1991 - Amkoullel, l'enfant peul. Arles, Actes Sud, 409 p.

Boucher F., Guegan M., 2002 - Les fromageries rurales au Pérou. Montpellier, Cirad, 121 p.

Bourdieu P., 1994 - Construction sociale de l'économie, raisons pratiques. Paris, Le Seuil, 302 p. 
Casabianca F., Valceschini E., 1996 - Construction sociale de la qualité. Rapport final, AIP Inra, 344 p.

CIRAD-SAR, 1996 - Systèmes agroalimentaires localisés : organisations, innovations et développement local. Rapport Cirad, Montpellier.

FISCHLER C., 2003 - Le paradoxe de l'abondance. Sciences Humaines, 135 : 22-26.

Gomez Tejada A., 1974 - Canto popular de las comidas. Buenos Aires, Ed. Boedo, 120 p.

Harouno Y., 2001 - « Le sorgho ». In : Le grain, le cour et le mot: poésie africaine, Dakar, Ed. Feu de Brousse/Montpellier,Cirad.

LÉvi-Strauss C., 1964 - Le cru et le cuit. Paris, Plon, 398 p.

MAuss M., 1980 - « Les techniques du corps ». In : Sociologie et Anthropologie, Paris, PUF.

Muchnik J., 2002 - « Les systèmes agroalimentaires localisés : intérêt, approche, interrogations ». Colloque Syal, Montpellier 16-18 octobre 2002, Cirad.

MuchniK J., 2003 - « Les mets et les mots : connaissance poétique de la nourriture ». Conférence EHESS. Séminaire Anthropologie des produits et des techniques alimentaires, 23 juin 2003.

Muchnik J., de SAinte Marie C., 2003 - Processus d'innovation dans le développement agro-alimentaire local, bilan à mi-parcours. Rapport Inra-SAD.

N'Doye F, 2001 - Évolution des styles alimentaires à Dakar. Montpellier, Cirad.

Ortigues E., 1989 - Entretiens. Le Coq-Héron, 115 : 58-72.

SAdE YaOVi D., 2001 - «La nourriture qui unit ». In : Le grain, le cour et le mot : poésie africaine, Dakar, Éd. Feu de Brousse/Montpellier, Cirad.

Slaïmany M.T., 2001 - « Méchoui et thé ». In : Le grain, le cour et le mot : poésie africaine, Dakar, Éd. Feu de Brousse/Montpellier, Cirad.

ThUillier Cerdan C., 1996 - Organisation alimentaire urbaine au Bénin, l'approvisionnement de Cotonou en produits vivriers. Thèse, université de Paris-X Nanterre.

TREMOLIÈRES J., 1968 - Manuel élémentaire d'alimentation humaine. Paris, ESF, 2 tomes 557 et 516 p.

Vian B. - « Ballade pessimiste ». In : Poésie 2003, Paris, Maison de la poésie. 


\section{Qualité des aliments, qualité de I'alimentation}

\section{Xavier LEVERVE}

Nutritionniste

\section{Introduction}

Comme chaque mammifère, l'Homme est caractérisé par l'existence de besoins nutritionnels élevés, indispensables pour satisfaire aux différentes fonctions qu'impliquent sa physiologie et son mode de vie. Ces besoins sont couverts à partir de différents constituants prélevés dans le milieu extérieur sous forme d'aliments, d'eau et d'oxygène. Cela est assuré par les fonctions métaboliques et de respiration. Selon leur devenir, on peut classer ces différents éléments en deux groupes : ceux qui servent de matériaux pour la synthèse des différentes molécules biologiques et ceux dont l'oxydation permettra de dégager l'énergie nécessaire pour transformer la matière afin de constituer des molécules de la vie. Un troisième groupe correspond à des substances qui sont des éléments de contact avec l'extérieur : molécules "signal ", agents infectieux, éléments toxiques, etc.

À côté des éléments métaboliques proprement dits, les fonctions cognitives supérieures qui sont au centre du « comportement alimentaire », grâce à l'intégration de données psycho-affectives, socio-économiques et environnementales, font partie également de la complexité du tableau final. De ce fait, la nutrition et l'alimentation qui l'assure doivent être comprises comme dépassant très largement le cadre de la simple fourniture de substrats vers une fonction de relation avec les différents éléments de l'environnement, intégrés au sein d'un vaste réseau de signalisation per- 
mettant la défense et l'adaptation des organismes dans toute la complexité du règne vivant.

Ainsi l'alimentation s'avère une fonction beaucoup plus complexe que ne le laisserait penser la simple somme des différents aliments qu'elle contient, de la même façon que les aliments ne peuvent pas être résumés à la somme des nutriments qui les constituent. L'objectif de cette brève revue est de mettre en lumière différentes situations physiologiques caractéristiques de l'homme, ou de certains modèles animaux, afin d'illustrer la subtilité de leurs relations avec la complexité de l'alimentation.

\section{Le métabolisme énergétique : généralités}

Parmi les mammifères de taille comparable, les besoins énergétiques de l'homme sont particulièrement élevés. Ils sont chez l'adulte de l'ordre de 30 à 35 kcal/kg/jour en fonction de différents éléments dont naturellement la dépense liée à l'activité musculaire. Chez l'enfant en croissance, ils sont beaucoup plus élevés, et ce d'autant plus que l'enfant est jeune (le double chez le nouveau-né). De grandes disparités de dépenses existent entre les différents organes en rapport avec les fonctions principales qu'ils assurent (fig. 1). Ainsi, le cerveau, le foie, le cour et les reins, qui tous ensemble ne représentent qu'à peine $5 \%$ du poids du corps, correspondent à eux seuls à plus de $60 \%$ de la totalité des dépenses énergétiques. Le cerveau, dont la masse représente à peine $2 \%$ du poids du corps, consomme à lui seul plus de $20 \%$ de l'ensemble de la dépense énergétique de l'organisme. Ce haut niveau de dépense énergétique correspond principalement au maintien de gradients ioniques élevés de part et d'autre de la membrane cellulaire permettant d'atteindre des potentiels importants, base de la genèse des influx nerveux. Ce n'est pas tant la « pensée » qui coûte cher que le maintien en l'état d'un système capable de penser ! Le foie représente lui aussi à peu près $2 \%$ du poids du corps et $20 \%$ de la dépense énergétique, un coût expliqué par des fonctions de synthèses métaboliques majeures, le foie étant la plus grande « machine à transformer et à synthétiser » les biomolécules de l'organisme. Le cour, comme l'ensemble des deux 
Figure 1.

Dépenses énergétiques variables selon les organes.
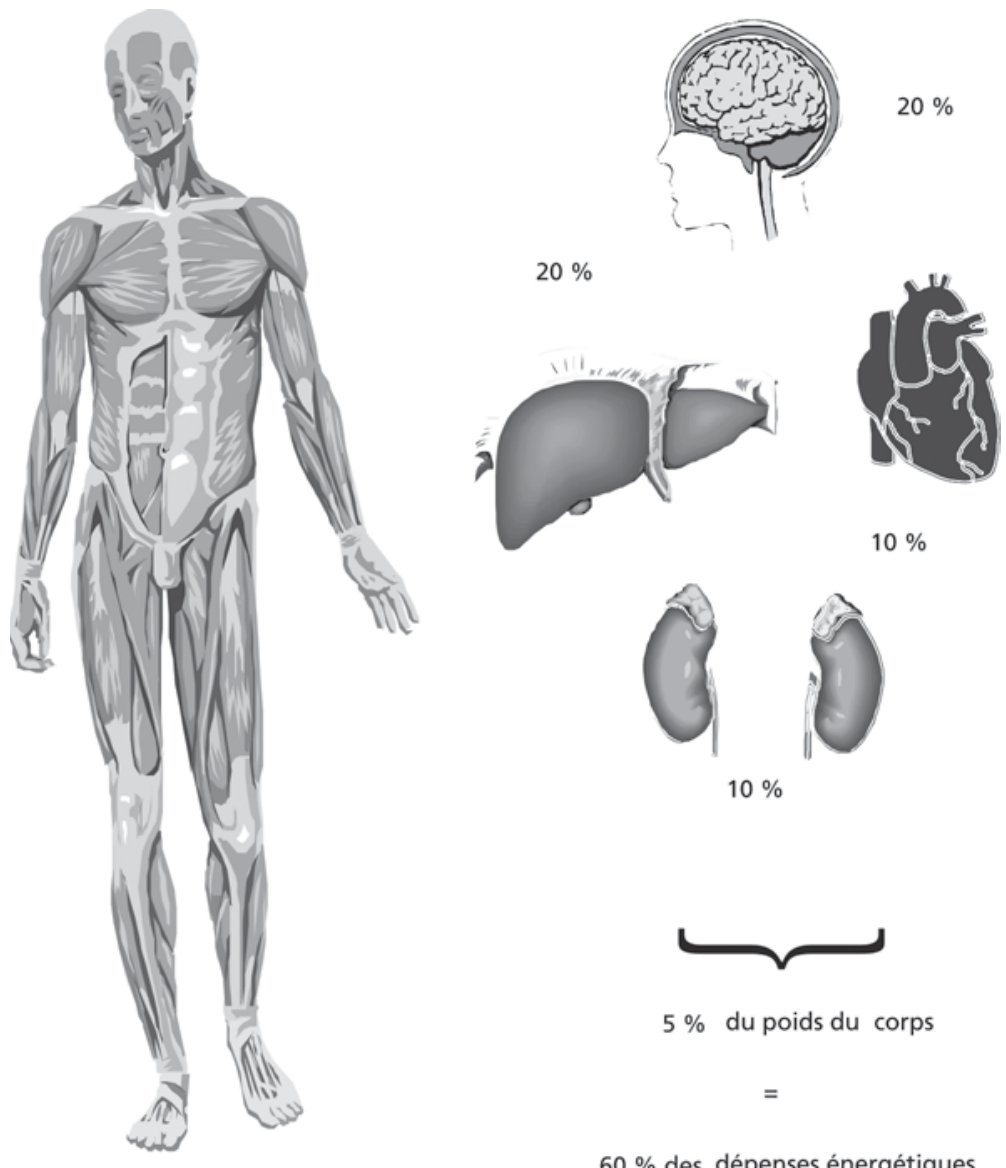

$10 \%$
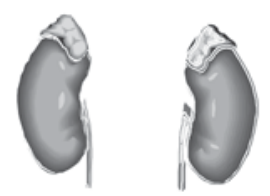

$10 \%$

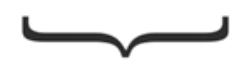

$5 \%$ du poids du corps

$=$

$60 \%$ des dépenses énergétiques

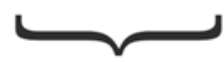

$20 \%$

reins, représente $0,5 \%$ du poids du corps et $10 \%$ de la dépense énergétique, pour la fonction mécanique de pompe sanguine dans le cas du myocarde et pour la réabsorption de l'eau et du sel, à travers une fonction rénale éminemment coûteuse mais indispensable à la vie. À l'opposé, si l'on considère la masse musculaire totale, qui représente $45 \%$ du poids du corps et plus de $80 \%$ de 
la totalité des protéines de l'organisme, cet ensemble ne représente que $20 \%$ des dépenses énergétiques de repos.

Une partie notable de la dépense énergétique est liée au coût représenté par le maintien actif de la température corporelle au niveau constant de $37{ }^{\circ} \mathrm{C}$. En effet, si le coût énergétique est réellement exorbitant, l'avantage potentiel est décisif, qui permet à nos cellules de fonctionner de la même manière quelles que soient les contraintes thermiques extérieures. Ainsi, si l'on compare les dépenses énergétiques de l'Homme avec celles d'un reptile, on constate que pour une masse équivalente, un crocodile a une dépense énergétique environ dix fois plus faible. Cela permet bien évidemment une réduction des besoins alimentaires en rapport, car le coût de l'entretien métabolique de cet animal est également de l'ordre de 10 fois inférieur à ce qu'il est chez un mammifère. On voit bien l'avantage alimentaire évident en faveur du crocodile. Cependant, le fait que cet animal soit dépendant de la température du milieu pour assurer le maintien d'une température indispensable à la réalisation de fonctions métaboliques (fonctionnement des enzymes) le rend particulièrement dépendant des conditions extérieures. Ce sont d'ailleurs justement les différentes conditions environnementales qui, in fine, font des caractéristiques métaboliques d'une espèce ou d'une évolution données un avantage ou un handicap. Cet aspect de la thermogenèse doit être largement considéré dans la réduction des besoins énergétiques de l'Homme moderne, car à côté de la voiture, de l'ascenseur et plus généralement des différentes machines réalisées par l'Homme, les moyens modernes de chauffage ont conduit à une réduction importante des dépenses.

Le second poste variable de dépense énergétique qui peut être considérable est représenté par l'activité physique. Ainsi, et à titre d'exemple, certaines étapes particulièrement difficiles du Tour de France peuvent représenter jusqu'à 6000 ou $8000 \mathrm{kcal}$ par jour, c'est-à-dire une quantité qui est à la limite de ce qu'un intestin normal peut métaboliser et absorber. Là encore, cet élément qu'est la variabilité de la dépense énergétique liée à l'activité physique doit être pris en compte dans la réflexion sur l'augmentation de la masse corporelle liée à l'obésité, laquelle est de plus en plus fréquemment rencontrée dans notre société. En effet, la situation sédentaire de la société moderne a réduit considérable- 
ment ces différents postes de dépense énergétique et peut ainsi contribuer notablement à l'augmentation du stockage adipeux.

\section{Le métabolisme énergétique aérobie : place de l'oxygène dans la vie}

Le métabolisme énergétique de l'homme, comme celui de tout animal aérobique, est caractérisé par une dépendance étroite visà-vis de l'oxygène. Lors des conditions initiales de l'apparition de la vie sur la terre, l'oxygène n'était présent qu'à l'état de traces dans l'atmosphère. Son apparition quantitative est le résultat du métabolisme énergétique d'espèces qui ont utilisé (et utilisent encore !) directement l'énergie de la lumière solaire. En effet, le dérivé métabolique final (ou déchet) de la photosynthèse est l'oxygène moléculaire qui est libéré dans l'atmosphère. De ce fait, le métabolisme énergétique des organismes photosynthétiques tels que les plantes ou certaines bactéries qui initialement vivaient dans les océans a conduit à l'accumulation progressive de l'oxygène sur la terre il y a environ 2,5 milliards d'années jusqu'à atteindre la concentration que nous connaissons aujourd'hui $(20,93 \%)$ et dont la constance est le fait de l'équilibre entre production (photosynthèse avec fractionnement de l'eau en oxygène et hydrogène) et consommation (métabolisme aérobie avec réduction de l'oxygène en eau). Cette accumulation d'oxygène dans l'atmosphère s'est révélée être un élément très toxique. En effet, l'oxygène est un puissant oxydant à cause de sa structure chimique particulière : existence de deux électrons célibataires sur sa couche périphérique. De ce fait, il est capable d'oxyder la plupart des molécules biologiques telles que l'ADN, les lipides membranaires ou les protéines, en les rendant impropres à leur fonction initiale, voire dangereuses. Il est un toxique considérable et le prix Nobel Christian de Duwe a pu parler « d'holocauste par l'oxygène » au cours de cette période, tant les conséquences sur la vie terrestre de l'apparition de l'oxygène ont été considérables. En effet, cette apparition de l'oxygène s'est accompagnée d'une disparition relativement importante des espèces vivantes de l'époque 
que l'on estime grossièrement à plus de $90 \%$. Ladaptation des espèces qui ont réussi à supporter de telles conditions drastiques de stress oxydant est passée par deux voies principales : le développement d'une vie strictement anaérobie, c'est-à-dire en se cachant soigneusement de l'oxygène (c'est le cas de certaines espèces du monde bactérien) ou l'émergence de puissants moyens de défenses antioxydantes. La stratégie de défense antioxydante est essentielle à la survie de toute forme de vie exposée à l'oxygène (le parallèle avec les radiations ionisantes émanant du soleil ou du génie de l'Homme est intéressant). Elle a pris le chemin de deux voies complémentaires : la synthèse de molécules capables d'absorber les éléments dangereux (les radicaux libres) - il s'agit des antioxydants - et l'émergence de voies métaboliques spécifiques capables de se débarrasser des molécules toxiques en reformant les composés initiaux, condition indispensable pour assurer la stabilité de l'environnement. La multiplicité des réponses apportées rend bien compte du danger majeur que représente cette exposition à l'oxygène et explique bien l'extrême variété des solutions métaboliques (les défenses antioxydantes) sélectionnées. Cependant, l'une d'entre elles mérite d'être distinguée par l'ampleur des bouleversements physiologiques qu'elle a apportés. Il s'agit de la respiration. En effet, la réponse la mieux adaptée, apportée par l'évolution à l'apparition de l'oxygène à partir de la photosynthèse, a été d'assurer sa " retransformation » en eau dans la mitochondrie grâce à la chaîne respiratoire. Le couplage de cette libération d'énergie à la synthèse d'ATP (la phosphorylation oxydative) a permis, suprême élégance, de se débarrasser d'un composé toxique, l'oxygène, en le transformant en une source quasi inépuisable d'énergie sous forme d'ATP. Ainsi, notre alliance avec l'oxygène est-elle la plus étroite possible : strictement indispensable à la vie, l'oxygène est en même temps l'élément le plus toxique auquel les êtres vivants sont exposés.

\section{Le métabolisme énergétique aérobie : glucides ou lipides ?}

Alors que les plantes constituent l'essentiel de leurs réserves sous forme de glucides (amidon), les animaux eux constituent celles-ci 
sous forme de lipides. La sélection d'un stockage énergétique sous forme lipidique chez les animaux est probablement le fait d'un avantage considérable en termes de masse, facteur important dans la gestion des contraintes imposées par les mouvements. En effet, les lipides contiennent davantage d'énergie que les glucides puisque $1 \mathrm{~g}$ de lipide libère environ $9 \mathrm{kcal}$, tandis que $1 \mathrm{~g}$ de glucide n'en libère que la moitié, c'est-à-dire environ $4 \mathrm{kcal}$. De plus, le stockage de glucides s'accompagne d'un stockage d'eau proportionnel pour répondre aux contraintes osmolaires, alors que le stockage des lipides est strictement dépourvu d'eau du fait de leur nature hydrophobe. Ainsi, au total et à masse équivalente, la quantité d'énergie stockée dans $1 \mathrm{~g}$ de glycogène est beaucoup moins importante que celle stockée dans $1 \mathrm{~g}$ de graisse, d'où l'avantage évident en termes de gestion de la masse corporelle. De fait, le stockage lipidique est largement privilégié en valeur absolue chez l'homme puisqu'un sujet en bonne santé de $70 \mathrm{~kg}$ possède environ $100000 \mathrm{kcal}$ dans sa masse lipidique, alors qu'il ne contient que $700 \mathrm{kcal}$ environ comme réserve glucidique (glycogène) (fig. 2).

La prédominance du stockage énergétique sous forme de lipides contraste fortement avec le fait que le métabolisme énergétique repose largement sur une oxydation de glucose. Ainsi, le cerveau, dont le métabolisme représente à lui seul environ $80 \%$ de la quantité de glucose oxydé par l'organisme, en consomme 150 grammes par $24 \mathrm{~h}$, ce qui correspond à la libération de $600 \mathrm{kcal}$. Ce

Figure 2.

Différents stockages chez l'homme.

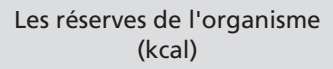

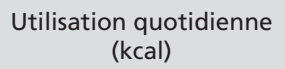

glucides : 700

(cerveau) (80\%)

lipides : 860

protéines : 240

en outre :

$1 \mathrm{~g}$ de sucre $=4 \mathrm{kcal}$

$1 \mathrm{~g}$ de lipides $=9 \mathrm{kcal}$ 
contraste est d'autant plus saisissant que l'Homme ne possède pas l'équipement métabolique lui permettant de synthétiser du glucose à partir des lipides. Ainsi, alors que le stockage lipidique est prédominant, l'oxydation de glucose reste un poste incontournable. Cela explique que l'organisme ait dû développer différentes voies métaboliques lui permettant de réconcilier ces deux aspects opposés, notamment à travers la gluconéogenèse qui permet à l'organisme de synthétiser de nouvelles molécules de glucose à partir des acides aminés contenus dans les protéines musculaires. Limpossibilité d'utiliser les acides gras du tissu adipeux explique que la synthèse de novo de glucose soit totalement assurée par les protéines musculaires. En d'autres termes, cela signifie que lors d'apports glucidiques exogènes insuffisants, l'organisme humain doit impérativement utiliser ses propres protéines musculaires pour la synthèse de glucose. Le corollaire est que même chez les obèses ayant d'importantes réserves énergétiques, le jeûne ou la restriction calorique impliquent une fonte musculaire qui représente une limite importante aux régimes restrictifs mal contrôlés.

\section{Abondance alimentaire et longévité}

Différents travaux effectués sur plusieurs espèces animales ont mis en lumière une relation entre la quantité de nourriture consommée et la longévité. En particulier, il a été montré chez des rongeurs comme chez d'autres espèces - et cela pourrait concerner les primates, voire l'homme - que la réduction de la prise alimentaire était responsable d'une augmentation de la longévité. Si l'on considère une courbe actuarielle de survie, c'est-àdire l'évolution du nombre d'individus vivants à chaque instant donné, on peut décrire deux valeurs caractéristiques : le temps écoulé jusqu'à la mort de $50 \%$ des animaux (médiane) et le temps caractérisant la longévité de l'animal qui a vécu le plus longtemps (longévité maximale). De nombreux éléments intercurrents peuvent interférer avec la durée de survie correspondant à la médiane, comme par exemple la survenue d'événements délétères précoces pathologiques. Par contre, la longévité maximale correspond aux caractéristiques métaboliques effectives qui conditionnent la longévité de l'espèce. Ainsi, des souris nourries 
ad libitum présentent une longévité maximale qui s'allonge proportionnellement à la réduction de la prise calorique de 85 à 50, voire $40 \mathrm{kcal}$ par semaine. Entre une prise alimentaire ad libitum ou réduite à $40 \mathrm{kcal}$ par semaine, on constate que la longévité double pratiquement, passant de 34 semaines à 60 semaines (fig. 3). Cela laisse penser bien sûr que l'excès de prise alimentaire a un effet négatif sur la longévité. Si cet élément est sans doute vrai, il faut également considérer que le choix que fait spontanément l'animal n'est pas celui de la longévité maximale, mais celui d'une prise alimentaire plus importante. Il s'agit probablement de l'une des nombreuses conséquences de la vie particulière de ces animaux en cage, des conditions où l'activité est extrêmement réduite et la disponibilité alimentaire considérable, contrairement à ce qui se passe dans les conditions normales de vie sauvage, où l'animal doit chercher activement sa propre subsistance. Il est intéressant de souligner combien les conditions dans lesquelles l'animal présente une survie prolongée en réponse à une restriction calorique sont particulières, l'animal n'ayant par exemple jamais à fuir devant un danger. Il est vraisemblable que

Figure 3.

Effets de la restriction calorique sur la longévité chez la souris (WEINDRUCH et al., 1986).

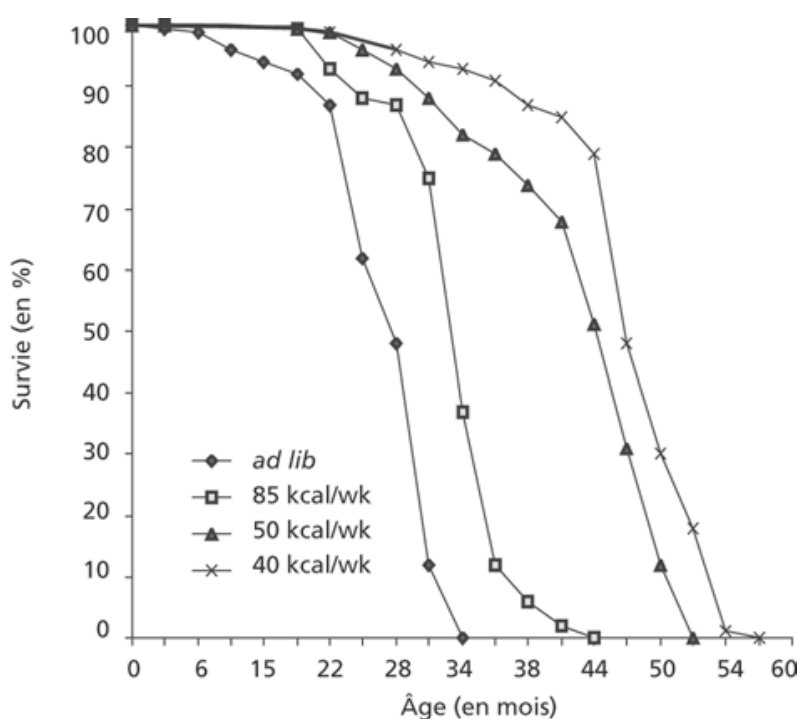


la condition particulière de restriction calorique extrême dans l'exemple de la survie la plus prolongée ne soit pas compatible avec des conditions de vie normale sauvage comportant la recherche de nourriture et la fuite devant des prédateurs. De manière intéressante, des rats naturellement obèses ont une durée de survie qui est considérablement plus longue que celle de leurs congénères non obèses lors d'un jeûne prolongé ( 80 jours versus 10-12 jours). Ainsi, un fort ou un faible stockage énergétique sous forme de graisse peut représenter tour à tour un avantage ou un inconvénient en termes de survie, l'avantage ou l'inconvénient étant complètement le fait des conditions extérieures.

\section{Le stockage adipeux : une capacité essentielle à la survie}

Ainsi, la faculté de stockage sous forme de tissu adipeux peut représenter dans certaines situations physiologiques très particulières un avantage considérable. Les manchots sont des oiseaux qui ont été conduits à se reproduire dans des conditions très inhospitalières sur la banquise de l'Antarctique, loin de la mer où l'abondance nutritionnelle est importante, avec des températures extérieures extrêmement basses et un environnement tout à fait hostile, sans doute pour échapper aux prédateurs. Cet environnement métabolique très particulier de leur reproduction (ponte de l'œuf par la femelle et couvée de celui-ci et du poussin par le mâle) correspond à une phase de jeûne considérable. Les oiseaux mâles sont capables de jeûner entre 2 et 3 mois dans ces conditions très inhospitalières. La capacité considérable de stockage lipidique de ces oiseaux lorsqu'ils vivent dans l'environnement d'une abondance nutritionnelle importante, comme les eaux poissonneuses proches de la banquise, alliée à une adaptation métabolique particulièrement marquée à la situation de jeûne prolongé, permet à ces animaux une survie dans ces conditions inhospitalières pour la plupart des autres animaux.

Il est intéressant de rapprocher cette situation métabolique de celle de l'homme lors de sa naissance. En effet, le nouveau-né humain se trouve dans une situation métabolique extrêmement précaire. Durant toute la vie embryonnaire in utero, le foetus a été 
alimenté à partir des nutriments fournis par la mère, notamment le glucose. L'acquisition de capacités métaboliques gluconéogéniques spécifiques après la naissance est un impératif absolu pour la survie. Cependant la transcription et la synthèse, pour la première fois, de la PEPCK, enzyme clé de la gluconéogenèse, ne sont possibles que si l'insuline est très basse, ce qui impose que la glycémie soit également très faible, un événement potentiellement très délétère pour le cerveau. Contrairement à la plupart des autres fotus, le fœtus humain accumule au cours du dernier trimestre de la grossesse une certaine quantité de tissus adipeux qui représentent une réserve énergétique tout à fait notable. Ce stockage adipeux, caractéristique de l'espèce humaine, lui permet de passer le cap difficile de la naissance du point de vue énergétique. En effet, les besoins du cerveau constituent chez le nouveauné humain environ $80 \%$ du métabolisme énergétique total, une dépense énergétique élevée qui représente une fragilité considérable. Ainsi, à la naissance, le nouveau-né a à résoudre une équation difficile : des besoins énergétiques très élevés, un stockage énergétique principalement lipidique et une quasi-absence de capacité de synthèse de glucose. Cette situation de contrainte métabolique extrême est résolue grâce à une voie métabolique très spécifique qui est la cétogenèse. Celle-ci permet de fabriquer des corps cétoniques pour alimenter le cerveau à partir des lipides stockés dans le tissu adipeux. Ainsi, les premières heures d'hypoglycémie suivant la naissance n'ont pas de conséquences délétères sur le cerveau, du fait de la synthèse de ces mêmes corps cétoniques à partir des lipides. C'est la raison pour laquelle les prématurés, qui n'ont pas ces réserves énergétiques lipidiques peuvent se trouver en situation de faillite énergétique importante.

À côté de leur contenu énergétique, une autre propriété importante des lipides réside dans la forte quantité d'oxygène que nécessite leur combustion. Cette quantité est bien plus grande que pour les glucides. Là encore, il s'agit d'un avantage ou d'un inconvénient selon l'environnement. Un exemple permet de situer simplement cette question. Le cœur est un gros consommateur d'énergie, dont la source principale est représentée par les lipides puisque $80 \%$ de la dépense énergétique cardiaque est assurée par l'oxydation des acides gras. Cependant, si l'oxygène devient un facteur limitant, par exemple lors de la vie à très haute altitude des 
sherpas dans l'Himalaya, il a été montré que l'utilisation de glucose devenait préférentielle, l'avantage de la plus faible consommation d'oxygène compensant le moindre contenu énergétique.

\section{La plasticité métabolique : l'atout pour une survie dans des conditions très variées}

Des différents éléments rappelés ci-dessus, il ressort que le métabolisme est d'une extrême plasticité. Cette plasticité est l'atout qui permet l'adaptation optimale aux nombreuses contraintes environnementales et/ou comportementales physiologiques ou pathologiques. Il est aussi vain que faux de prétendre que, dans l'absolu, tel ou tel nutriment est préférable ou néfaste. Il est troublant de réaliser qu'actuellement vivent sur terre des populations aux habitudes alimentaires très éloignées, voire opposées, et pourtant elles vivent... Ainsi l'alimentation traditionnelle des populations esquimaudes comporte à certaines époques de l'année une proportion très élevée, sinon exclusive, de viande et de graisse (obtenue à partir de la chasse aux phoques), tandis qu'à un autre endroit de la planète des peuples asiatiques pauvres ont une nourriture essentiellement faite de riz et de quelques végétaux. Dans les deux cas, le métabolisme se moule sur l'environnement. À côté des contraintes environnementales, les modifications comportementales représentent une autre classe importante de pression évolutive. La réponse métabolique est avant tout une réponse dont la finalité n'est sans doute pas le maintien d'une composition corporelle définitive ou "idéale ». Toute la difficulté de l'appréhension du phénomène métabolique planétaire qu'est l'obésité réside dans la confrontation de contraintes psychologiques, environnementales et métaboliques différentes, voire potentiellement opposées (la prise alimentaire en réponse à un stress psychologique, par exemple). La coexistence de dénutrition majeure et d'obésité dans la plupart des pays pauvres illustre bien la difficulté à laquelle se heurte notre compréhension. L'histoire de l'alimentation de l'homme a oscillé entre les nécessités de survie au cours des grandes famines et l'adapta- 
tion aux situations de pléthore et la caractéristique majeure du métabolisme réside justement dans son extrême plasticité, c'està-dire une quête permanente d'adaptation des moyens à une fonction ou à une finalité.

\section{Référence bibliographique}

Weindruch R., Walford R.L., Fligiel S., Guthrie D., 1986 - The retardation of aging by dietary restriction in mice: longevity, cancer, immunity and lifetime energy intake. J. Nutr., 116 : 641-654. 



\section{Qualifier la nutrition, les savoirs \\ et les régulations}

\section{Francis AKINDÈS}

Sociologue

Laliment et la question de l'alimentation, en tant que tels, ne sont pas des préoccupations nouvelles dans le champ scientifique. Ce qui est nouveau, c'est le souci collectif de la qualité de l'aliment et de l'alimentation et l'insistance croissante sur cette dimension qualitative dans les politiques de sécurité alimentaire.

D'où vient alors cet intérêt pour la qualité dans le champ alimentaire ? Les exigences de qualité plongent leurs racines dans les exigences de l'innovation, elles-mêmes liées aux mutations dans les systèmes de production et d'offre sur le marché. Le monde de l'entreprise en était le creuset. Mais, progressivement, le souci de la qualité a irradié tous les champs sociaux, notamment celui de l'alimentation. Ici, les peurs liées à la " malbouffe» et à ses conséquences pour l'organisme humain en ont renforcé l'intérêt collectif.

La question de la qualité a pris de l'importance dans le monde des entreprises surtout à partir des années soixante-dix. Ce regain d'intérêt pour la qualité, nourri par l'environnement concurrentiel au cœur des mutations du système de production industriel, fera émerger un ensemble de pratiques managériales. La recherche de la qualité se traduira par la mise en œuvre de procédés et de procédures nés d'interactions entre les clients et les producteurs directs pour créer et offrir la garantie de produits de qualité. La multiplication des cercles de qualité dans les entreprises japo- 
naises et le foisonnement des démarches de qualité sont à placer dans cette dynamique.

Dans la foulée, les exigences de qualité ont contribué à la production d'une multitude de normes internationales censées certifier autant la qualité du processus que la qualité des produits. On en arrive maintenant au concept de " qualité totale » et l'on pose le problème de plus en plus en termes d'organisation de l'ensemble même de l'entreprise par rapport à l'objectif qualité.

Le champ alimentaire a été particulièrement sensible à la problématique de la qualité parce que la chose ingérée touche à la vie ou à la survie de l'organisme vivant. Le souci de qualité de l'aliment et de l'alimentation s'est renforcé avec la crise de confiance liée aux usages des OGM et surtout après l'affaire de la « vache folle ». Il a progressivement trouvé sa justification dans le double principe de responsabilité et de précaution. Reposer la question de la qualité de l'aliment et de l'alimentation, c'est donc aborder un objet de passion, à la frontière du biologique et du socio-anthropologique. Et les deux textes précédents de Leverve et Muchnik rendent bien compte des caractéristiques socio-biologiques du fait alimentaire au cœur duquel doit se loger la problématique de la qualité. L'enjeu de la réflexion ici tient dans la façon de garantir la qualité de l'alimentation en tenant compte à la fois de la dimension biologique et de la dimension sociologique de l'alimentation. Or, la dimension biologique va bien au-delà du « bio » derrière lequel se cachent des impensés environnementaux. C'est bien cela que démontre le texte de Xavier Leverve en réponse à la question que nous formulons comme suit : pourquoi mange-t-on ce que l'on mange ?

Ce texte nous apprend que ce que nous mangeons ou, pour être plus précis, ce dont notre organisme a besoin est pratiquement imposé par l'environnement dans lequel nous vivons, nos activités physiques mais aussi par notre type physiologique. Mieux, tout cela s'inscrit dans un héritage physiologique qui transcende les générations. En d'autres termes, les contraintes de notre environnement déterminent au plan biologique nos besoins alimentaires. Mais les choix alimentaires ne sont pas que biologiquement déterminés. Ils ont une signification sociale. Autrement dit, quelque chose se passe dans nos têtes lorsque notre corps ingurgite de la nourriture. Le texte de José Muchnik nous fait quitter le corps 
pour questionner les systèmes de représentation socialement construits autour du fait alimentaire. Laliment et l'alimentation sont à la fois des analyseurs identitaires et aussi de sociabilité : avec qui mangeons-nous et à quelle occasion ? Les réponses à ces questions révèlent les jeux et les enjeux de sociabilité ainsi que les interactions sociales autour de l'alimentation. Et d'ailleurs, je voudrais aussi attirer l'attention sur l'idée que l'alimentation peut être aussi un analyseur de liens sociaux. Elle peut être un champ social privilégié d'observation de la reliance sociale, au sens où l'entend le sociologue Bolle de Bal, comme de la déliance sociale. Dans certaines capitales africaines, des travaux de recherche sur l'alimentation en période de crise économique ont montré que, par exemple, une des manières de gérer les incertitudes alimentaires en situation de réduction du pouvoir d'achat tient dans la sélection de la composition des groupes de commensalité. Pour résister à la crise, l'accès aux produits de la marmite devient sélectif. L'expression tous azimuts de la solidarité familiale ou communautaire ne résiste donc plus aux contraintes de gestion rigoureuse du budget des ménages.

Désormais, penser les trois paramètres que sont la production, la distribution et la consommation en prenant en compte les interférences entre les fonctions biologiques déterminées par l'environnement et la fonction socio-anthropologique du fait alimentaire devrait constituer un nouveau défi dans la conception des politiques de sécurité alimentaire. La bonne pratique en la matière ne sera plus seulement de garantir la quantité nécessaire à la reproduction du corps biologique, mais aussi de veiller à ce que la chose mangée ait un sens dans et pour le corps social. La démarche qualité en matière de sécurité alimentaire devra intégrer cet équilibre entre le micro et le macro, la quantité et la qualité, suivant les spécificités des contextes environnementaux et sociaux. Vu sous cet angle, on perçoit mieux jusqu'à quel point la tendance à la standardisation pose problème et combien le fait alimentaire est plus que jamais au centre d'enjeux importants de société.

En termes d'enjeux de société, nous touchons à cette tension dans le domaine de l'alimentation entre la forte tendance à l'uniformisation des règles de l'OMC et les formes de résistance par la spécification des identités des produits grâce à la certification, la 
labellisation et la définition des AOC ; toutes choses qui influent sur la coordination des décisions en matière de commerce international de l'alimentation derrière lequel se cachent d'importants enjeux financiers.

Mais lorsque l'on est d'accord sur l'idée de respect des différences dans l'expression des besoins alimentaires, comment alors les prendre en compte dans le processus d'élaboration des politiques alimentaires ? Quelle peut être l'échelle d'élaboration pertinente des politiques alimentaires permettant d'intégrer ces paramètres? L'échelle locale ? Régionale ? Nationale ? Ou encore la conjugaison des trois niveaux à la fois ? Une fois l'échelle d'intervention déterminée pour garantir la qualité des produits, quelles seront les instances de régulation de la pluralité d'intérêts en présence ?

Justement, par rapport à la régulation de la qualité, les capacités des nations sont inégales lorsqu'on sait que la qualification ellemême passe par la mise en place d'une batterie de règles de droit. Ce qui suppose, au niveau national, une expertise qualifiée en état de vigie permanente, un État régulateur mais aussi des organisations de la société civile qui contribuent à la production, à la coordination et à l'application des règles du jeu par les différents agents en interaction, que ce soient les producteurs, les distributeurs ou les consommateurs dont la sécurité est en jeu. Or dans les pays du Sud, cette masse critique fait défaut et la question de l'efficience de l'État reste posée. Ce qui laisse planer de sérieux doutes sur tout projet de régulation de la qualité au niveau national. Dans le meilleur des cas, on est en face d'États qui, bon gré mal gré, produisent des règles de jeux ou de contrôle, mais sans avoir ni les moyens, ni la volonté de les faire appliquer. Ils sont, de ce fait, débordés par les acteurs qui, diversement dotés, usent de ressources de contournement de ces règles. Face à la déficience de l'État, se développe dans le cercle des agences de coopération internationale une rhétorique de survalorisation, voire de sursollicitation d'une supposée société civile. Ce sont là des sousentendus lourds de sens politique. Une ethnographie du fonctionnement de ces structures qualifiées avec empressement de « civiles » nous convie à plus de prudence. Au lieu de partir du présupposé qu'elles existent, il nous paraît plus réaliste de parler de processus de « civilisation » de la société. Ce qui suppose que, si l'on souhaite l'impliquer plus et mieux par exemple dans 
la régulation de la qualité, entre autres, il faut contribuer au renforcement des acquis et à l'accélération de cette dynamique civique par la démocratisation.

Renforcer donc les capacités de régulation de l'État et accompagner les dynamiques naissantes d'implication de la société civile émergente dans les pays du Sud. Ce sont là deux chantiers susceptibles de contribuer durablement à améliorer la régulation de la qualité. Il semble finalement que c'est sur ces deux leviers qu'il faut jouer. Ainsi, toute la question de la qualification de l'alimentation renvoie-t-elle, dans ce cas, à la problématique de la gouvernance et à la définition des échelles de gouvernance. Finalement, le problème de la qualification ne passe-t-il pas aussi par le renforcement des nouvelles formes de gouvernance en privilégiant à chaque fois les interactions de proximité, notamment avec les producteurs et les consommateurs ? José Muchnik propose le Syal, système agroalimentaire localisé, comme échelle d'intervention. Dans un tel schéma, la territorialisation apparaît comme étant une des stratégies possibles de gestion des incertitudes liées à la qualité. Elle devient un moyen efficace de gestion des risques attachés à l'asymétrie d'informations sur les produits alimentaires. Car il paraît plus simple au consommateur de se fier à ce qui est plus proche. On le voit bien : dans le régime de qualification des produits alimentaires et dans le processus de construction sociale de la garantie de la qualité d'une bonne alimentation, la maîtrise de l'information sur les produits devient un facteur décisif. 

Partie 2

Instaurer

des droits

à se nourrir 



\section{Pour des politiques de nutrition publique}

Francis DELPEUCH

Nutritionniste

Sécuriser aujourd'hui l'alimentation de la planète, ce n'est pas seulement assurer une production alimentaire suffisante, ou fournir des aliments plus sûrs, ou garantir une meilleure accessibilité aux aliments à toutes les couches sociales, ou se préoccuper des conditions de production des aliments et donc de la protection de l'environnement, ou encore préserver la santé et la nutrition des populations, mais c'est tout cela. Ces différents objectifs peuvent paraître contradictoires et les différentes politiques sectorielles qui en ont la charge sont d'ailleurs souvent en conflit. Des politiques alimentaires intégrées, basées sur de nouveaux modèles, sont à l'évidence nécessaires et attendues. Et cela d'autant plus que les systèmes alimentaires sont partout, au Nord comme au Sud, aux prises avec des changements majeurs et très rapides, notamment l'industrialisation de ces systèmes et l'urbanisation des populations et des modes de vie, dans un contexte général de mondialisation.

\section{Les problèmes de santé publique liés à l'alimentation sont multiples}

Aujourd'hui, la scène mondiale reste dominée par des problèmes nutritionnels de grande ampleur, qu'ils soient persistants malgré les efforts et certains progrès ou, pour certains d'entre eux, émergents et en augmentation rapide dans les pays du Sud. Le chiffre 
peut-être le plus connu, grâce au plaidoyer de la FAO, est celui de la faim dans le monde, soit 800 millions de personnes qu'on estime être globalement sous-alimentées du fait d'une carence chronique en énergie. $95 \%$ de ces personnes appartiennent au monde en développement et les trois quarts sont des ruraux et des producteurs agricoles. Mais d'autres données témoignent de la diversité des problèmes : 30 millions de bébés naissent chaque année avec un poids de naissance trop faible dû à une malnutrition fotale, soit près du quart des naissances dans les pays en développement. Plus de 150 millions d'enfants de moins de 5 ans sont atteints par un retard de croissance ou une insuffisance de poids, soit 1 enfant sur 3. Au moins deux milliards de personnes sont touchées à des degrés divers par ce qui a été qualifié de « faim cachée » au début des années 1990, c'est-à-dire des carences en micronutriments tels que le fer, la vitamine A, liode ou le zinc. Déjà massivement présentes dans les sociétés industrialisées, les malnutritions liées à une surnutrition (maladies non transmissibles liées à l'alimentation et aux modes de vie comme l'obésité, le diabète, les maladies cardio-vasculaires, certains cancers) touchent un nombre croissant de personnes dans les pays émergents et dans les pays pauvres. L'Organisation mondiale de la santé évoque ainsi une épidémie mondiale d'obésité, avec 300 millions d'adultes d'ores et déjà obèses et près d'un milliard en surpoids ; l'obésité infantile est également en forte progression.

Au total, c'est plus de la moitié de la population mondiale qui est atteinte par une forme ou une autre de malnutrition.

\section{Les conséquences sur la santé et le développement sont prouvées et fortes}

$\mathrm{Au}$ cours des deux dernières décennies, la recherche scientifique a montré que les conséquences des malnutritions et des carences en micronutriments sont bien plus considérables qu'on ne l'admettait auparavant, même lorsqu'elles sont sous des formes modérées. Limpact sur les sociétés est énorme : la mortalité et la morbidité sont accrues; ainsi, 6 millions d'enfants de moins de 5 ans meurent chaque année en raison de la malnutrition et d'une 
maladie infectieuse associée, ce qui représente environ la moitié des décès dans cette tranche d'âge. Les survivants ont des séquelles conséquentes en termes de développement physique et intellectuel. Lanémie par carence en fer augmente les risques de mortalité maternelle et diminue les capacités d'apprentissage et de travail ; la carence en vitamine A est la première cause de cécité évitable et augmente la mortalité des jeunes enfants.

Les personnes mal nourries ont moins de chance d'acquérir une éducation de base, d'avoir des compétences sociales satisfaisantes et de contribuer au bien-être de leur famille et au développement de leur communauté et de leur pays. Cela va notamment à l'encontre des efforts actuels qui visent à réduire la pauvreté. En augmentant la morbidité et la mortalité, les malnutritions accroissent aussi les coûts de santé de manière considérable. Enfin, les problèmes nutritionnels peuvent se répercuter d'une génération à l'autre et entraîner ainsi pour les sociétés des conséquences à très long terme.

\section{Une causalité complexe et des déterminants sociaux}

Le schéma conceptuel proposé en 1990 par l'Unicef pour la malnutrition des jeunes enfants, et aujourd'hui adopté sous diverses formes par la communauté scientifique internationale, illustre bien la complexité des facteurs en cause (fig. 1). Au-delà des causes immédiates au niveau des individus, il existe des causes sousjacentes au niveau de la famille et de la communauté où s'entremêlent alimentation, santé et soins dans la relation causale à la malnutrition ; les causes fondamentales sont importantes au niveau de la société et au niveau international impliquant tous les facteurs - politiques, économiques, sociaux, culturels, religieux qui peuvent limiter l'utilisation des ressources, et en conséquence multiplier les secteurs concernés par les questions de nutrition : santé à l'évidence mais aussi et d'abord agriculture, économie, commerce et industrie, législation, environnement, etc.

Ce cadre conceptuel à trois niveaux de causes avait été initialement développé pour les maladies de carences, mais il est clair qu'il peut s'appliquer aussi aux maladies non transmissibles liées à l'alimentation. 
Figure 1.

Cadre conceptuel des causes de malnutrition et mortalité.

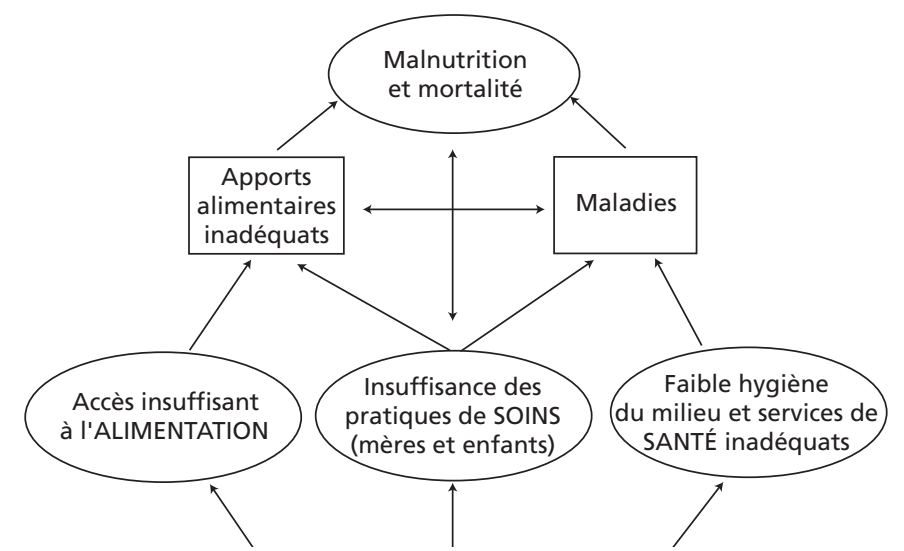

Manifestations

Causes

immédiates

Connaissances insuffisantes, pratiques inadéquates et attitudes descriminatoires limitent l'accès des ménages aux ressources réelles

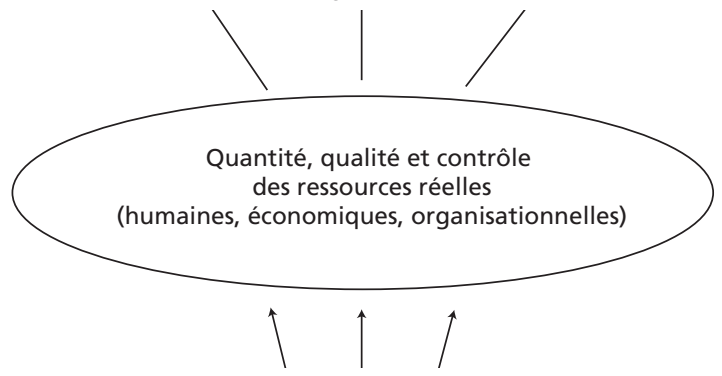

Causes

fondamentales (dans la société)

Les systèmes politiques, culturels, religieux, économiques et sociaux, incluant le statut des femmes, limitent I'utilisation des ressources potentielles

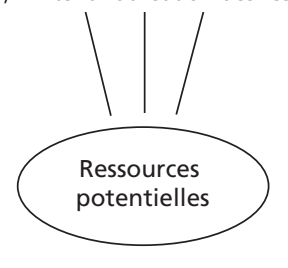

Les facteurs impliqués sont alimentaires comme non alimentaires, les déterminants sont souvent sociaux dès lors qu'on dépasse les causes immédiates et le niveau individuel, et c'est l'environnement au sens large qui est concerné, le plus souvent sur fond de pauvreté. Nous sommes ici loin du modèle classique d'intervention en santé, reposant sur le lien entre une cause unique et une maladie, héritage probable des théories pastoriennes qui ont largement dominé le monde médical et la santé publique tout au long du $\mathrm{xx}^{\mathrm{e}}$ siècle. 
Pour ne prendre qu'un exemple, la sécurité alimentaire, c'est-àdire l'accès à des aliments adéquats et nutritifs, est une condition préalable évidente pour une bonne nutrition, et les politiques agricoles ont ici un rôle majeur à jouer, pour peu qu'elles soient fondées sur des objectifs de bien-être nutritionnel, ce qui n'a été qu'exceptionnellement le cas. Pour autant, de nombreux autres facteurs influencent le processus d'amélioration de la nutrition, tels que le statut des femmes dans la société et leur accès à l'éducation, mais aussi le poids des maladies infectieuses, la structure des soins de santé primaires, l'engagement gouvernemental au niveau local et national dans les questions de santé et de nutrition, etc. C'est l'ensemble de ces questions qui doivent être traitées de manière intégrée.

\section{Des évolutions rapides et des situations de transition plus complexes}

Une véritable épidémie de maladies chroniques non transmissibles s'amorce pour les prochaines décennies dans l'ensemble du monde. Ces maladies, principalement l'obésité, le diabète, les maladies cardio- ou cérébro-vasculaires et certains cancers, conduisent à une morbidité accrue et coûteuse, et à une surmortalité précoce à l'âge adulte. Cette évolution a touché en premier lieu un certain nombre de pays émergents, à ressources importantes et aux économies relativement bien intégrées dans les réseaux internationaux ; mais progressivement, le phénomène s'est propagé à des pays à moyens ou faibles revenus mais à croissance rapide, et même aux sociétés urbaines de pays pauvres. Plus qu'un simple passage des malnutritions par carence aux maladies chroniques, il s'agit d'un cumul, au moins momentané, de ces deux types de pathologies. Ainsi, dans les pays en développement la maigreur et l'obésité touchent simultanément la population adulte en grand nombre (fig. 2). Cette épidémie peut s'expliquer par une augmentation des facteurs de risque de ces maladies, ellemême provoquée par des déterminants à effet cumulatif tout au long de la vie, au premier rang desquels l'alimentation au quoti- 
Figure 2.

Population adulte (en millions) affectée par la maigreur et l'obésité selon le niveau de développement (source OMS, 2000).

Insuffisance pondérale

Obésité

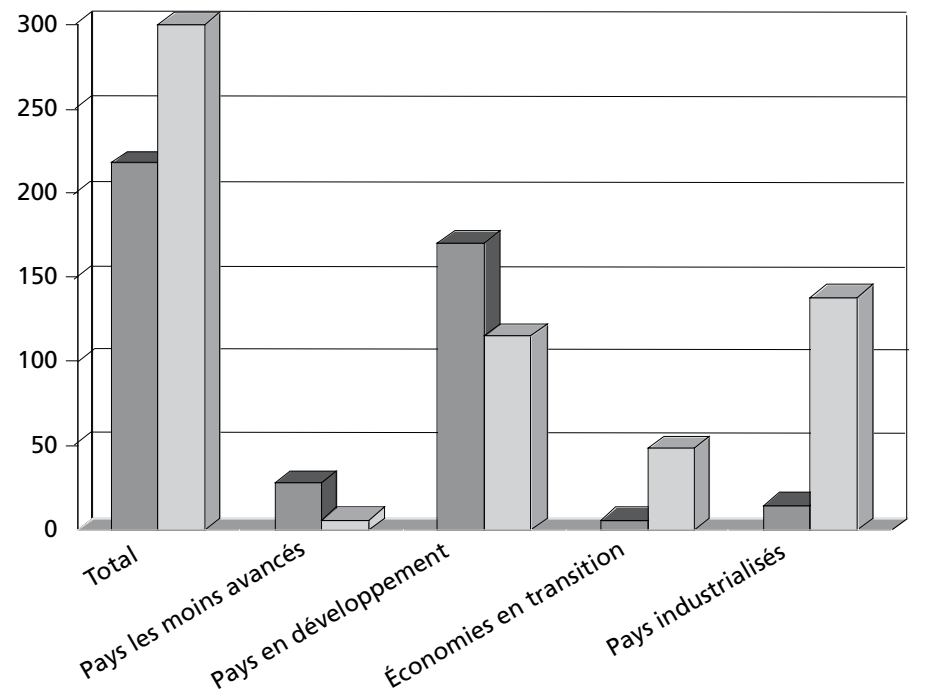

dien et la diminution de l'activité physique. Le trait le plus significatif des changements alimentaires est l'adoption de régimes déséquilibrés sur le plan de la qualité nutritionnelle, trop riches en calories et avec une proportion trop élevée de graisses saturées, de sucre, de sel, et insuffisante en céréales non raffinées, fibres, fruits et légumes, et donc en micronutriments. Dans le même temps, des modes de vie plus sédentaires diminuent les besoins énergétiques en deçà des apports consommés.

Cette évolution trouve sa source dans un contexte marqué par plusieurs changements majeurs : changement technique avec l'industrialisation des systèmes alimentaires de la production à la consommation en passant par la transformation et la commercialisation des aliments ; changement social avec l'urbanisation massive des populations au Sud ; changement démographique avec le vieillissement de ces populations. Lindustrialisation des systèmes alimentaires et l'urbanisation transforment profondément la manière avec laquelle les aliments sont produits et consommés. 
Elles modifient les pratiques alimentaires vers une plus grande dépendance d'aliments produits par d'autres, une augmentation de la consommation d'aliments manufacturés, énergétiques mais à faible densité nutritionnelle, et une consommation croissante de produits animaux. Elles posent des questions aussi bien sur le plan de leurs conséquences sur la santé humaine que sur le plan de l'environnement. Par rapport aux stratégies d'amélioration du niveau de santé et de nutrition, elles posent aussi la question du contrôle de la qualité de l'alimentation : qui contrôle réellement cette qualité et quel contrôle peuvent avoir les gens sur leur propre alimentation ?

Si ces transitions ne sont pas nouvelles dans l'histoire des sociétés, elles paraissent se produire de plus en plus rapidement dans des conditions très différentes de celles qu'ont connues les pays industrialisés, notamment une pauvreté persistante et une urbanisation qui n'est pas toujours en rapport avec la croissance économique. Au cours des dernières années, l'échelle et la vitesse de ces changements semblent avoir été amplifiées par la restructuration néolibérale globale connue sous le nom de mondialisation. Cette évolution peut comporter des avantages certains mais aussi des conséquences négatives. Par exemple, les effets de la libéralisation du commerce mondial, du marketing des firmes mondiales, de l'occidentalisation des modes de vie sur le niveau de nutrition et de santé des populations restent encore largement à documenter.

Des observation récentes révèlent également des liens en apparence paradoxaux entre sous-nutrition et surnutrition. Il s'agit d'une part de la coexistence au sein de la même famille d'une malnutrition de type carentiel (retard de croissance, insuffisance pondérale) chez un jeune enfant et d'un surpoids chez un adulte et parfois chez la mère de cet enfant ; on mesure ici le nouveau défi posé aux politiques de prévention. Il s'agit d'autre part de la confirmation des liens qui peuvent exister chez une même personne entre une malnutrition (carence énergétique et nutritionnelle) pendant la vie foetale ou la petite enfance et une plus grande susceptibilité aux maladies chroniques liées à l'alimentation à l'âge adulte lorsque les conditions d'alimentation changent. Cette " programmation foetale » des maladies chroniques s'explique par une adaptation métabolique durable de l'organisme pour faire face à des conditions défavorables d'alimentation et de santé ; ce 
véritable phénotype économe se révèlerait inadapté par la suite lorsque l'alimentation se modifie dans le sens d'une plus grande abondance et d'un déséquilibre par excès en certains nutriments. Les changements évoqués plus haut (transition, urbanisation, industrialisation) fournissent précisément les conditions pour que s'exprime cette plus grande susceptibilité aux maladies chroniques chez des populations qui ont été fréquemment exposées pendant leur vie foetale et leur petite enfance à des déficits énergétiques et nutritionnels, ce qui est souvent le cas dans les pays en développement. D'autres liens entre différentes périodes de la vie ont été mis en évidence pour divers types de malnutritions. Ces observations ont des implications considérables pour les politiques publiques, certaines interventions (ou absences d'intervention) pendant l'enfance et l'adolescence pouvant avoir des effets défavorables sur la santé à long terme ; elles impliquent de considérer les questions alimentaires et nutritionnelles en termes de cycle de vie selon une approche récemment proposée.

\section{Des politiques publiques nécessaires et renouvelées}

Au terme de ce constat, il est clair que la multiplicité des problèmes de santé publique liés à l'alimentation, la complexité des causes et des situations, la rapidité des changements en cours exigent des politiques publiques et une approche intégrée et qu'il n'y a pas de solution purement technique. Les décideurs politiques ne peuvent plus faire reposer leurs actions sur la seule hypothèse qu'on réduira la faim et les malnutritions dans le monde simplement en produisant plus d'aliments. Répondre à la fois aux problèmes de malnutrition par carence et par excès, parfois au sein des mêmes communautés, tout en relevant les défis posés par les projections démographiques à l'horizon 2050 requiert notamment de reformuler l'esprit et les méthodes des politiques et programmes conduits jusqu'à présent.

En 1992, la Conférence internationale sur la nutrition (CIN), première conférence intergouvernementale sur les problèmes alimentaires et nutritionnels, a constitué un premier tournant dans la perception et l'approche de ces problèmes par la communauté 
internationale. Avant la CIN, une étude avait montré que les politiques alimentaires des PED ne comportaient en général aucun objectif nutritionnel, dans un contexte pourtant massif de faim et de malnutritions. En 1990, le groupe d'étude de l'OMS sur le régime alimentaire, la nutrition et la prévention des maladies chroniques attirait l'attention sur l'acuité de cette question en Europe en déclarant que les politiques agricoles et économiques liées à celle de la Communauté économique européenne n'étaient pas nécessairement compatibles avec les notions actuelles d'alimentation et de santé. Après la CIN, des plans nationaux d'action pour la nutrition, véritables ébauches de politiques nutritionnelles, ont été élaborés dans de nombreux pays. Un fort accent a été mis sur les carences en micronutriments; des succès ont été enregistrés dans des domaines comme la promotion de l'allaitement maternel ou l'iodation universelle du sel pour prévenir la carence en iode. Mais la situation globale ne s'est pas améliorée autant qu'on aurait pu l'espérer, avec une réduction lente des malnutritions carentielles, une montée épidémique des MNTA, maladies non transmissibles liées à l'alimentation et aux modes de vie, et des situations très contrastées entre continents et entre pays. Lors des ateliers de suivi de la CIN, un manque de volonté politique a été souvent évoqué. Mais s'agit-il vraiment d'un manque de volonté politique, ou plutôt d'un manque d'État pour de nombreux pays après le passage des programmes d'ajustement structurel et l'irruption de la mondialisation ? Ne s'agit-il pas également d'un besoin de nouveaux modèles ? En dépit des changements de perception, beaucoup d'acteurs politiques et économiques restent à convaincre, l'alimentation et la nutrition étant toujours largement considérées comme des sous-produits de la croissance économique et de la production agricole.

Aujourd'hui, l'enjeu principal est de réduire à court terme les malnutritions par carences tout en limitant la montée des MNTA et les conséquences négatives à long terme.

La priorité doit être accordée à la prévention. Il n'y aura pas de changements dans les modes de production et de consommation et d'évolution vers une alimentation équilibrée et des modes de vie plus sains sans mobilisation sociale forte. L'éducation et l'information continues du public sont donc nécessaires, ô combien ; mais pour autant, elles ne sont pas suffisantes. Les politiques 
publiques dans leur ensemble sont concernées et le principal défi pour des politiques alimentaires renouvelées sera de parvenir à proposer des régimes alimentaires de bonne qualité nutritionnelle et sanitaire à un coût le plus bas possible dans le respect des cultures et des préférences alimentaires, tout en préservant l'environnement, le tissu social et l'équité. À l'évidence, de nouveaux systèmes alimentaires favorables à la santé, à la nutrition et au bien-être sont nécessaires. Les raisons pour agir sont fortes mais la question est complexe et le terrain politique aussi. Les changements doivent toucher tous les maillons de la chaîne alimentaire et, pour être effectifs, ils nécessiteront de vaincre des résistances à différents niveaux et de dépasser des intérêts puissants et contradictoires. Au niveau international, ces changements dépendent également de l'issue de plusieurs batailles politiques et débats actuels sur les questions de subventions/protection, sur les effets du commerce mondial sur la santé, sur la place des biotechnologies, sur l'environnement et les changements climatiques, sur le droit à l'alimentation.

Toutefois, diverses initiatives en cours autorisent un optimisme relatif et offrent des opportunités d'avancer.

1) Notre meilleure compréhension des relations entre l'alimentation et la santé nous donne de bons arguments pour plaider ; elle s'accompagne d'une prise de conscience par le grand public de l'importance de ces relations.

2) Même si des réserves peuvent être formulées quant à l'atteinte des objectifs, il est important que le Sommet du Millénaire (2000) ait adopté comme un de ses premiers objectifs de développement la réduction de la faim et des malnutritions et l'éradication de la pauvreté extrême.

3) Lors du suivi du Sommet mondial de l'alimentation (2002), le droit à l'alimentation et à une nutrition adéquate dans le contexte de la sécurité alimentaire nationale a été reconnu. Des directives volontaires sont en cours de rédaction et devraient être disponibles dès 2004. Bien que ces directives n'aient aucun caractère juridique contraignant, il s'agit d'une avancée potentiellement importante, susceptible d'influencer le cours de la mondialisation car favorisant la mise en œuvre des régulations indispensables. Ces directives fournissent l'opportunité de concrétiser le droit à l'alimentation, les gouvernements comme les sociétés civiles 
pouvant s'en emparer pour les traduire en termes d'objectifs; et cette opportunité apparaît fondamentale pour un droit qui est un des plus anciens mais aussi l'un des plus bafoués.

4) L'émergence du développement durable et l'approche intégrée qu'il suppose offrent un cadre conceptuel général et obligent à considérer les questions de nutrition et de santé sur le fond, audelà d'une approche biomédicale trop étroite. La conscience émerge qu'il n'y aura pas de développement durable si les questions de nutrition et de santé ne sont pas traitées, mais aussi qu'il sera impossible, inversement, d'éliminer la faim et les malnutritions sans des écosystèmes sains.

5) Nous disposons d'ores et déjà d'ébauches de nouveaux modèles sur lesquels nous pouvons construire ; pour ne prendre qu'un exemple, on peut citer le modèle de politique alimentaire de la région européenne de l'OMS qui repose sur trois piliers : sécurité sanitaire des aliments, approvisionnement alimentaire durable, nutrition. Plusieurs autres piliers peuvent et doivent être envisagés en fonction des contextes.

Sur ces bases nouvelles, le monde pourra certainement nourrir le monde pour peu que l'action publique et qu'une recherche résolument tournées vers la résolution des problèmes alimentaires et nutritionnels soient mobilisées. Le défi reste néanmoins redoutable. Mais a-t-on vraiment le choix ? 



\section{L'Ifpri et sa contribution à la recherche et à l'action dans le domaine des politiques alimentaires et nutritionnelles}

Marie T. Ruel

Nutritionniste

\section{L'Ifpri, sa mission, sa vision et ses sphères $d$ 'action}

$\mathrm{Au}$ cours des dernières années, d'impressionnants progrès dans les sciences de l'agriculture et dans la production alimentaire ont contribué à nourrir une population mondiale croissante. Mais d'énormes défis restent à relever. Parmi les 4,5 milliards de personnes vivant dans le monde en développement, 1,2 milliard sont chaque jour confrontées à la pauvreté et à ses conséquences ; environ 800 millions font face à l'insécurité alimentaire, tandis que 160 millions d'enfants de moins de cinq ans souffrent de malnutrition. Les ressources naturelles sur lesquelles repose la production alimentaire se dégradent et la productivité agricole, qui bénéficiait jusqu'ici d'une croissance rapide, est en déclin. En 2020, la planète comptera 1,5 milliard de personnes supplémentaires, ce qui contribuera à augmenter considérablement la pression sur les ressources naturelles.

La perspective de l'Ifpri (International Food Policy Research Institute) est un monde libéré de la faim et de la malnutrition. 
Cette perspective se fonde sur le droit fondamental à une nourriture suffisante qui est indissociable de la dignité intrinsèque de la personne humaine. Il s'agit d'un monde dans lequel chaque personne a accès à la nourriture en quantité et qualité suffisantes pour mener une vie saine et productive et dans lequel les décisions concernant l'alimentation sont prises de manière transparente et avec la participation des consommateurs et des producteurs.

La mission de l'Ifpri est d'apporter des solutions permettant de réduire la faim et la malnutrition. Cette mission découle de celle $\mathrm{du}$ CGIAR (Consultative Group on International Agricultural Research) : "Parvenir à une sécurité alimentaire durable et réduire la pauvreté dans les pays en développement par le biais de la recherche et d'activités liées à la recherche dans les domaines tels que l'agriculture, l'élevage, l'exploitation des forêts, la pêche, la politique et la gestion des ressources naturelles. »

Afin d'atteindre ses objectifs, l'Ifpri met l'accent sur :

- une recherche pertinente et de qualité dans le but d'identifier et d'analyser diverses politiques internationales, nationales et locales qui peuvent contribuer à améliorer la sécurité alimentaire et la nutrition. Laccent est mis sur l'amélioration de la situation dans les pays pauvres et particulièrement les populations en situation de précarité alimentaire, et sur la gestion solide des ressources naturelles, lesquelles constituent les piliers de l'agriculture ;

- le renforcement des capacités des populations et institutions dans les pays en développement qui participent à la recherche sur les politiques alimentaires ;

- la communication : l'Ifpri s'engage activement dans la communication auprès des politiques, diffusant les résultats de recherche auprès de tous ceux qui sont susceptibles de les appliquer ou de les utiliser, et maintient un lien permanent entre la recherche et l'action sur le terrain.

Les activités de recherche et de communication sur les politiques alimentaires et nutritionnelles à l'Ifpri s'effectuent par l'entremise de quatre divisions de recherche et de vulgarisation, et d'un département de communication ainsi que d'une initiative, Perspective Vision 2020. Un court résumé de ces différentes sphères d'activité est présenté ci-dessous.

1/ La division de l'Environnement et la Technologie de la production : la pauvreté, une productivité agricole insuffisante et la 
dégradation de l'environnement contribuent à la détérioration des conditions de vie dans le monde en développement. Afin de formuler des politiques susceptibles de freiner cette détérioration, la recherche à l'Ifpri se penche sur des domaines comme la gestion de l'eau, les terres fragiles, les droits de propriété et l'intensification durable des systèmes de production agricole. L'Ifpri poursuit également des recherches sur les problèmes liés à la biotechnologie ainsi que sur les opportunités que cette technologie peut offrir aux pays en développement.

2/ La division de la Consommation alimentaire et Nutrition : la sécurité alimentaire repose fondamentalement sur l'amélioration de l'accès économique à la nourriture et sur la capacité d'utiliser les aliments pour la croissance et la nutrition. Afin d'éliminer les contraintes qui limitent la capacité des plus pauvres à se nourrir, l'Ifpri poursuit des recherches sur les programmes visant à réduire la pauvreté, sur les programmes de micro-finance, la sécurité alimentaire en zones urbaines, la sexo-spécificité du développement et la répartition des ressources au sein des ménages, et les carences alimentaires, en mettant l'accent sur les carences en micro-nutriments.

3/ La division de Marchés, Politiques commerciales et Institutions : des politiques, des institutions et une infrastructure rurale inadéquates produisent des marchés agricoles inefficaces où les pauvres paient plus cher pour leur nourriture et les producteurs sont moins rémunérés pour leurs produits. Afin de rendre les marchés, les politiques commerciales et les institutions qui les supportent plus favorables pour les populations pauvres, l'Ifpri poursuit des recherches sur les effets des accords commerciaux internationaux et régionaux, et sur ceux de la mondialisation et des réformes de politique macro-économique dans le contexte de l'agriculture, sur l'efficacité institutionnelle, la diversification de la production et des revenus, les activités post-récolte et l'industrie agroalimentaire. 4/ La division de Stratégies du développement et Gestion publique : dans leur effort pour atteindre les Objectifs de Développement du Millénaire (Millenium Development Goals), les gouvernements et les agences de financement se tournent de plus en plus vers l'Ifpri pour recevoir son appui en ce qui concerne le développement de stratégies et de politiques d'investissement et de réformes institutionnelles. Dans son travail sur les stratégies alimentaires et agri- 
coles, l'Ifpri utilise une approche globale qui prend en ligne de compte l'ensemble de l'économie. Afin de juger de la possibilité de mettre sur pied des réformes, l'Ifpri prend aussi soin de bien étudier les contraintes et les modèles de gestion publique existants.

5/ Le département de Communication : les résultats de recherche sur les politiques qui sont à la pointe du progrès doivent être communiqués de manière à encourager l'action et à s'assurer que les pauvres en bénéficient. L'Ifpri fournit une information destinée à améliorer les conditions de vie des pauvres en guidant les décideurs, en renforçant la capacité des pays en développement à mener leur propre recherche en politiques alimentaires et en contribuant à une meilleure compréhension des thèmes sousjacents aux politiques alimentaires.

6/ L'Initiative Perspective 2020 : elle a été lancée par l'Ifpri en 1993, dans le but de développer et promouvoir une vision commune et un consensus pour l'action de manière à répondre aux besoins alimentaires, tout en réduisant la pauvreté et en protégeant l'environnement. Cette initiative génère, elle aussi, de l'information et encourage des débats qui influencent l'action des gouvernements, des organisations non gouvernementales, du secteur privé, des organisations internationales et d'autres acteurs de la société civile. Un de ses buts principaux est de développer une information de qualité, pertinente et disponible à temps sur les questions les plus urgentes.

\section{La recherche sur les politiques alimentaires et nutritionnelles à I'Ifpri}

Étant donné la nature spécifique de la mission et de la vision de l'Ifpri, le thème de la nutrition est un thème commun à la majorité de ses programmes et de ses activités de recherche. Cet exposé, cependant, met l'accent sur trois programmes en particulier, qui touchent différents aspects des politiques alimentaires et nutritionnelles. Ces programmes sont les suivants : 1) changements globaux dans les modèles alimentaires et la qualité de l'alimentation ; 2) le programme de biofortification ; 3) l'analyse de l'établissement des politiques et du rôle de l'État, du secteur privé 
et des sociétés civiles en matière de politiques alimentaires, agricoles, nutritionnelles et de gestion des ressources naturelles.

Pour chacun de ces programmes, un bref résumé de la problématique qui motive le programme de recherche est présenté, de même que ses objectifs et activités principaux, et enfin l'impact espéré.

\section{Changements globaux dans les modèles alimentaires et la qualité de l'alimentation}

Pour assurer la sécurité alimentaire des populations pauvres, il ne suffit pas simplement de leur assurer l'accès à une quantité suffisante d'aliments répondant à leurs besoins énergétiques, mais il faut aussi s'assurer que la qualité de leur régime alimentaire est adéquate. Le terme qualité de l'alimentation se réfère à un régime qui assure un apport adéquat en nutriments essentiels, en particulier les micro-nutriments, soit les vitamines et les minéraux, qui sont essentiels pour assurer la santé, la croissance, le développement et la survie des individus.

Il est maintenant reconnu que les carences en micro-nutriments sont parmi les problèmes nutritionnels les plus répandus dans le monde et que la carence en fer, par exemple, est un problème extrêmement fréquent chez les femmes, y compris celles qui vivent dans les pays industrialisés (fig. 1).

Figure 1.

L'importance des problèmes nutritionnels dans le monde.

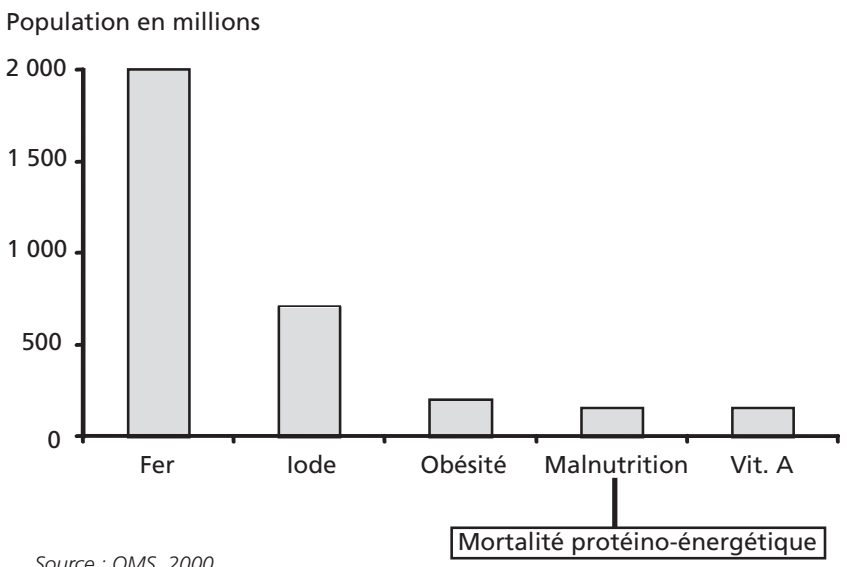


Par ailleurs, avec le phénomène d'urbanisation rapide que connaissent de nombreux pays en développement, l'obésité est maintenant un des problèmes nutritionnels les plus communs, au troisième rang après les carences en fer et en iode. Cette tendance est due principalement aux énormes changements dans les modèles alimentaires qui, à leur tour, sont dus en grande partie à la croissance économique, à l'augmentation de la disponibilité d'un nombre varié d'aliments et à un accès plus facile à ces aliments, même parmi les fractions les plus pauvres de la population. Les changements dans le style de vie, incluant un rythme de vie accéléré et l'incorporation d'un nombre croissant de femmes sur le marché du travail, contribuent également aux changements dans les habitudes alimentaires. Les populations consomment de plus en plus d'aliments prêts à servir (fast food), lesquels ont souvent une forte teneur en sel, en sucre raffiné et en graisses saturées. Ces éléments, lorsqu'ils sont consommés en trop grande quantité, et aux dépens des fruits et légumes frais, des céréales à grain entier et d'autres aliments riches en fibres, augmentent les risques de maladies chroniques telles que les maladies cardio-vasculaires, le diabète, l'obésité et certaines formes de cancer. Ces problèmes, qui autrefois étaient concentrés chez les populations de niveau économique élevé, sont maintenant de plus en plus communs au sein des populations à faible revenu, même dans les pays en développement. Ce phénomène global lié à l'urbanisation et à la mondialisation est appelé transition nutritionnelle.

Le résultat de ces tendances est un nouveau paradigme : les pays en voie de développement, qui sont toujours aux prises avec l'énormité du problème de la malnutrition, doivent maintenant développer de nouvelles approches et stratégies pour aussi prévenir (et réduire) la croissance des maladies chroniques et de l'obésité. Ce phénomène, dénommé « double fardeau », afflige un nombre croissant de pays à divers niveaux de la transition nutritionnelle. On peut observer ce phénomène de coexistence des problèmes de malnutrition et d'obésité au sein d'un même pays et les changements dans l'importance relative de l'obésité à mesure que les pays progressent dans leur développement économique (fig. 2).

Il est important de reconnaître aussi que les problèmes d'obésité et de maladies chroniques ne sont plus uniquement des problèmes de « riches ». Un exemple frappant est celui du Mexique (fig. 3), où 
Figure 2.

Coexistence de la malnutrition et de l'obésité.

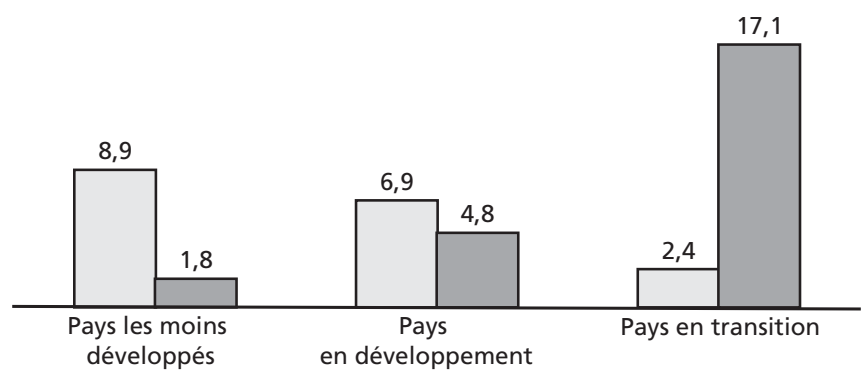

$\square \mathrm{IMC}<17$ (malnutrition) $\square \mathrm{IMC}>=30$ (obésité)

IMC : Indice de Masse Corporelle

Source : www.who.int/nut/db_bmi.htm

Figure 3.

L'embonpoint n'est pas seulement un problème de riches.

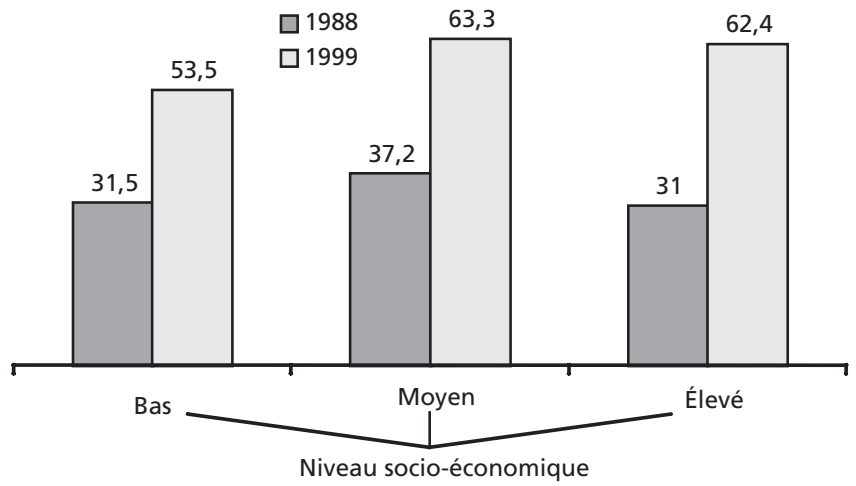

Les chiffres indiquent la prévalence de l'embonpoint en pourcentage de la population. L'embonpoint est mesuré par un Indice de masse corporelle supérieur à 25.

la prévalence de l'embonpoint au sein des populations à plus faibles revenus était presque aussi élevée (53,5\%) que chez les groupes à plus hauts revenus $(62,4 \%)$ en 1999. Laugmentation extrêmement rapide de l'embonpoint à travers tous les groupes socio-économiques au cours d'une période d'à peine 10 ans est aussi très frappante et témoigne à la fois de l'importance et de la rapidité du phénomène de la transition nutritionnelle dans certains pays. 
Le but principal du programme de l'Ifpri est d'identifier les politiques alimentaires et nutritionnelles qui peuvent aider à améliorer la qualité des régimes alimentaires des populations pauvres. Ce programme a pour objectif ultime la réduction et l'élimination des carences en micro-nutriments et la prévention des effets néfastes de la transition nutritionnelle.

\section{Le programme de biofortification}

En collaboration avec le Centre international sur l'agriculture tropicale (Ciat), l'Ifpri a récemment mis sur pied un vaste programme de recherche et de communication sur la biofortification. Ce programme définit la biofortification comme étant « l'utilisation de méthodes traditionnelles et avant-gardistes pour augmenter la teneur en micro-nutriments de certaines cultures de subsistance, avec comme objectif ultime l'amélioration de l'état nutritionnel des individus et populations qui les consomment ». Lélimination des carences en micro-nutriments requiert l'intégration d'une variété d'approches complémentaires, telles que l'approvisionnement en suppléments des groupes de population les plus à risques, l'enrichissement de certains produits alimentaires consommés par la majorité de la population ainsi que la diversification alimentaire. La biofortification est une approche additionnelle et complémentaire qui a l'avantage de pouvoir atteindre les populations les plus marginales, c'est-à-dire celles qui vivent de l'agriculture de subsistance de même que les populations qui reçoivent la majorité de leurs calories et autres nutriments des céréales de base. Un autre avantage de la biofortification est que, contrairement à d'autres approches comme par exemple la diversification alimentaire, elle ne requiert pas que les populations changent leurs habitudes alimentaires. La biofortification permet aussi d'améliorer l'état nutritionnel des populations en fournissant plus d'un micro-nutriment à la fois ; par exemple, la sélection de variétés à haute teneur en fer permet habituellement d'obtenir aussi une haute teneur en zinc. Qui plus est, les variétés à haute teneur en minéraux comme le zinc et le fer sont également des variétés offrant de nombreux avantages agronomiques, tels qu'une meilleure résistance aux infections et un plus haut rendement. Le résultat est une situation où tous les partis sont gagnants : les producteurs bénéficient de produits 
agricoles plus performants et les consommateurs bénéficient d'aliments plus riches en micro-nutriments.

\section{L'analyse de l'établissement des politiques et du rôle de l'État, du secteur privé et des sociétés civiles}

Cette recherche se centre sur les thèmes suivants :

- les rôles complémentaires des différents intervenants et secteurs dans le domaine de la politique alimentaire et les responsabilités qui leur incombent, y compris les outils nécessaires à une politique visant à une information efficace des populations en situation de précarité alimentaire et le besoin d'orientations internationales cohérentes sur la sécurité alimentaire ;

- la manière dont est structurée la politique visant à améliorer la sécurité alimentaire et nutritionnelle - comprenant l'influence de la recherche sur la mise en place des politiques - et la manière dont les politiques sont appliquées, y compris les rapports entre la santé, l'alimentation et la nutrition ;

- le niveau des gouvernements (décentralisation) dans l'accomplissement des politiques liées à la sécurité alimentaire et dans la mise à disposition de biens publics liés à la nutrition ;

- les principes d'une bonne gestion publique, comme la prise de responsabilités, les droits de l'homme (y compris le droit de l'homme à une alimentation adéquate), la transparence et la conscience sociale de la gestion des entreprises au sein du système alimentaire.

Le fait d'associer plus étroitement la recherche sur l'appartenance sexuelle à la recherche sur les systèmes politiques et sur la gestion publique apportera un nouveau regard sur la situation. LIfpri et ses partenaires sont aussi en train d'accroître la recherche actuelle visant à comprendre le rôle des institutions de marché et non commerciales au sein des systèmes alimentaires locaux et nationaux.

\section{Conclusion}

Il est possible d'accélérer considérablement le progrès vers l'Objectif de Développement du Millénaire visant à réduire de 
moitié la faim dans le monde dans les douze années à venir, et d'avancer rapidement vers la concrétisation d'une sécurité alimentaire durable pour tous. Les activités de recherche sur les politiques alimentaires, de renforcement des capacités et de communication des politiques qui sont menées par l'Ifpri et ses organisations partenaires sont à même de jouer un rôle essentiel dans l'éradication de la faim. Le gain sera énorme en termes de bienêtre humain, de croissance économique, d'équité et de durabilité écologique. 


\section{Des politiques de nutrition Responsabilités des politiques et des chercheurs}

\section{Mohamed AG. BENDECH}

Nutritionniste

La nutrition est au carrefour d'un certain nombre de disciplines. Elle a aussi plusieurs dimensions qui doivent être prises en compte pour assurer sa contribution effective au développement national.

Chacun de nous ici se sent responsable de renseigner le Politique. Or les politiques de nutrition sont envisagées à plusieurs niveaux, notamment international, régional et national, et ces différents niveaux de formulation et de mise en œuvre de politiques sont interdépendants. Il me semble donc qu'ils ne peuvent pas être dotés d'autonomie totale si l'on veut progresser vers la complémentarité et la synergie de leurs résultats.

Quel que soit le niveau considéré, trois constats peuvent être dégagés. Premièrement, l'importance de la nutrition (fréquence, causes, conséquences et stratégies d'intervention) est de plus en plus reconnue dans certains milieux de décision du Nord et du Sud. Cela se traduit par sa prise en compte dans les objectifs du sommet mondial de l'Enfance, mais aussi, comme l'écrit Marie Ruel, dans les Objectifs de Développement du Millénaire et de plus en plus, dans les pays du Sud, dans le cadre stratégique de la lutte contre la pauvreté.

Deuxièmement, des recherches ont clairement établi les liens possibles entre la nutrition et les autres secteurs tels que l'agriculture, la santé, l'éducation, l'économie et l'environnement. 
Troisièmement, des évolutions rapides sont apparues, caractérisées par des transitions nutritionnelles assez complexes observées dans plusieurs pays du Sud où l'on parle actuellement du triple fardeau (infections, carences et pathologies de "surcharge »). Cette complexité n'est pas encore prise en compte dans les politiques actuelles. Par ailleurs, une question fondamentale me semble être : faut-il changer les politiques actuelles pour réduire ces décalages qu'on observe entre les besoins rendus, les besoins découlant de la situation nutritionnelle, et la rigidité, je souligne le mot, la rigidité actuelle des politiques de nutrition existantes ?

Qu'est-ce qui doit nous guider si l'on doit aller dans le sens de changements de politique ? Qu'est-ce qui doit guider les changements souhaités ? Et quelle doit être cette nouvelle vision reflétée par ces politiques de nutrition ?

Il faut d'abord préciser la vision commune que l'on souhaite entre deux options alternatives : celle qui consiste à voir les politiques de nutrition comme des entités autonomes et complémentaires des autres politiques gouvernementales sectorielles - comme celles de l'agriculture, de la santé et de l'éducation - et celle qui en fait seulement des composantes de ces politiques sectorielles.

La situation actuelle est très hétérogène, au Nord comme au Sud. Dans plusieurs pays, les politiques de nutrition sont dotées d'une certaine autonomie et existent dans le même ordre de considération que les autres politiques sectorielles. En revanche, dans d'autres pays, la nutrition n'est qu'une composante des politiques sectorielles.

La formulation de ces politiques ne se fait pas sur la base d'une analyse de situation rigoureuse et ne repose pas sur les évidences scientifiques les plus récentes. Or, la formulation des politiques doit mériter un effort aussi important que les autres étapes du processus, comme la mise en œuvre. Elle doit se faire, je pense, dans un cadre global privilégiant la prévention et la prise en compte des problèmes émergents, des besoins des pauvres et de l'ensemble des groupes spécifiques.

La gestion et la coordination de la mise en ouvre des politiques de nutrition est une autre étape essentielle à surveiller.

Il faut s'assurer de qui fait quoi, et avec quelles ressources et quelles compétences. En effet, dans les pays du Sud surtout, les ressources humaines compétentes, expérimentées et stables sont 
rares. Or, elles sont indispensables pour traduire l'engagement des gouvernements en programmes efficaces.

Pour moi, on ne capitalise pas assez dans les programmes politiques les leçons apprises du passé. Et je ne suis pas persuadé que le plaidoyer, dans le domaine de la nutrition, suffise à mobiliser les ressources, notamment les ressources humaines, sur lesquelles j'insiste énormément.

Et enfin, comment s'assurer que chaque secteur programme les interventions relevant de sa compétence tout en respectant la cohérence d'ensemble ?

Je pense que la réponse à cette dernière question peut prévenir des conflits institutionnels qui sont souvent relevés dans le secteur de la nutrition.

Le dernier aspect que je souhaite souligner relève de l'évaluation et de la recherche dans le domaine de la nutrition.

Il me semble important de mettre l'accent, avec Francis Delpeuch, sur la recherche de nouveaux modèles d'intervention. Il faut aussi mettre au point de nouveaux modèles d'évaluation pour renseigner régulièrement les décideurs sur les évolutions et les adaptations à opérer. Ces modèles d'évaluation doivent permettre de comprendre les processus, mais aussi d'apprécier les changements.

Une question que l'on pourrait se poser dans le domaine de l'évaluation des politiques est la suivante : comment instaurer un débat juste et équitable sur les solutions proposées par la recherche? Le cas de la biofortification évoqué par Marie Ruel illustre bien cette nécessité. L'utilisation des plantes fortifiées par transgenèse est en voie d'être considérée comme une arme pour lutter contre la faim dans le monde. Face à cette question, le débat est engagé et des législations sont soit élaborées, soit en voie de l'être dans les pays du Nord. En revanche, dans les pays du Sud en général et en Afrique en particulier, cette question est rarement évoquée.

Il s'agit bien maintenant, pour résumer, d'instaurer des débats dans la perspective de mettre à la disposition des décideurs des solutions justes et équitables, en se penchant principalement sur la dimension humaine.

Un des enjeux que j'y vois est celui de l'autonomie de la recherche dans le domaine de l'alimentation et de la nutrition, particulièrement dans les pays du Sud, mais aussi dans les pays du Nord. 

Partie 3

Concevoir

une nouvelle

cohérence

des politiques

agricoles

et alimentaires 



\section{Politiques alimentaires et agricoles en Afrique subsaharienne}

\section{Le possible et le nécessaire}

\section{Georges COURADE}

Économiste

«Aujourd'hui les politiques agricoles se retrouvent quasiment nues face à la question déterminante du prix des produits agricoles, privées des instruments essentiels que sont les droits de douane, les systèmes de gestion de l'offre et de stabilisation des prix.

Cette situation est particulièrement dramatique pour les producteurs des pays qui n'ont pas les moyens

d'adopter un système d'aides directes alors que les pratiques de découplage des pays riches tendent à consolider la tendance aux bas prix mondiaux. »

A. Danau (2003)

Parler de politique (policy) dans les domaines de l'agriculture et de l'alimentation suppose de relier ces questions à un milieu géographique investi, à un territoire et à des producteurs qui sont des paysans, des exploitants ou des entrepreneurs. C'est comprendre les formes de connivence entre États, monde agricole et industrie agroalimentaire (politisation de ces formes de concertation et d'alliances diverses ou politics), mais aussi la globalisation que ce secteur a été un des premiers à expérimenter. On est à la fois « enraciné » dans un 
terroir, attentif aux politiques publiques clientélistes tout en étant au cœur de la mondialisation, ce qui n'est pas sans donner le tournis, d'autant que, dans l'ensemble de ces échelles, agriculture et alimentation sont à la charge de plus en plus des acteurs dominants et dominés, par suite « du moins d'État » mondial et national. Et l'ombre portée des grands producteurs mondiaux (USA, Europe, groupe de Cairns ${ }^{1}$ ) reste un phénomène majeur qui interdit toujours certaines évolutions souhaitables. Parler de politique publique enfin, c'est se situer parmi les tenants de l'État palliatif et/ou régulateur au plan de la théorie économique. Notre vision du devenir de l'agriculture et de la gestion des territoires géographiques nous y conduit naturellement : l'État produit du territoire agricole, l'aménage et cherche à canaliser les flux marchands et financiers pour assurer la sécurité alimentaire et garantir le développement durable. Il était important de l'indiquer en préalable à ce texte pour éviter tout malentendu.

Dans ce contexte, la référence au paysan, à la paysannerie, rituelle parfois, me semble devoir être relativisée, si ce n'est à titre de mythe fondateur et mobilisateur du mouvement rural familial, car « entrer en développement, pour une société paysanne, c'est nécessairement prendre place dans un espace économique plus vaste que son propre espace, où la décision lui échappe toujours plus ou moins. C'est en fait participer à un mouvement qui, à plus ou moins brève échéance, fera d'elle autre chose qu'une société paysanne » (Couty, 1984).

Ce texte se propose de survoler les dynamiques locales/globales dans le secteur agricole et alimentaire et d'évaluer les chances de mise en œuvre de politiques alimentaires et agricoles dans les pays du Sud les plus vulnérables, africains notamment, dans le contexte actuel de libéralisation et de normalisation. À l'ouverture toujours plus grande des marchés s'ajoute un grand effort de normalisation des produits pour définir des qualités, des compositions et se prémunir contre les risques sanitaires. Cet effort de normalisation s'exerce à différentes échelles par le biais de l'autodiscipline, qui tend à se substituer à une réglementation contraignante d'origine étatique.

1 Ce sont les pays exportateurs agricoles qui, forts de leurs coûts de production et d'une faible instrumentation du vote " paysan ", combattent toute forme de protection de l'agriculture (Australie, Nouvelle-Zélande, Argentine, etc.) au nom de la liberté du commerce. 
Compte tenu de l'ampleur du sujet et de la diversité des situations, parler du Sud en général n'avait pas de sens. Nous avons choisi de nous centrer sur le sous-continent qui pose le plus de problème, l'Afrique noire, en le comparant à l'Inde. L'Union indienne et l'Afrique subsaharienne sont en effet les grandes régions de la planète les plus touchées par la vulnérabilité alimentaire et nutritionnelle, tout en affichant des résultats agricoles opposés : autosuffisance d'un côté, dépendance de l'autre. Dans les années soixante, on craignait la famine récurrente en Inde et ce pays l'évita en 1966 grâce à plus de 10 millions de tonnes de céréales américaines ! Et il surmonta cette malédiction à partir des années quatre-vingt grâce à une politique d'augmentation de l'offre combinée à une politique alimentaire fondée sur la redistribution de stocks importants. En 2003, l'Inde exporte des aliments, conduit le groupe des 21 dans la conférence de l'OMC à Cancún, connaît une croissance de plus de $8 \%$ annuels, alors que l'Afrique subsaharienne a évité de justesse une pénurie alimentaire touchant l'Afrique australe, orientale et la corne de l'Afrique, et n'affiche qu'un taux de croissance de moins de $4 \%$, susceptible seulement de stabiliser les revenus, la croissance de la population restant encore forte. Alors que quatre pays sahéliens se sont battus sans succès contre les subventions accordées aux quelques milliers de planteurs de coton américains au nom de leurs propres planteurs de coton, l'Inde se range aux côtés des agro-exportateurs capitalistes comme le Brésil, ayant oublié qu'elle fut liée à Liverpool pour ce même coton ! En fait, elle a " décolonisé » son économie agricole, ce que l'Afrique n'est pas parvenue à faire. La population de l'Inde va dépasser celle de la Chine et les cinquante États d'Afrique subsaharienne vont afficher, en 2030, 1,2 milliard d'individus, dont la moitié de ruraux. C'est dire l'importance que revêtent ces questions pour les plus démunis dans les campagnes comme dans les villes de ces régions.

\section{Ce que politiques alimentaire et agricole veulent dire}

Mettre l'accent sur les politiques alimentaires, c'est mettre au centre des préoccupations le consommateur, qui peut ne pas être 
producteur et rural et qui se préoccupe de son accès géographique et économique à une alimentation de qualité sanitaire correspondant à ses goûts (libre arbitre que combattent parfois les normes nutritionnelles, comme on le voit autour de l'alimentation carnée et végétarienne). Il peut y avoir ainsi contradiction entre politique agricole et politique alimentaire, l'une productive, voire productiviste, l'autre sanitaire, nutritionnelle et sociale, quant aux prix et aux formes de régulation des quantités stockées et aux normes applicables aux uns et aux autres. Aborder les politiques publiques dans un secteur suppose aussi la prise en considération des choix macroéconomiques comme variables contraignantes majeures quand ceux-ci se déclinent en termes d'ajustement structurel.

La politique agricole stricto sensu se réfère sur le plan économique à toutes les mesures directement soumises au contrôle du gouvernement : politique des prix et mesures fiscales, y compris taux de change et subventions. Elle se réfère aussi aux objectifs et moyens des institutions mises au service du monde rural et aux dépenses de l'État pour l'agriculture et le monde rural. La politique alimentaire englobe tous les efforts collectifs des gouvernements pour influencer les milieux responsables, les agriculteurs, les consommateurs et les agents de commercialisation alimentaire, prévenir famines et pénuries alimentaires, et améliorer l'alimentation des plus vulnérables tout en préservant l'accès économique, géographique et temporel à un bol alimentaire convenable pour l'ensemble de la population. Non autonomes, ces politiques s'insèrent dans des stratégies globales, des projets de société implicites ou explicites. Elles résultent d'un arbitrage permanent entre groupes sociaux et opérateurs du système alimentaire dont les intérêts sont contradictoires, si ce n'est opposés. La régulation du système est donc primordiale, qu'elle relève des instruments de l'État (contrôle des prix, importations et stockages de régulation ou de sécurité, garanties par des normes et des contrôles de qualité, distributions ciblées géographiquement ou socialement, et subventions aux produits alimentaires de base, aides sociales ou alimentaires, projets nutritionnels, etc.) ou du marché ou d'un mélange évolutif des deux.

Repenser les politiques publiques en Afrique ne doit pas nous conduire à remettre en question les fonctions " régaliennes » de l'État, qui comprennent tout autant la sécurité alimentaire et sanitaire que la sécurité publique des personnes dans des pays soumis 
à des risques alimentaires majeurs, même si nous devons considérer les échelles géographiques et les arrangements sociaux leur permettant de répondre aux problèmes posés. Subsidiarité et « politiques intermédiaires » seront ainsi mises en avant dans la recherche de politiques alimentaires et agricoles adaptées au contexte, ce qui supposera une redéfinition des rapports à l'État central.

\section{Ce qui change avec la globalisation actuelle}

Lagriculture et l'alimentation ont connu dès l'Antiquité romaine des processus d'internationalisation plus ou moins prononcés, si bien que la globalisation n'est pas un phénomène nouveau pour les professionnels de la terre et de l'agroalimentaire qui ont appris à la subir comme à s'y mouvoir pour y faire prévaloir leurs intérêts, avec une efficacité différentielle entre le Nord et le Sud, et pour s'y affronter avec des armes productives inégales. Il faut penser local et raisonner global pour définir des politiques agricoles et alimentaires réalistes. Lactuelle phase de globalisation ne fait que changer la donne par les nouveaux outils qu'elle propose et les nouvelles formes de régulation qu'elle tente d'imposer : utilisation des produits financiers dérivés de couverture (hedge funds) pour tenter de maîtriser la volatilité des prix ou spéculer, pressions hégémoniques pour libéraliser les marchés et diminuer les stocks de sécurité et de régulation, prolifération de normes sanitaires, productives et éthiques d'autodiscipline visant à limiter les effets négatifs d'une production et d'une transformation anarchiques et peu vigilantes à l'égard de la gestion de la planète ou du sort des paysanneries pauvres (commerce équitable).

La masse des producteurs agricoles enfin, s'ils ne constituent pas la totalité des pauvres de la planète au sens de la Banque mondiale (moins de 2 \$ par jour et par personne) et selon les indicateurs de développement humain (voir le rapport annuel du Pnud), représente cependant plusieurs milliards d'individus. Et ils se trouvent dans des nations démunies ou émergentes, incapables de mettre en œuvre politiques agricoles ou alimentaires ou ayant opté pour la pressurisation des campagnes et un exode rural massif pour réaliser un développement à marche forcée (Extrême-Orient). 
Qui plus est, les contours de la pauvreté monétaire ne correspondent pas à la géographie de la vulnérabilité qu'est supposée combattre la politique alimentaire et nutritionnelle. Autrement dit, si les « pauvres » subissent les risques alimentaires, de nombreux « non-pauvres » restent vulnérables parmi les ruraux, les ajustés des villes ou les groupes familiaux construits hors du système communautaire habituel (familles monoparentales, etc.). Cette difficulté à appréhender les groupes vulnérables n'est pas sans poser des problèmes pour tout projet politique visant ces populations-cibles (problème de coût/avantage compatible avec les budgets disponibles).

\section{Les déterminants du dépérissement apparent de l'État africain}

LAfrique subsaharienne est loin d'être sortie des mesures d'ajustement en 2004. Le Cameroun par exemple, éligible à l'initiative PPTE (Pays pauvres très endettés) d'allègement de sa dette, achève son huitième programme d'ajustement structurel. Qui dit ajustement dit mise sous tutelle des finances de l'État par le Fonds monétaire international et révèle, d'une certaine manière, une incapacité à mettre en œuvre une politique agricole, alimentaire ou nutritionnelle, même si la volonté politique existait et même si les fonds dégagés par l'initiative PPTE utilisée à $10 \%$ de leur montant permettaient dans ce vaste secteur des projets articulés.

À cet élément extérieur invalidant l'initiative étatique s'ajoute l'état de délabrement de l'État, rongé de l'intérieur par la corruption et par ses choix redistributifs. Pour se rendre compte de la situation, prenons l'exemple du Nigeria (Courade, 1986 ; Courade et Marchal, 1994), le pays le plus peuplé de l'Afrique subsaharienne libéré récemment d'une " dictature » prédatrice, celle de Sani Abacha. Lagriculture y fut un fleuron lors de l'indépendance. Il fut ainsi dans les années soixante numéro 1 mondial dans la production d'huile de palme qu'il importe aujourd'hui et un producteur important de coton et de cacao, sans compter sa place au premier rang des productions vivrières (ignames ou sorgho). Voilà pourtant un pays disposant d'une manne pétrolière 
conséquente à partir des années soixante-dix et qui a dilapidé une partie de ses ressources agricoles en une décennie, suite au «syndrome hollandais » : aggravation des disparités ruraux-citadins par suite d'augmentations générales de salaires produisant de l'inflation, importations considérables d'aliments et exode rural massif, tout cela asphyxiant les producteurs ruraux. Le traitement de choc du FMI dès 1983, s'il a désengorgé les ports nigérians et appauvri l'ensemble des consommateurs, n'a pu recréer l'importante base agricole de ce pays. Le rétablissement espéré des grands équilibres est pourtant passé par la stabilisation de la demande et la relance de l'offre productive, agroalimentaire notamment.

Le tableau 1 donne les éléments structurant le diagnostic du FMI qui a conduit à cette situation d'appauvrissement généralisé, reconnu depuis peu par les institutions de Bretton Woods. Il faut ici souligner combien il est difficile de reconstituer le système agricole d'un pays une fois qu'il a été mis à bas, en s'en tenant à une approche sectorielle incapable de refonder les liens systémiques et la dynamique du monde agricole.

\section{Tableau I.}

Le diagnostic de crise du FMI (Hugon, 1985).

\begin{tabular}{|c|c|c|}
\hline Causes & Symptômes & Effet \\
\hline \multirow{4}{*}{$\begin{array}{l}\text { Excès de demande } \\
\text { sur l'offre }\end{array}$} & Excès de masse monétaire & Inflation \\
\hline & Salaires élevés & Déficits budgétaires \\
\hline & Pas d'épargne publique & $\begin{array}{l}\text { Recours massif } \\
\text { aux investissements } \\
\text { extérieurs }\end{array}$ \\
\hline & $\begin{array}{l}\text { Excès de consommation } \\
\text { des administrations }\end{array}$ & Endettement de l'État \\
\hline \multirow[t]{4}{*}{ Prix administrés } & Faibles prix agricoles & $\begin{array}{l}\text { Déficit et importations } \\
\text { alimentaires }\end{array}$ \\
\hline & $\begin{array}{l}\text { Prix subventionnés } \\
\text { au consommateur }\end{array}$ & $\begin{array}{l}\text { Déficit des entreprises } \\
\text { publiques }\end{array}$ \\
\hline & Taux de change surévalué & $\begin{array}{l}\text { Déficit commercial } \\
\text { et des paiements }\end{array}$ \\
\hline & Taux d'intérêt réels négatifs & $\begin{array}{l}\text { Insuffisance d'épargne } \\
\text { intérieure }\end{array}$ \\
\hline
\end{tabular}


Parler de politiques publiques alimentaires et agricoles des pays du Sud, c'est donc pour la plupart des pays tenter de qualifier un objet non identifié actuellement. La question qui se pose se trouve être par conséquent la nécessité de ces politiques et, si la réponse est positive, la capacité des pays du Sud d'en conduire une. Et pourtant, la nécessité d'une intervention étatique dans le domaine de la production des aliments, de leur circulation et de leur accessibilité ont mobilisé l'attention vigilante des empires chinois et romain avant notre ère ! On n'imagine aucun État africain en mesure de réaliser une politique agricole mobilisant les capitaux que l'Europe ou les États-Unis peuvent mettre en ouvre. Il faut donc explorer les formes d'action qui ont des coûts-avantages permettant d'atteindre graduellement les objectifs assignés à ces politiques : autosuffisance satisfaisante, sécurité alimentaire minimale des plus démunis ou sécurité nutritionnelle et sanitaire renforcées.

En tout état de cause, il n'y a pas de politique publique sans État. Les signes du dépérissement étatique africain n'annoncent pourtant pas un État cliniquement mort. Loin s'en faut, si l'on interroge les habitants du pays. Le sentiment national ne fait pas de doute dans l'ex-Zaire, RDC, malgré le dépeçage du pays et le pillage massif et prolongé des ressources. Dans des pays hors de l'œil du cyclone de la guerre civile, l'État douanier, gendarme, percepteur, voire banquier ou producteur existe encore. Parfois solidement, comme au Burkina Faso, au Cameroun ou au Mali par exemple.

Avant de parler de «volonté politique », il faut parler de choix coordonnés à long terme, fondés sur une légitimité et une capacité à intervenir. Si l'Inde a un État puissant, qu'en est-il de l'Afrique subsaharienne ? On a assisté ces deux dernières décennies à la privatisation de la souveraineté (RENO, 1999) dans la quasi-totalité du sous-continent. La levée des impôts et des droits de douane dans de nombreux pays relève de sociétés privées. Le contrôle politique du territoire et des populations qui y vivent reste ténu dans de nombreux pays en proie ou non à des guerres civiles. La privatisation de pans entiers de l'économie et des domaines régaliens de l'État reste cependant un tour de passe-passe permettant aux élites comme aux dirigeants de continuer à percevoir les bénéfices des rentes externes (marché juteux des changes au Nigeria, vente du cacao ghanéen via le Togo) comme internes (diamants en 
Sierra Leone, or, cobalt, diamants en RDC, etc.). Au Zaïre de Mobutu, tout s'achetait et se vendait via des filières clandestines visibles par tous ! Les budgets officiels en faveur de l'agriculture ne dépassaient pas cependant $1 \%$ du budget total au Gabon ou au Congo dans les années quatre-vingt ! Lappareil administratif a été sérieusement dégraissé (ajustement oblige), parfois divisé par 12 comme au Zaïre ou par 5 comme au Nigeria avec le départ des fonctionnaires dépensiers (éducation, santé, agriculture).

Les dirigeants d'États fantômes gardent cependant la haute main sur les relations internationales, qui restent profitables à la reproduction de leur pouvoir (maintien du système d'alliance et d'affiliation), mais ils estiment contre-productifs pour leur maintien au pouvoir les investissements sociaux et agricoles. Et ils bénéficient de l'aide internationale comme de celle de forces extérieures (gendarmes français, notamment). À l'intérieur, ils survivent en appliquant de manière sélective les lois, en divisant leurs opposants éventuels et en sapant l'appareil bureaucratique. Pour les firmes multinationales, la continuité apparente d'États sans capacité à administrer reste cependant essentielle pour sécuriser leurs transactions ou conserver leur notation. Elles s'installent donc dans des enclaves sécurisées, des États dans l'État.

Enfin, peut-on parler de politiques alimentaires là où il n'y a pas d'État-providence, de protection face aux grands risques de la vie et d'action sociale à l'endroit des plus démunis ? Certains grands pays émergents comme le Mexique sont allés fort loin. Le système alimentaire mexicain, tentative populiste d'encadrer la population, fut démantelé suite aux déséquilibres budgétaires qui entraînèrent une dévaluation. Sécuriser l'alimentation du Sud, c'est demander à l'État-protecteur (pour ses producteurs et ses groupes vulnérables) d'être aussi assureur en dernier ressort face aux catastrophes naturelles et au jeu de yo-yo des prix dans la suite logique de l'État bismarckien. Cela renvoie aussi aux deux questions fondamentales sur l'État soulevées par Aristote qui dépassent le domaine agro-alimentaire : quel est le meilleur gouvernement et qui est en capacité de gouverner ? Il est en effet difficile de dépolitiser le politique comme l'avancent les institutions de Bretton Woods avec le mot-valise de « bonne gouvernance » et l'on sait bien que le « management » ne peut faire l'économie de la légitimation de l'autorité. 
Y a-t-il aujourd'hui des éléments politiques ou technologiques qui supposeraient une modification d'approche dans le domaine agroalimentaire ? Les objectifs du Millénaire en matière de réduction du nombre de sous-alimentés et de malnutris ne sont pas atteints, si bien que l'on propose pour les pays d'Afrique la révolution transgénique que l'on refuse dans certains pays du Nord par crainte de risques encore non précisés, la biotechnologie n'ayant pas mesuré les effets non désirés de l'introduction massive des nouvelles plantes dans les champs et les assiettes. La demande de normes dans un domaine aussi sensible reste donc très forte et se traduit par des textes multiples, nationaux et internationaux, que scrute avec de plus en plus de vigilance une société civile mondiale auto-proclamée ! Il faut donc se résigner à penser que pénuries, malnutrition, voire disettes n'ont pas d'effets dévastateurs sur la reproduction politique du pouvoir, démocratique ou pas. La faible réduction de la vulnérabilité indienne par le BJP (Bharatiya Janata Party : Parti du peuple indien) semblerait corroborer cette idée : les famines étaient autrement plus inacceptables pour « la plus grande démocratie au monde » à l'époque du parti du Congrès !

\section{Des politiques avec contraintes ou des contraintes sans politique ?}

Si l'Inde affiche ainsi son intention de jouer dans la cour des Grands, c'est qu'elle a eu une politique agricole très élaborée, reflétant le nationalisme alimentaire volontariste des dirigeants, soucieux de ne pas dépendre de la puissance américaine (souverainisme alimentaire ?). Elle reposa sur la " révolution verte » de première génération et une maîtrise élevée du milieu où celleci pouvait donner ses meilleurs résultats. Le prix acquitté pour cette politique fut élevé et parfois sous-estimé par les thuriféraires de cette révolution agricole : aggravation des inégalités géographiques et sociales, problématique céréalière (blé et riz au détriment des légumineuses), importation d'intrants plutôt que de céréales dans un premier temps (l'Inde fut le premier importateur mondial d'engrais), déflagration de Bhopal pour produire des pesticides, et problèmes écologiques majeurs. Autosuffisante, 
l'Inde a pu réduire le nombre de sous-alimentés qui restent encore très nombreux puisqu'elle n'a pas su ou voulu engager les réformes de structure permettant de réduire drastiquement le nombre de paysans sans terre. À partir des années quatre-vingtdix, elle s'insère graduellement dans le marché international, tout en gardant des stocks alimentaires élevés achetés sur le marché national et en ciblant mieux ses distributions subventionnées d'aliments. Les subventions aux intrants et les crédits bonifiés diminuent, mais persistent. Bref, elle a gardé une régulation interne forte en utilisant les exemptions des accords Gatt/OMC.

À l'inverse, l'Afrique subsaharienne, sous tutelle, entre après la dévaluation du franc CFA en 1994 dans l'ère libérale... à sa manière. L'héritage en termes de politiques était rudimentaire : stabilisation inopérante des cours de quelques produits exportés, péréquation souvent détournée de son objet entre riz importé bon marché et riz national hors de prix, subventions du peu d'engrais consommé, sociétés régionales de développement coûteuses, grands projets hydro-rizicoles ou sociétés de développement à bout de souffle et myriades de petits projets contradictoires, vulgarisation agricole training and visit à l'impact discuté, recherche agricole insuffisante et tournée vers les cultures d'exportation, etc. Limpression d'échec était souvent patente chez les petits paysans et les éleveurs, même si les planteurs et les maraîchers paraissaient s'en tirer. On a pu dire que les cultures coloniales de rente (cacao, café, coton, etc.) ont été les réussites de l'agriculture familiale africaine, avec, plus récemment, l'essor du maraîchage et du vivrier marchand «boosté » par la dévaluation du franc CFA. Pas de variétés améliorées dans le secteur vivrier traditionnel, peu ou pas de stocks de régulation alimentaire, fonctionnement des caisses contre les producteurs (ponctions), « biais urbain » plus ou moins manifeste, inefficacité des offices céréaliers bureaucratisés.

Lajustement structurel ne pouvait se présenter que comme une « réforme juste », même s'il faisait mal socialement. Le marché allait se charger de soutenir les plus pauvres, les ruraux et les producteurs et non les clients des régimes et les citadins comme avant, selon les experts de Washington.

C'était sans compter sur le jeu des acteurs, des dépendants des régimes, des importateurs, des « courtiers » du développement et des commerçants. Si l'approvisionnement a gagné en efficacité 
là où les bureaucraties cherchaient à réguler (régulation = ponction trop souvent), les prix varient très fortement dans les régions à soudure (période d'épuisement de la récolte précédente avant l'arrivée de la nouvelle, caractérisée par l'épuisement des greniers individuels, communautaires ou publics dans les zones à régime pluviométrique à longue saison sèche). Les privatisations « façon » ont souvent remis en selle les potentats habituels et les barons des régimes. Les incitations à la production dépendent des opportunités de marché, la consommation d'engrais au prix non subventionné a baissé, et la vulnérabilité alimentaire a augmenté.

\section{Les politiques possibles}

\section{Les choix essentiels de politique alimentaire}

Que peut-il rester des politiques alimentaires et agricoles dans ces conditions ? Faut-il des réserves de grains de sécurité ou de régulation, ou s'en remettre à une politique des flux tendus, quitte à ne pas disposer des quantités nécessaires en temps utile et au bon endroit ? Peut-on s'en remettre au marché pour organiser les échanges ou faut-il réguler par les greniers et les prix ? Faut-il apporter les nutriments manquants (médicaments, produits importés, plantes fortifiées par transgénèse) ou rechercher une solution paysanne locale ou nationale ? Peut-on toucher les plus vulnérables par des actions ciblées (femmes et enfants via dispensaires et écoles) ou subventionner les denrées de base consommées par les plus pauvres, eu égard au coût comparé de ces diverses actions ? Enfin, faut-il nourrir sa population par des importations bon marché, ou rétribuer mieux les producteurs, quitte à gérer des « troubles sociaux » en ville quand le pain, les haricots, le maïs ou le riz sont trop chers ? Vastes questions pour les politiciens et pour la Banque mondiale, supposée ne pas faire d'ingérence et prôner une "bonne gouvernance » (au sens de gestion technique efficiente des ressources et de recherche de compromis légitimes entre acteurs aux intérêts forcément contradictoires). Bref, le politique sans les jeux politiciens qui sont l'essence même du théâtre politique africain ! 
Si des pistes peuvent être proposées, une fois les grands choix entérinés, ce serait du côté des mesures indirectes adaptées à chaque contexte social, économique et écologique, produisant des effets sans coûts élevés tout en renforçant la négociation locale et régionale : réduire les incertitudes de l'environnement économique comme les risques productifs, soutenir des réseaux de greniers et stocks décentralisés visant à minimiser pénuries et hausses anormales des prix et s'engager dans des actions visant à diminuer la vulnérabilité des producteurs et des consommateurs à l'échelle la plus opérationnelle compte tenu des capacités des États. Bref, prévenir plutôt que guérir, jouer de sa légitimité pour mobiliser les volontés plutôt que de se substituer aux acteurs, adopter une politique prudente et non descendante redonnant aux communautés elles-mêmes dans le cadre des politiques intermédiaires le soin de négocier les arrangements nécessaires pour améliorer leur sécurité. On est loin de l'État-providence tout en s'acheminant vers un État de proximité.

\section{Les orientations de base des politiques agricoles en Afrique}

Quelques choix majeurs s'imposent dans le domaine agricole en relation avec les politiques alimentaires. Qui constituent les acteurs fondamentaux ? Les paysans, agriculteurs familiaux attachés à un terroir, ou les entrepreneurs agricoles ? Faut-il produire suffisamment sur son territoire pour sécuriser sa consommation (autosuffisance), ou avoir recours massivement à l'extérieur ? Quel équilibre trouver entre aliments de base et produits d'exportation, et comment appuyer les producteurs nationaux ? Des choix s'imposent naturellement dans certains pays, ailleurs, c'est plus ouvert.

Quelques spécificités africaines se doivent d'être prises en compte dans l'élaboration des politiques agricoles :

- les frontières nationales ne délimitent pas le champ d'action puisqu'elles constituent des lieux d'échanges agroalimentaires majeurs en fonction des politiques de change, de la convertibilité des monnaies et des choix de politiques de prix des pays frontaliers (Ghana par rapport au Togo ou à la Côte-d'Ivoire), d'où la nécessité de politiques agricoles sous-régionales ; 
- les spécialisations historiques ont empêché en bien des régions (pas dans toutes !) la convergence agriculture/élevage qui permet la reconstitution de la fertilité de certaines parcelles par fumure (et donc une intensification agricole) et l'utilisation possible de la traction animale qui démultiplie les possibilités de mise en valeur ;

- la tenure foncière se caractérise à la fois par la superposition et l'enchevêtrement de droits sur les terres, les cultures annuelles et arbustives et les pâturages, si bien qu'il n'y pas de " terres vacantes et sans maîtres » et que la compétition foncière devient un enjeu politique majeur là où des spéculations arbustives se sont développées en présence d'autochtones-allochtones (cacao dans le Sud-Ouest ivoirien). Ainsi, la colonisation de terres neuves s'avère très conflictuelle et l'imposition d'un cadastre foncier avec un droit de propriété de type romain peut déboucher sur des guerres civiles ;

- les systèmes d'irrigation ont été peu développés en Afrique précoloniale, si l'on excepte Madagascar et les côtes guinéennes faute d'État fortement coercitif (mode de production asiatique inexistant), si bien que les grands périmètres hydrauliques ont eu des succès mitigés malgré leur coût colossal : c'est donc sur l'agriculture pluviale ou de bas-fonds que l'on peut fonder un développement agricole ;

- le système filière-plante, s'il a donné de bons résultats pour les cultures de rente choyées par la sélection variétale, a laissé à la traîne les systèmes de culture associés cultures annuelles/arbustives, agroforesterie, d'où viendra sans nul doute une meilleure sécurisation alimentaire. Cette sécurisation suppose plus de recherche publique dans un secteur où celle-ci ne pourra pas se voir rémunérer par les paysans-clients qui survivent (est-ce réaliste ou faut-il mettre une croix dessus dans le contexte actuel de privatisation du peu de recherche consacrée aux plantes vivrières ?)

- les milieux écologiques africains sont divers et fragiles. Ils n'ont pas supporté la charrue des colons français et britanniques et ils n'ont pu accueillir de véritables révolutions vertes dans le secteur vivrier, si l'on met à part le mais hybride qui s'est largement développé en Afrique orientale où il était une culture traditionnelle : tout cela suppose un intérêt scientifique pour les plantes vivrières de base ( sorghos et mils, tubercules, féculents) et une recherche adaptative qui n'existe plus ; 
- les paysanneries africaines sont ouvertes à l'innovation qui maximise l'investissement travail et la profitabilité autant que le rendement à l'hectare, contrairement à ce qui est souvent avancé, mais c'est en se calant sur leurs stratégies économiques et sociales et leurs systèmes complexes de culture et de production qu'on peut les appuyer dans le sens souhaité ;

- l'urbanisation importante (50\% de la population vit en ville) comme des taux de change plus proches de l'équilibre (en zone CFA en 1994) ont permis au vivrier marchand (maraîchage, cultures de base) de conquérir ou reconquérir le marché intérieur en bien des pays et aux termes de l'échange rural-urbain de commencer à se rééquilibrer. Cela doit constituer un axe essentiel de la politique agricole ;

- les filières d'exportation ont été favorisées durant l'époque étatiste en ce qui concerne la distribution d'intrants (plantes améliorées, engrais subventionnés, crédits bonifiés) et l'appui institutionnel (priorité scientifique, coopératives, vulgarisation, etc.). Il en a été de même au plan macro-économique (stabilisation des prix, contrôles de qualité) ou pour créer un environnement porteur (pistes rurales, etc.). Un rééquilibrage s'impose.

En clair, il importe de repenser l'approche classique de la politique agricole, celle qui a été prônée jusque dans les années quatrevingt (tabl. 2).

\section{Les contraintes des évolutions à long terme}

Rappelons ici d'abord le fossé qui se creuse de plus en plus entre ce que recouvrent les termes de sécurité alimentaire et de développement durable en Afrique et en Europe, et ce qui en découle : OGM refusés par les Européens mais bons pour les Africains. Les États minima ne sont pas totalement démunis dans la situation actuelle en jouant sur les registres de la ruse où ils sont devenus imbattables et en mobilisant le peu de régulation mondiale qui existe. On peut utiliser les exemptions, détourner les conditionnalités, bref, contourner les pratiques dominantes conseillées, voire imposées, ce que ne manquent pas de faire l'Inde et l'Afrique subsaharienne avec plus ou moins de succès. Ils ne peuvent pourtant pas, pour des raisons internes comme externes, aller bien loin dans la mise en œuvre de politiques agricoles et ali- 
Tableau II.

L'approche productiviste classique de la politique agricole et ses objectifs.

\begin{tabular}{|c|c|}
\hline $\begin{array}{l}\text { Mise en valeur } \\
\text { de la base productive, } \\
\text { risques à contrôler } \\
\text { et aptitudes à valoriser }\end{array}$ & $\begin{array}{l}\text { Préserver les équilibres écologiques, prévenir } \\
\text { les dégradations et les risques, évaluer } \\
\text { les potentialités transformables en ressources } \\
\text { et l'aptitude culturale du complexe eau-sol-plantes } \\
\text { en fonction des technologies accessibles, } \\
\text { optimiser les rendements à l'hectare }\end{array}$ \\
\hline $\begin{array}{l}\text { Mobilisation } \\
\text { de la force de travail, } \\
\text { potentiel et contraintes } \\
\text { socio-économiques }\end{array}$ & $\begin{array}{l}\text { Mesurer pression et compétition foncières résultant } \\
\text { des densités et de la cohabitation des populations, } \\
\text { force de travail disponible et mobilisable sur place } \\
\text { ou par migration en fonction des revenus } \\
\text { et des activités, établissement d'un zonage } \\
\text { des productions en fonction des caractéristiques } \\
\text { population-milieu }\end{array}$ \\
\hline $\begin{array}{l}\text { Optimisation } \\
\text { agronomique } \\
\text { des systèmes et unités } \\
\text { de production }\end{array}$ & $\begin{array}{l}\text { Évaluation des combinaisons terre/travail/intrants/ } \\
\text { savoir-faire mises en œuvre par les exploitants, } \\
\text { des successions culturales et itinéraires techniques, } \\
\text { de l'association élevage-agriculture dans les systèmes } \\
\text { de production et optimisation dans un souci } \\
\text { de diversification, de sécurisation alimentaire } \\
\text { et de revenus plus importants }\end{array}$ \\
\hline $\begin{array}{l}\text { Régulation des filières, } \\
\text { prix et marchés }\end{array}$ & $\begin{array}{l}\text { Évolution de l'offre et de la demande à l'échelle } \\
\text { régionale, nationale et internationale par produit } \\
\text { et par agent et du commerce transfrontalier licite } \\
\text { et illicite, mesure de la compétitivité relative } \\
\text { des filières et des revenus à la journée de travail, } \\
\text { capacité des acteurs à assurer la commercialisation } \\
\text { à des coûts acceptables, quantités stockées, } \\
\text { régulation par les prix, les règlements, les normes }\end{array}$ \\
\hline Appui institutionnel & $\begin{array}{l}\text { Diffusion des innovations techniques et sociales } \\
\text { (recherche, vulgarisation, cadre incitatif, etc.), mise } \\
\text { en œuvre d'infrastructures efficaces (routes, } \\
\text { transport, hydraulique, crédit), efficacité des liaisons } \\
\text { inter-institutionnelles, suivi qualité de la production } \\
\text { et formation, évaluation des projets et maîtrise } \\
\text { des coûts organisationnels }\end{array}$ \\
\hline Macro-économie & $\begin{array}{l}\text { Poids de l'agriculture dans les finances publiques, } \\
\text { politique d'importation/exportation, discriminations } \\
\text { tarifaires et non tarifaires, taux de change favorable/ } \\
\text { défavorable, prospective par système agraire, zone } \\
\text { et produit, effets induits des politiques } \\
\text { dans les autres secteurs }\end{array}$ \\
\hline
\end{tabular}


mentaires, en fait sociales et nutritionnelles comme nous l'avons vu. Peut-on encore parler de politiques agricoles alimentaires nationales sans plaisanter et sans repenser la régulation mondiale (FMI, BM, OMC, etc.) ?

\section{Politiques sans État ou sans volonté ?}

On le sent bien aujourd'hui, une véritable politique alimentaire reste de l'ordre du discours politicien ou de l'hypothèse de travail, même dans des États-nations fortement charpentés et économiquement robustes. Du moins tant que la pression des choix du Nord et les évolutions tendancielles restent ce qu'elles sont. Si l'économie de marché n'a pas eu que des effets négatifs dans la sécurisation de l'approvisionnement, elle ne suffit pas pour résoudre la vulnérabilité alimentaire, pour faire face aux risques et pour augmenter la résilience des acteurs les plus démunis. On n'a jamais autant senti le poids du consensus de Washington avec la mise sous tutelle de la quasi-totalité des États du Sud par les institutions de Bretton Woods, la concurrence déloyale imposée aux agricultures du Sud par celles subventionnées du Nord et l'impact du consensus qui se dessine pour faire des OGM l'arme ultime contre les famines, etc. Par delà ce débat sur la globalisation actuelle, il faut constater aussi que les plantes orphelines (légumineuses, céréales dites secondaires, tubercules et féculents) sont toujours délaissées par la recherche " main stream », c'est-à-dire d'inspiration américaine, que les terres irrigables concentrent de plus en plus l'essentiel de la production agricole et que l'appareil industriel met toujours à très forte contribution le monde rural pour financer son développement ou en tirer sa force de travail (Europe de 1850 à 1950, Chine actuelle). Ces dynamiques de long terme peuvent-elles être inversées ou seulement aménagées? Il ne faut pas sans doute pas « insulter l'avenir »!

\section{Références bibliographiques}

Bhalla G. S., Racine J. L., Landy F., 2002 - Agriculture and the World Trade Organisation: Indian and French perspective. Paris, MSH, 316 p. 
Courade G., 1986 - « La dynamique de l'espace nigérian ». In : Le Nigeria contemporain, Paris, CNRS : 21-43.

Courade G., 1989 - « Le risque d'insécurité alimentaire : de l'imprudence écologique au démantèlement de l'État-providence ». In : Le risque en agriculture, Paris, Orstom : 575-597.

COURADE G., 1998 - Ajustement structurel et ouverture des marchés : moins de pénuries, mais de nouveaux risques alimentaires. Canadian Journal of Development Studies, 14 : 123-139.

Courade G. (éd.), 2000 - Le désarroi camerounais : l'épreuve de l'économie-monde. Paris, Karthala, coll. Économie et développement, 283 p.

Courade G., Marchal J.-Y., 1994 - « Nigeria, l'Afrique du nombre », « Les trois centres du Nigeria », « Nigeria : imprévisible trajectoire ». In Dubresson A., Marchal J.-Y., Raison J.-P. : Les Afriques au sud du Sahara, Paris, Belin-Reclus, Géographie universelle : 170-203.

Couty Ph., 1984 - Le développement rural en questions. Paris, IRD, $174 \mathrm{p}$.

DAnAu A., 2003 - « Collectif Stratégies alimentaires ». In Ray D.E. et al. : Repenser la politique agricole des États-Unis : changer d'orientation pour assurer des revenus aux agriculteurs du monde entier, Agricultural Policy Analysis Center, University of Tennessee (traduction française du CSA, Bruxelles).

EGG J., GABAS J. J. (dir.), s.d. - La prévention des crises alimentaires au Sahel : dix ans d'expérience d'une action menée en réseau (1985-1995). Paris, Club du Sahel, 210 p.

Griffon M., Henry P., Lemelle J. P., 1991 - Les politiques agricoles et alimentaires en Afrique : méthodes et outils d'analyse et d'aide à la décision. Paris, Mincoop, 186 p.

HugON P., 1985 - La crise financière en Afrique subsaharienne et l'intervention du Fonds monétaire international. Nanterre, Cahiers du Cernea, 13, 64 p.

RENO W., 1999 - « La privatisation de la souveraineté et la survie des États faibles ». In Hibou B. : La privatisation des États, Paris, Karthala : 133-161.

ScoOnes I., ThOMPSOn J. (dir.), 1999 - La reconnaissance du savoir rural. Paris, Karthala, coll. Économie et développement, 474 p.

Winter G. (coord.), 2000 - Inégalités et politiques publiques en Afrique : pluralité des normes et jeux d'acteurs. Paris, Karthala, 452 p. 


\section{Insécurité alimentaire dans le monde Implications pour les pays européens}

\section{Henri JOSSERAND}

Économiste

Cette contribution présente une vue d'ensemble de l'évolution de la production alimentaire dans le monde et fournit quelques caractéristiques et tendances des crises alimentaires de ces trente dernières années. Elle passe ensuite en revue les tendances actuelles et leurs conséquences pour les politiques européennes. Quelques aspects des travaux de la FAO en ces domaines sont enfin évoqués.

\section{Croissance de la production alimentaire : réelle mais insuffisante et mal répartie}

Par rapport à 1970, la quantité d'aliments produits dans le monde s'est accrue. Leur valeur alimentaire en termes de kilocalories par personne/jour a augmenté de $18 \%$. Cependant, ces gains ont été très inégaux entre diverses régions du monde et à l'intérieur de chaque pays.

L'Afrique subsaharienne, en particulier, demeure le continent qui reste au plus bas niveau alimentaire généralisé.

Malgré les engagements pris par la communauté internationale durant le Sommet mondial de l'alimentation en 1996 pour 
Figure 1.

La croissance de la production alimentaire (kcal/pers./jour)

de 1979 à 2000. Les prévisions pour 2030. (source : FAO)

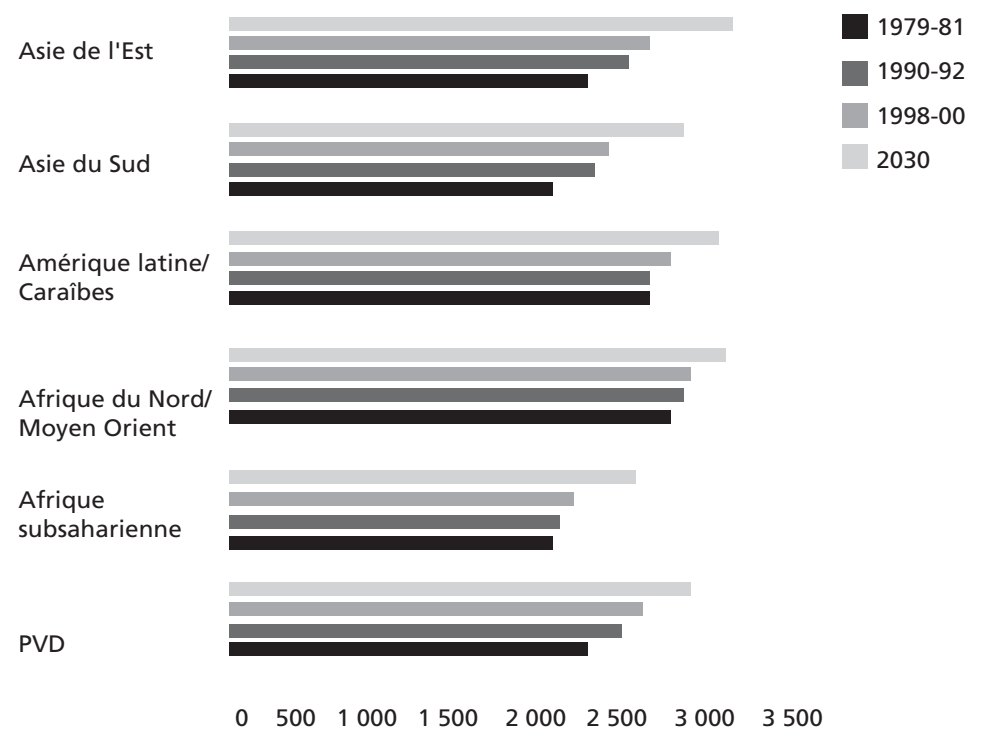

réduire la malnutrition de moitié en 2015, les progrès accomplis cinq ans après demeurent insuffisants. Si pendant cette période on a pu diminuer le nombre des mal nourris de 6 millions par an, il aurait fallu tripler ce nombre pour atteindre l'objectif de 2015.

Globalement, l'aide au développement stagne et prend de plus en plus des allures d'aide d'urgence, surtout en Afrique subsaharienne où l'investissement dans l'agriculture au titre de l'aide et du financement multilatéral a considérablement diminué.

Toutes les régions du monde ont réalisé des progrès depuis les années soixante-dix ; les avancées les plus notoires en termes absolus et relatifs ont eu lieu en Asie du Sud-Est (fig. 1).

\section{Crises alimentaires : variété et complexité des facteurs déterminants}

Les crises alimentaires aiguës attirent l'attention, mais le fait est que la majeure partie de la malnutrition est « silencieuse »; elle 
frappe les couches les plus pauvres des populations de nombreux pays. Les désastres naturels, surtout s'ils ont lieu en Asie, peuvent frapper un grand nombre de personnes, mais les effets se font généralement sentir à court ou moyen terme. Une plus petite proportion de la population du monde est atteinte par des crises à la fois aiguës et prolongées, en majeure partie en Afrique subsaharienne. La cause principale de la malnutrition chronique dans le monde demeure la pauvreté. Les crises alimentaires frappent actuellement presque 40 pays, dont 23 en Afrique subsaharienne. Les crises alimentaires sont de deux natures. Les premières sont dues à des phénomènes naturels, tels que la sécheresse. Ces crises tendent à être de courte durée (bien qu'il existe des pays où elles sont récurrentes). Les autres sont principalement dues à des conflits entretenus par la rente de l'exploitation des ressources extractives et basés sur un état déficient de participation populaire aux mécanismes politiques et de gouvernance. Ces crises sont plus complexes et peuvent perdurer pendant de nombreuses années.

La figure 2 illustre la distribution actuelle des crises alimentaires aiguës et leurs causes principales. La situation est parfois compliquée par le fait que, pour les crises à long terme, les facteurs humains et naturels se conjuguent pour entraîner une prolongation ou récurrence de la crise.

Le Smiar ${ }^{1}$ a récemment fait une étude rétrospective des causes de crises alimentaires dans le monde pour la période 1986-2003. Celles-ci sont nombreuses, mais peuvent être organisées en trois catégories principales :

- causes naturelles (sécheresses, inondations, tremblements de terre, etc.) ;

- crises dues à des causes humaines (guerres civiles, conflits frontaliers ou internationaux, etc.) ;

- effets simultanés ou combinés des deux causes précédentes.

1 Le Smiar (Système mondial d'information et d'alerte rapide) suit régulièrement la situation alimentaire dans le monde et produit cinq publications annuelles concernant les produits alimentaires de base, cinq publications sur la situation alimentaire par pays, pour tous les pays du monde, et trois rapports spéciaux sur I'Afrique. Le Smiar fait aussi, avec le Programme alimentaire mondial, 20 à 25 évaluations de la situation dans les pays en crise et publie des rapports suite à ces missions. 


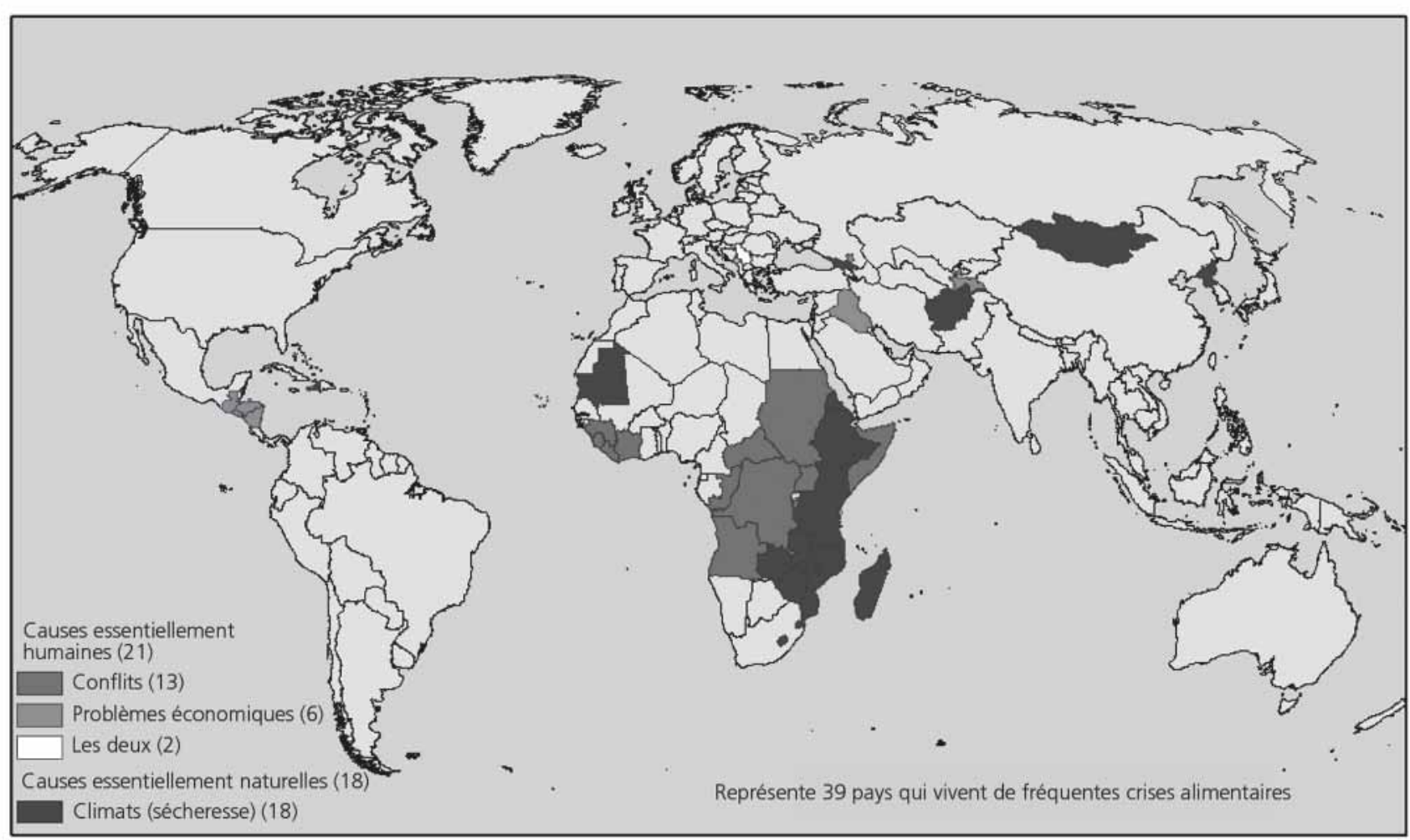

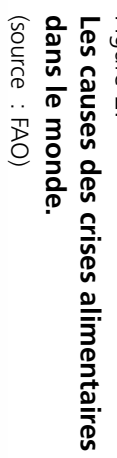


Les données pour la période 1986-2003 suggèrent que l'année 1992 a été une période charnière avant laquelle le nombre de pays en crises naturelles dominait, alors qu'à partir de 1992, les crises causées par l'homme sont devenues dominantes en nombre de pays affectés.

Pour certains pays, des crises de type différent se sont succédé sur une longue période.

C'est le cas par exemple de l'Angola pendant dix-huit ans, de la Mongolie pendant douze ans, de Haiti pendant seize ans et du Tadjikistan pendant douze ans.

\section{Tendances majeures à moyen terme (2010)}

On prévoit que la croissance globale de l'offre et de la demande en produits alimentaires tombera au niveau de 0,3\% par an et par personne. Il est probable que les régions de croissance alimentaire les plus rapides seront en Asie (Chine, Inde en particulier). Dans les pays en voie de développement, la croissance de la demande alimentaire sera de l'ordre de 0,4\% par an et par personne.

On assistera cependant probablement à un ralentissement du commerce mondial des produits de base et à un raffermissement des cours de produits alimentaires, surtout les céréales. La Chine, en particulier, se profile comme gros acheteur futur sur le marché mondial des céréales.

Laugmentation escomptée des prix des denrées alimentaires de base aura probablement des conséquences négatives pour les pays en développement importateurs nets d'aliments ; leur facture d'importations alimentaires sera vraisemblablement à la hausse.

Globalement, les perspectives actuelles pour les pays déficitaires en aliments ne sont pas encourageantes, en raison des contraintes internes et externes qui continuent de peser sur leurs secteurs agricoles et sur les revenus de leur population. Par conséquent, il est peu probable que l'on puisse réduire sensiblement la malnutrition dans le monde à court ou moyen terme. 


\section{Politiques européennes : une complexité croissante...}

Léventail des politiques européennes qui portent directement ou indirectement sur la sécurité alimentaire dans le monde est très vaste, même si l'on ne considère que les politiques mises en œuvre au nom d'une Union européenne en voie d'expansion.

En premier lieu, l'aide au développement appuie la production agricole et l'augmentation des revenus des populations, la sécurité alimentaire étant à la fois affaire de disponibilité et d'accessibilité, c'est-à-dire de pouvoir d'achat. La Commission veille en outre de très près à ce que l'aide alimentaire fournie en cas de crises n'ait pas d'effets négatifs sur les prix et les revenus des producteurs agricoles des pays concernés.

Limpact de la politique agricole commune sur certains pays en développement peut être négatif ; les compensations offertes en échange à travers un certain nombre d'accords spéciaux sont réparties en fonction de la capacité de divers pays à se " positionner » sur certains créneaux clés dont l'avantage fluctue au fil des années. Au niveau des pays européens, de nombreuses politiques peuvent aussi avoir des effets complexes. Par exemple, une politique d'immigration peut-elle prévoir comment l'augmentation de rapatriements monétaires vers un pays d'origine peut être contrecarrée par la disponibilité de main-d'œuvre agricole immigrée en Europe, conduisant à un renchérissement des importations et à une érosion des préférences.

\section{Un rendez-vous à ne pas manquer}

En tant que puissance économique mondiale majeure, l'Europe peut influer grandement, pour le meilleur ou pour le pire, sur les conditions dans lesquelles les pays moins favorisés peuvent réduire la pauvreté et sa conséquence directe, la malnutrition. Lintérêt européen à long terme à promouvoir la croissance et la stabilité économique de par le monde est évident. L'Europe a les moyens analytiques et financiers d'effectuer les investissements nécessaires en exigeant un engagement proportionnel chez ses partenaires. Il reste à s'assurer que les moyens politiques de le faire sont tout aussi bien mis en œuvre. 


\section{Le difficile chemin des politiques de sécurité alimentaire en Afrique}

\section{John IGUÉ}

Géographe

Mes commentaires s'articulent autour de cinq points distincts.

Je voudrais tout d'abord insister sur la complexité des pays du Sud. Ces derniers sont extrêmement variés par leur géographie, leur culture et leur histoire. Cette complexité de situations n'autorise plus des comparaisons faciles et ne permet pas de régler les problèmes de la même manière. De ce point de vue, j'adhère totalement à ce que Courade écrit de la comparaison de l'Asie avec l'Afrique.

Le deuxième point sur lequel je voudrais attirer l'attention est celui des objectifs que l'on assigne dans les pays du Sud aux politiques alimentaire et agricole. En effet, dans les pays asiatiques, les politiques alimentaires et agricoles visent à faire de ces pays, naguère sous-développés, des pays émergents. En Afrique au contraire, les objectifs de la politique alimentaire sont passés par des étapes évolutives qui méritent d'être signalées :

- au début des indépendances, les objectifs assignés à l'agriculture étaient de permettre aux États africains d'amorcer leur processus de développement. On peut donc dire que la mission assignée à l'agriculture est essentiellement celle du développement ;

- à partir de 1981 avec le démarrage des Programmes d'ajustement structurel, les objectifs qui sont assignés à l'agriculture ne sont plus ceux du développement, mais plutôt des objectifs de paiement des dettes. Ce changement d'objectifs me paraît important à 
évoquer pour comprendre pourquoi les efforts consentis à moderniser le secteur agricole africain n'ont pas débouché sur le progrès des sociétés. Cela permet de comprendre les raisons des échecs évoqués par Courade. Après 1981, les principales activités agricoles ont été menées pour permettre aux États de payer les dettes contractées au début des indépendances pour la réalisation des infrastructures et équipements de base : routes, ports, aéroports, équipements scolaires et sanitaires, etc. Ces préoccupations n'ont donc pas permis à l'agriculture d'être orientée vers les politiques de sécurité alimentaire. On a plutôt privilégié la concentration des investissements vers des productions spéculatives dont la vente à l'extérieur amènerait les devises nécessaires pour payer les dettes. Cette orientation a posé beaucoup de problèmes sur lesquels je souhaite que l'on insiste pour comprendre la différence d'option entre l'Asie et l'Afrique. Alors qu'en Asie, Chine et Inde par exemple, on est préoccupé par la logique de faire de l'agriculture la base de l'économie avec des révolutions agricoles assez poussées, en Afrique on est plutôt resté cantonné à la spéculation rentière autour des filières comme le cacao, le café et le coton. En Afrique, on vendait pour payer les dettes et en vendant ainsi, on n'a pas pu réaliser les accumulations nécessaires pour faire de l'agriculture la base du développement et de la sécurité alimentaire.

Troisièmement, au-delà de ces objectifs extrêmement différents de l'Afrique et de l'Asie, les problèmes à résoudre ne sont pas non plus les mêmes. En Afrique, la question de l'équilibre de l'environnement reste au cœur des préoccupations, avec des sécheresses périodiques, notamment dans la zone soudano-sahélienne. Il fallait résoudre les problèmes liés à ces dégradations de l'environnement et maîtriser les dégâts causés par l'avancée du désert qui en résulte. Il fallait également faire face à d'importants problèmes sociaux, notamment une évolution démographique galopante. Dans la zone, le taux de croissance démographique est de l'ordre de 2,8 \% par an, entrainant une forte proportion de jeunes dans la population et une forte urbanisation.

Aujourd'hui, les problèmes de l'Afrique en matière de développement agricole sont de nourrir convenablement ces jeunes, dont la plupart sont des populations à charge, et de faire face à la demande des villes en nourriture. Or, les objectifs assignés à l'agriculture ne sont pas de nourrir la population, mais plutôt de 
payer les dettes. Cette situation crée beaucoup de difficultés dans la manière de gérer les politiques agricoles, d'où l'importance de l'aide au développement pour permettre à cette partie du monde de faire correctement face à ses différents problèmes

Quatrièmement, au moment où il fallait régler tous les problèmes sociaux évoqués ci-dessus, les États africains étaient confrontés à des problèmes d'ajustement avec le désengagement complet de la plupart des secteurs vitaux de l'économie, comme certains auteurs ont eu à le montrer dans leurs communications. Ces désengagements de l'État posent beaucoup de problèmes. Vous êtes tous des spécialistes du monde rural. Le développement du monde rural passe par des contraintes que le secteur privé africain, dans son état actuel, ne peut pas assumer. La première de ces contraintes est le financement du secteur agricole dont l'amortissement reste lent et incertain. En effet, quand on plante, il faut attendre longtemps avant de récolter. Cette récolte est souvent compromise par des aléas climatiques et par la fluctuation des prix internationaux. Mais ce problème de financement n'est pas le plus épineux. Le plus épineux est celui de l'encadrement correct des producteurs, sans lequel il n'y a pas de succès dans l'agriculture. Le secteur privé ne peut pas assurer correctement cet encadrement parce que celui-ci ne se fait qu'à travers un contrat de confiance entre les producteurs à la base et l'État. Ce sont ces évolutions qui expliquent la faiblesse du secteur agricole en Afrique comparé à celui de l'Asie. Ici, les bases du développement agricole sont ébranlées par les réformes imposées par les institutions internationales. LAfrique éprouve de la peine à s'adapter à ces réformes entraînant, en conséquence, des crises parfois profondes dans le secteur rural. Toujours dans ce débat politique, les filières porteuses sont également devenues concurrentielles avec beaucoup d'autres régions du monde. Pour le montrer, on peut citer le cas de la filière cacaoyère avec l'Asie, de la filière palmier à huile avec la Malaisie et la filière coton avec les États-Unis. Tous les problèmes qui ont été évoqués ces jours-ci à Cancún relèvent de cette concurrence des filières. Les conditions dans lesquelles se développe l'agriculture africaine ne sont plus favorables. Tous ceux qui conseillent à l'Afrique de produire pour payer les dettes souhaitent en même temps que ces produits soient bradés sur le marché international. Dans ces conditions, l'Afrique ne peut pas aller plus loin par rapport aux objectifs de développement agricole, dont le 
premier serait d'assurer correctement et convenablement la sécurité alimentaire des populations.

Le dernier point sur lequel je voudrais insister concerne les problèmes actuels de l'Afrique. Parmi ces problèmes, il y a les crises politiques qui résultent de la faillite des institutions. Mais en parlant de ces crises politiques, on évoque très peu cette faillite des institutions. Pourtant, celle-ci fait plus de ravages que les crises politiques elles-mêmes. En effet, les différentes réformes institutionnelles suggérées par les bailleurs de fonds nécessitent une nouvelle refondation de l'État en Afrique et une nouvelle redéfinition des rapports sociaux. En l'absence de cette refondation de l'État et de cette redéfinition des rapports sociaux, la démocratisation, malgré ses aspects positifs, se fait dans la douleur et entraîne par conséquent beaucoup de ravages. Celle-ci a complètement dénaturé les États, les rapports sociaux, etc. L'organisation d'élections périodiques qui paraît comme l'un de ses meilleurs acquis n'est pas toujours adaptée aux sociétés africaines à travers les différents systèmes de régulation des rapports sociaux au niveau traditionnel. On pourrait citer l'exemple du Rwanda et du Burundi pour l'illustrer. Les nouvelles formes de démocratie modifient donc les anciens rapports sociaux à travers les différents privilèges qui en résultent, notamment ceux relatifs aux droits fonciers. La modification des rapports sociaux entraînée par la démocratisation de l'État et de la société provoque des inquiétudes qui débouchent sur des revendications identitaires et sur la tribalisation des pouvoirs politiques en Afrique. Cette tribalisation est devenue un handicap à la politique libérale et à la privatisation des instruments du développement, notamment le droit à la terre. Cette situation est devenue un des facteurs limitants de la politique agricole et de la politique de sécurité alimentaire tout court.

Lautre situation sur laquelle je voudrais attirer l'attention et qui me paraît aussi importante est le phénomène de la mondialisation. Cette mondialisation est imparfaite. Cette imperfection entraîne même pour les pays développés beaucoup de conséquences négatives : inégal développement, inégale répartition des facteurs de production, chômage, etc. Dans un monde aussi imparfait, quelles sont les chances des pays pauvres de pouvoir élaborer des politiques de développement cohérentes et susceptibles de répondre aux différents besoins de leur population ? 
J'ai tenu à évoquer brièvement ces problèmes pour montrer que les perspectives d'avenir des pays africains passent nécessairement par la refondation des États sur des bases nouvelles autres que celles que nous sommes en train de privilégier aujourd'hui. Si on ne le fait pas, aucune politique agricole et alimentaire ne pourra être menée avec succès. C'est une question que je pose ici. Une autre perspective est la nécessité d'améliorer les mécanismes de partenariats entre le Nord et le Sud. Ce partenariat a pris un sérieux coup avec les différentes crises qui affectent l'Afrique, notamment la crise ivoirienne. Cette dernière a porté un coup dur à la sphère francophone en Afrique faute d'un leader politique digne et respectable dans le milieu. En conséquence, tous les pays francophones d'Afrique de l'Ouest, à l'exception du Mali et du Bénin, sont en situation de crise politique latente. La dernière tentative de coup d'État au Burkina Faso atteste bien de notre inquiétude.

Somme toute, les questions du développement agricole et de la sécurité alimentaire durable ne peuvent trouver de solutions heureuses qu'à travers une mondialisation parfaite et la renégociation des rapports Nord-Sud. La mondialisation débouche désormais sur la renégociation de tous les accords commerciaux. Elle exige aussi un discours libéral qui pousse les États à redéfinir leurs relations avec les multinationales, dont certaines sont plus puissantes que les États africains pris individuellement. Ces États africains ont signé avec des pays du Nord des accords de coopération fondés sur des intérêts mutuels. Lintervention des multinationales dans les relations internationales fausse la base de ces accords fondés sur des intérêts mutuels. Les multinationales sont des entreprises égoïstes dont l'intérêt se base uniquement sur le profit, qui se fait le plus souvent aux dépens des pays pauvres. La lutte devient donc âpre entre les intérêts égoïstes des multinationales et la nécessité pour les pays du Sud d'assurer un minimum de bien-être à leurs populations. Cela entraîne par conséquent des tensions assez fortes dans la manière dont sont exploitées les ressources de développement dont disposent ces pays pauvres. Il me paraît alors utile d'avoir une bonne compréhension de ces situations conflictuelles pour montrer les limites des politiques de développement, et singulièrement des politiques de développement agricole menées actuellement par les pays africains. 

Partie 4

Repenser

la mondialisation 



\section{Les agricultures du Sud et les responsabilités européennes}

\section{Michel GRIFFON}

Agronome et économiste

Lactualité de cette fin d'année 2003 met les questions relatives aux rapports entre les agricultures des pays du Sud et celles des pays du Nord au premier plan : c'est en effet au débat agricole Nord-Sud, dit la presse, que l'on devrait l'échec de la réunion de Cancún, et donc l'arrêt du processus de négociation de l'actuel round de l'OMC que l'on a qualifié de " Round du Développement » et qui a commencé à Doha.

Il y a, bien évidemment, des causes économiques au blocage de Cancún. La principale porte sur les subventions agricoles de l'UE et des USA qui sont récusées par un grand nombre de pays, en particulier le nouveau " groupe des 21 » dont le leader est le Brésil, et dont les positions de négociation sont finalement proches de celles des grands pays exportateurs de céréales et de grains que sont les pays du groupe de Cairns. Il y a aussi et surtout l'opposition des USA à réduire les subventions à la production cotonnière qui ont contribué à faire baisser les prix internationaux en 2003 et qui mettent en situation difficile les pays cotonniers d'Afrique de l'Ouest. Mais il y a beaucoup d'autres contradictions potentielles dont on parle peu, en particulier celles qui opposent les pays en développement entre eux dans leurs relations commerciales à propos des pics tarifaires. Cependant, c'est le choc des intérêts du Nord et du Sud qui est apparu comme la cause de l'échec. 
Ce blocage résulte aussi d'oppositions politiques, lesquelles sont bien évidemment très liées aux antagonismes économiques. Ainsi, l'accord entre les USA et l'UE pendant l'été 2003 sur le maintien des subventions agricoles à l'exportation (malgré leur niveau réduit) ne pouvait apparaître que comme une nouvelle version des accords politiques que ces très grandes puissances commerciales avaient l'habitude de conclure lors des rounds de négociation antérieurs, puisqu'elles imposaient par la force des choses aux pays tiers sans que ceux-ci aient eu véritablement un pouvoir de négociation. Pour les pays tiers, cet accord apparaissait donc comme une sorte de provocation les amenant à manifester leur refus de subir une éventuelle hégémonie des deux grands dans le débat. Le refus des USA de réduire leurs subventions à l'exportation du coton est apparu ensuite comme un signal politique supplémentaire de mépris par rapport aux pays les plus pauvres, d'autant que ce refus était assorti de la suggestion maladroite faite à ces pays de s'adresser au FMI si la baisse des exportations devait entraîner chez eux un choc macro-économique. Comment dès lors s'étonner du résultat ?

Cette situation de blocage durera sans doute quelque temps. La Commission européenne sera renouvelée et les USA entrent en période électorale dès la fin 2003. Ce n'est qu'après ces échéances que la négociation pourrait reprendre. Mais celle-ci pourrait être éventuellement plus difficile encore et les échéances être reportées assez loin : la fin de la " clause de paix » pourrait amener le Brésil à élever une plainte contre la PAC et demander un panel d'arbitrage ; les contradictions entre les USA et l'UE sur les OGM restent importantes ; il peut y avoir un risque de montée en puissance des rapports de force et de perte de crédibilité des panels si ceux-ci ne sont que partiellement ou pas respectés. Cette période apparaît donc comme une période d'hésitation entre un retour au bilatéralisme (qui consacrerait l'échec de cette réunion), ou un avènement d'un «régionalisme » (priorité aux préférences régionales) ou encore une confirmation du multilatéralisme (en cas de retour à la table des négociations et conclusion d'un accord). Le retour au bilatéralisme ne gênerait pas les USA qui d'ailleurs, en cette fin 2003, s'engagent dans des discussions bilatérales de manière ostensible, ainsi que dans des réunions de promotion des espaces commerciaux régionaux (grand marché des 
Amériques, accord Asie-Pacifique-Amérique). LUE pourrait faire la même chose avec l'Afrique et l'ensemble moyen-oriental à partir de son expérience passée de coopération avec ces deux régions. Mais tout le monde sait que l'utilisation d'accords multilatéraux reste la voie qui, en théorie, est la plus sûre pour que les pays en développement n'y perdent pas sur le long terme. La condition est, bien entendu, qu'ils fassent entendre leurs voix et défendent leurs intérêts pour obtenir un accord équitable, même s'ils subissent fréquemment des pressions pour accepter les compromis majoritaires. Cependant, une négociation avec de telles inégalités de rapports de force peut-elle aboutir à des situations équitables?

Pour s'interroger sur le rôle que pourrait avoir l'UE dans ce contexte et face à cette situation de non-équité, il faut prendre de la distance avec ces événements. On peut le faire de trois manières : voir la mondialisation alimentaire " de plus haut », dépasser la vision simpliste "Nord contre Sud », se projeter sur le long terme.

\section{Voir de plus haut la mondialisation alimentaire}

La mondialisation économique se fait beaucoup par le commerce, mais elle se fait aussi par d'autres mécanismes :

- les actions de la Banque mondiale et du FMI dans le cadre du consensus de Washington, qui ont abouti à la promotion des politiques d'ajustement structurel dont les résultats sont souvent négatifs en Afrique et dont l'effet d'ouverture des frontières va beaucoup plus loin que ce que les pays avaient négocié dans le cadre des accords antérieurs (Marrakech) ;

- le développement des mouvements de capitaux - investissements, transferts financiers, aide publique au développement - a été notablement réduit depuis plus de dix ans ;

- l'importance des migrations internationales et régionales, en particulier l'immigration définitive vers les pays du Nord qui est freinée, les mouvements des travailleurs qualifiés et des scientifiques du Sud vers le Nord ; 
- le développement des influences culturelles, et particulièrement la diffusion de nouveaux comportements alimentaires issus des pays les plus riches, dans les zones urbanisées du monde entier ; - le développement de flux d'information transfrontière au sein des sociétés civiles et particulièrement dans les réseaux d'ONG qui peuvent aider les élites des pays du Sud à mieux comprendre les enjeux des débats et à se positionner ;

- et surtout, l'apparition de grands problèmes environnementaux mondiaux : le changement climatique, la désertification, l'érosion de la biodiversité, la déforestation, l'émergence de maladies nouvelles s'étendant potentiellement à l'échelle mondiale, autant de menaces globales qui sont aussi des menaces particulières pour beaucoup de pays en développement.

Il est difficile de faire la prospective des effets de tous ces flux et de tous ces effets dans le domaine particulier de l'alimentation, de l'agriculture et de l'environnement qui nous occupe ici. On peut cependant en redouter les risques.

Que peut faire l'Europe dans ce domaine ? LEurope n'est pas un des lieux principaux d'influence dans cette évolution, bien qu'elle y participe. Elle ne pèse pas du poids positif que pourraient lui conférer son économie et sa capacité d'influence sur le cours des événements. Et pourtant, sa continuité territoriale avec l'Afrique et le Moyen-Orient la désigne comme étant fortement concernée par les risques potentiels d'une mondialisation mal maîtrisée, et comme devant dès lors anticiper les évolutions à venir afin d'en garantir la viabilité et l'acceptabilité.

\section{Sortir d'une vision opposant le Nord et le Sud $d$ 'une manière caricaturale}

Il y a de nombreux Sud, très différenciés. Le Brésil par exemple est un ensemble composite fait d'une agriculture de pauvres et de très petites exploitations à une extrémité de l'échelle sociale et d'une agriculture de grandes exploitations conquérante des marchés mondiaux à l'autre extrémité. C'est ce deuxième Brésil riche en terres, consommateur de forêt amazonienne et utilisant une 
main-d'œuvre extrêmement mal payée qui parle dans les conférences à l'OMC. La Chine, au contraire, a une agriculture pauvre dont une partie importante des paysans quitte les campagnes alors que le pays entre en période d'ouverture commerciale, qu'en même temps le mode de consommation de ses populations évolue très rapidement vers une importante demande en viande et que l'on s'inquiète pour l'avenir des capacités productives, par exemple du fait de la raréfaction de l'eau pour l'irrigation. Quel rôle jouera-t-elle dès lors dans les échanges agricoles mondiaux ? Sera-t-elle le très grand importateur que les agricultures nordaméricaine et européenne attendent ? L'Inde, autre poids lourd démographique et agricole, pourrait rapidement atteindre ses limites productives alors que sa population augmente encore et qu'elle est encore loin de se nourrir suffisamment. Comment s'insérera-t-elle dans les échanges agricoles internationaux elle aussi ? LAfrique du Nord et le Moyen-Orient devront accroître encore leurs importations, faute de pouvoir accroître leur production ; pourront-ils sans difficulté équilibrer leurs balances des paiements ? L'Afrique subsaharienne reste en situation tendue quant à sa sécurité alimentaire mais aucun signe ne semble indiquer qu'il y aura une inflexion positive dans le rythme de production. Les Sud, on le voit clairement, ont donc des situations très différentes, des intérêts divergents et des avenirs potentiels distincts. Raisonner l'avenir de la mondialisation implique d'analyser finement cette diversité.

Quant au Nord, lui aussi est divers et les intérêts des ensembles sont contradictoires. L'Europe élargie va devoir associer des agricultures très différentes en terme de productivité, réduire ses subventions aux exportations et s'adapter à une politique agricole finançant les activités de bien public des producteurs au titre de l'environnement. Les USA connaissent une évolution vers un accroissement rapide de la productivité des grandes fermes exportatrices et entendent rester les principaux exportateurs mondiaux. Le Canada, l'Argentine et l'Australie, pays ayant de très grandes structures d'exploitation et des niveaux élevés de compétitivité en raison de leur forte extensivité, sont en conflit contre les autres exportateurs que sont l'UE et les USA.

Au total, autant qu'une opposition Nord-Sud, sans pour autant en minorer l'importance politique, il y a aussi et surtout une colli- 
sion complexe des intérêts des espaces nationaux et régionaux entre pays du Sud, entre pays du Nord et quelquefois des contradictions fortes au sein d'un même pays. Le grand jeu des collisions et des alliances est donc loin d'être terminé. L'Europe ne donne pas l'impression de disposer encore d'une stratégie claire pour affronter cette complexité.

\section{Se projeter sur le long terme}

Nous connaissons tous le grand défi de l'agriculture mondiale à long terme. Rappelons-le rapidement : nourrir 9 milliards d'habitants en 2050 alors qu'aujourd'hui encore, plus de 800 millions de personnes dont les trois quarts sont dans l'agriculture ne mangent pas suffisamment ! Ce défi donne lieu à une littérature sans cesse renouvelée où s'opposent les tempéraments malthusiens (il n'y aura pas de place pour tous au « banquet de l'humanité ») et les tempéraments qui font confiance au génie humain pour trouver des réponses technologiques et économiques. Dans la littérature économique, on distingue à nouveau deux grandes voies : la voie de ceux qui font confiance aux mécanismes de marché au plan international pour que s'ajustent au fur et à mesure du temps l'offre et la demande alimentaire et la voie de ceux qui, par précaution, pensent indispensable de recourir à des politiques agricoles car on ne saurait laisser à des marchés au fonctionnement très imparfait le soin de répondre à une question aussi socialement et politiquement lourde que celle de la sécurité alimentaire des pays, des régions et de la planète. Je crois que ce sont les seconds qui ont raison. Le passé leur donne raison et l'avenir s'annonce plus délicat à gérer que le passé. Sans tomber dans un catastrophisme au demeurant assez peu utile, il y a suffisamment de travaux de prospective qui permettent aujourd'hui de s'inquiéter de la situation des agricultures qui devront accroître fortement leur production et qui manquent de surface, d'eau, de capital, ou qui risquent d'avoir à faire face à de graves problèmes environnementaux, climatiques ou même politiques. Face à ces risques, l'Europe, malgré ses efforts passés, n'a pas non plus encore de politique assez cohérente. Il est vrai qu'il ne s'agit pas d'une politique simple. Il lui faut en effet concilier des aspects quelquefois 
contradictoires, comme la résolution des problèmes communautaires, la réponse à la demande des pays qui lui demandent de revenir à une optique de fair trade en éliminant toute subvention couplée d'une manière ou d'une autre avec le niveau de la production, négocier pour que ses concurrents internationaux ne fassent pas du dumping écologique (par exemple "surpomper " les nappes phréatiques, détruire les forêts), rester flexible pour pouvoir faire face à d'éventuels besoins accrus de céréales en cas de réduction des stocks mondiaux, aller dans le sens d'un commerce plus équitable vis-à-vis des paysanneries qui exportent vers les consommateurs européens des produits tropicaux, savoir faire une place aux fruits et légumes du sud de la Méditerranée avant 2010, date à laquelle deviendront effectifs des accords de libreéchange, etc.

Certes, la résolution de ces contradictions est une tâche difficile. Mais l'Europe est bien placée pour jouer un rôle actif de proposition. Depuis de nombreuses années elle a proposé et mis en œuvre des politiques internes pour l'agriculture et l'environnement qui peuvent inspirer d'autres régions du monde. Elle a su définir des mécanismes originaux de solidarité avec les pays en développement. Elle a des expériences à faire valoir en matière de promotion de la qualité. Ses producteurs agricoles représentent une force organisée qui peut constituer un modèle utile dans le monde pour rétablir un pouvoir de marché qui soit en leur faveur. Elle doit cesser enfin d'accepter d'être le bouc émissaire de l'insatisfaction des grandes agricultures qui dans le monde lui reprochent ses subventions aux exportations afin que, une fois ce problème réglé, elle fasse valoir son point de vue pour promouvoir au plan international des agricultures écologiquement viables, économiquement vivables et socialement acceptables. 



\section{Pour une sécurité alimentaire durable des pays les plus pauvres Quelques enjeux}

\section{Gérard AZOULAY}

Économiste

Le nombre de personnes qui continuent de souffrir de sousalimentation a décru ces dix dernières années, mais à un rythme très inférieur aux objectifs fixés par les Sommets mondiaux de l'alimentation (1996 et 2002). Le nombre de personnes sousalimentées est estimé à 842 millions en 1999-2001 (10 millions vivent dans les pays industrialisés, 34 dans les pays en transition et 798 dans les pays en développement). Dans les PVD, la réduction touche à peine 2,1 millions de personnes par an, diminution très inférieure à celle qui serait nécessaire (22 millions par an) pour atteindre l'objectif fixé par les sommets mondiaux : la réduction de moitié en 2015 du nombre de personnes sousalimentées. Le taux de décroissance constaté est 10 fois inférieur à celui qui avait été souhaité. Mais les observations les plus récentes (FAO, 2003) font apparaître non plus une réduction annuelle, mais une croissance du nombre de sous-alimentés dans les cinq dernières années, en particulier dans les régions d'Afrique subsaharienne qui enregistrent la plus forte proportion de malnutrition chronique (34\%), d'Afrique du Nord et du Moyen-Orient. Les progrès sont importants en Chine, alors qu'en Inde, la tendance à la baisse s'est inversée. 
Ces évolutions récentes traduisent la persistance d'une problématique caractérisée par la disponibilité de nourriture à l'échelle de la planète (en fait, souvent au niveau des pays et des régions) mais aussi par une incapacité de tous les individus de produire ou d'accéder aux denrées. La question ancienne, mais tant négligée, de la répartition des richesses est centrale, car l'accroissement des inégalités de répartition des ressources disponibles à l'échelle de la planète est aujourd'hui tel que $15 \%$ de la population mondiale bénéficie de plus de $85 \%$ du revenu mondial. Lécart de revenu nominal par habitant a atteint le niveau record de 1 à 400 . À l'intérieur même de chaque pays, les inégalités croissantes de répartition du revenu national constituent l'un des facteurs essentiels de la persistance du problème de la faim.

Une forme d'organisation de l'économie agricole mondiale semble aujourd'hui largement rejetée : celle dans laquelle un petit nombre de pays gros producteurs et exportateurs d'Europe et d'Amérique du Nord satisfont de façon croissante les besoins des nombreux pays déficitaires. Dans ce schéma, ces derniers doivent recourir de plus en plus au marché mondial pour leurs approvisionnements alimentaires sous forme d'importations commerciales ou bien encore d'aides, en cas de difficultés de financement des importations. La Sécurité alimentaire mondiale (SAM) repose, dans ce cas, exclusivement sur le commerce international supposé accroître la consommation, être le moyen le plus économique de pallier l'instabilité de la production et éviter la constitution de stocks de sécurité coûteux.

Le scénario le plus souhaitable ne repose pas sur la capacité de quelques grands exportateurs à couvrir les besoins planétaires. La sécurité alimentaire de tous les habitants de la planète s'accommode mal de la constitution d'un marché mondial unique et homogène, « valeur totémique » du paradigme néoclassique et objectif explicite de l'Organisation mondiale du commerce. Elle repose sur le renforcement des capacités de production et d'accès en biens alimentaires de tous les individus, en particulier dans les "Pays à faible revenu et à déficit vivrier » (PFRDV). La plupart de ces pays - ils sont plus de 80 - ont la capacité physique et économique de pourvoir à leurs besoins. Ce schéma suppose la volonté politique d'élaboration et de mise en œuvre de véritables stratégies globales de sécurité alimentaire, alliant rôle du marché 
et de l'État, dans lesquelles la croissance de la production devient prioritaire par rapport aux échanges extérieurs. Mais cette évolution se heurte à de multiples contraintes liées à la globalisation et à ses disciplines commerciales, aux politiques économiques nationales, au rôle de la recherche, aux disponibilités en terre et en eau, à la réduction de la biodiversité, à l'évolution démographique et aux conflits locaux.

Comment les pays à faible revenu et à déficit vivrier peuvent-ils significativement accroître leurs productions domestiques et permettre l'accès de tous les individus aux disponibilités alimentaires ? Lobjet de cette intervention est de discuter trois points essentiels de l'environnement international qui constituent autant de débats cruciaux du point de vue de la capacité des pays du Sud les plus pauvres (PMA, pays africains...) à assurer leur sécurité alimentaire.

\section{Les limites de l'intégration des PFRDV dans le marché mondial}

L'existence d'un équilibre alimentaire planétaire offre-demande et le maintien d'un fort pourcentage d'individus qui ne satisfont pas de manière adéquate leurs besoins nutritionnels sont les conséquences, on le sait, des évolutions contradictoires de l'agriculture mondiale. Dans les pays industrialisés, des gains élevés de productivité et de fortes politiques de soutien public ont engendré des excédents de production importants. Les USA, l'UE ont écoulé leurs excédents sur le marché mondial par des politiques agressives de subventions aux exportations. Lune des conséquences majeures de ces politiques a été que le cours mondial n'a plus joué le rôle d'indicateur d'efficacité et de signal efficient dans le processus d'allocation des ressources, alors que les PVD ont été invités par le Gatt puis l'OMC, mais surtout dans le cadre des politiques d'ajustement, à fonder leurs choix productifs sur les signaux du marché mondial.

Les subventions aux exportations pratiquées par les pays du Nord ont un effet déstabilisant. Le déclin des prix mondiaux fait crô̂tre les subventions qui, à leur tour, relancent le processus. Ces 
prix ont un impact décisif sur la capacité des pays du Sud à dégager des revenus sur le marché mondial. Dans un récent rapport, l'Ifpri estime que les subventions aux agriculteurs du Nord ont eu pour conséquence une perte annuelle de 24 milliards de dollars aux exportations des pays du Sud. On sait, par ailleurs, l'impact négatif sur la production locale dans le Sud de la concurrence des produits subventionnés du Nord. Le sort négatif réservé récemment à Cancún à la demande de quatre pays africains (Bénin, Mali, Burkina et Tchad) producteurs de coton traduit bien le refus d'une régulation véritable de l'économie agricole mondiale. Rappelons que 25000 producteurs de coton des États-Unis ont perçu 3,9 milliards de dollars de subventions en 2001-2002, soit trois fois plus que le budget de l'Usaid (US Agency for International Development) destiné à 500 millions d'Africains. La demande des quatre pays portait sur l'arrêt des subventions, responsables de très importantes pertes de revenus pour plus de 10 millions de producteurs africains et, dans l'immédiat, sur le versement de compensations financières.

Les pays les moins avancés (PMA), les pays importateurs nets de produits alimentaires, les moins compétitifs, peuvent-ils s'insérer durablement dans le marché mondial et tirer profit du nouveau cadre du commerce des produits agricoles ? En modifiant les courants d'échanges, les termes de l'échange et les prix, ces réformes commerciales ont une incidence sur le revenu national et sa répartition, et donc un impact direct sur la capacité d'accès à la nourriture, la disponibilité des produits de base, les approvisionnements et leur stabilité.

Le processus de globalisation met en concurrence directe des systèmes agraires aux productivités sans commune mesure. La grande majorité des agriculteurs de la planète (plus de 2 milliards d'individus) relèvent de systèmes agraires qui n'ont aucun point commun avec le système le plus performant qui, lui, ne concerne qu'environ 20 millions d'agriculteurs des pays de l'OCDE.

Les niveaux de productivité atteints au Nord reposent sur l'incorporation systématique des résultats de la recherche dans la production et la mise en ouvre de politiques publiques de soutien interne de grande ampleur. Le montant des « équivalents subventions à la production» (MSG) calculé par l'OCDE en 2002 pour 
ses 20 millions d'agriculteurs représente 350 milliards de \$/an, soit près de 6 fois le montant de l'aide publique au développement (57 milliards de dollars par an), que ces mêmes pays de l'OCDE accordaient à 2,5 milliards de personnes ou encore près de 10 fois le montant de l'aide publique à l'agriculture (4 milliards de dollars par an, dont $21 \%$ à l'agriculture africaine).

Le type d'agriculture performante et intensive du Nord n'a pénétré que quelques zones limitées du Sud. L'essentiel de la paysannerie au Sud (plus de $80 \%$ en Afrique, plus de $50 \%$ en Amérique du Sud et en Asie) continue de n'utiliser que des outils manuels et la traction animale n'est utilisée que par $30 \%$ d'entre eux. Ainsi le rapport de productivité du travail entre ces deux groupes atteint en moyenne 1 à 500. Ces énormes disparités de productivité du travail n'empêchent pas la mise en confrontation directe des deux types d'agriculture. Les conséquences de cette confrontation sont préjudiciables à l'accès des populations aux denrées alimentaires dans les très nombreux pays qui ne peuvent participer à cette course à la compétitivité.

Considérons le niveau d'intégration des PMA et l'accès aux marchés du Nord. La situation des 49 PMA ne s'est guère améliorée dans la période la plus récente (2000-2002). Une étude de l'OMC montre que la participation des PMA dans le commerce mondial reste très faible ou marginale sur des marchés peu nombreux et sans diversification (38 des 49 PMA ont un indice de concentration supérieur à $50 \%$, ce qui veut dire que pour ces 38 pays, 3 produits représentent plus de $50 \%$ de leurs exportations globales et 15 de ces pays voient leurs produits agricoles représenter plus de $50 \%$ de leurs exportations totales). Sur plusieurs dizaines de milliers de produits classés dans le système harmonisé, seuls 8 d'entre eux voient la part des exportations des PMA être supérieure à $50 \%$ des exportations totales.

Entre 1996 et 2002, les importations en franchise de droits par les pays développés de produits exportés par les PMA se sont accrues. Selon les données purement tarifaires, $75 \%$ des produits des PMA sont admis en franchise de droits (la prise en compte du pétrole, principal produit d'exportation des PMA, réduit ce pourcentage à $69 \%$ ). Cependant, si une part importante des produits exportés par les PMA entre en franchise de droits sur les marchés du Nord, la progressivité des droits reste importante. Par ailleurs, 
des mesures non tarifaires viennent réduire l'impact de cet accès sans droits aux marchés des pays développés.

De la même façon, la plupart des produits agricoles provenant des pays ACP (Afrique, Caraïbes, Pacifique) entrent sans droits sur le marché européen. Cela est davantage encore le cas des PMA qui bénéficient de l'initiative européenne " tout sauf les armes » depuis 2001. Mais le système de préférences mis en place dans le cadre des accords de Lomé et ensuite de Cotonou ne parvient pas à permettre la croissance de la part des exportations des pays ACP vers l'UE. Cette part est passée de $8 \%$ en 1975 à 2,8\% en 2000. Elle ne permet pas non plus la diversification. Cependant, là aussi, les normes sanitaires et techniques, la progressivité des droits, la cohérence de la politique européenne constituent des facteurs très contraignants.

Ces diverses mesures commerciales ne parviennent pas à renforcer l'intégration de ces pays au marché mondial. Or, on sait que dans la logique de l'intégration la plus poussée au marché mondial, du point de vue de la sécurité alimentaire, les revenus tirés de l'exportation importent et sont seuls susceptibles de permettre le financement de disponibilités alimentaires importées. Les pays à déficits sont supposés par leurs avantages comparatifs dégager des ressources susceptibles de permettre les importations alimentaires et ainsi d'assurer la disponibilité et l'accès des individus aux biens. Cela implique une spécialisation dans des cultures de rente dont les cours soient stables et/ou dans des productions industrielles dont la composante en travail soit élevée. Ces dernières activités se situent souvent au-delà des spécialisations traditionnelles. Ainsi, la sécurité alimentaire au niveau national peut être assurée pour un PVD en forte croissance et ayant réussi sa diversification. Mais elle n'est nullement acquise pour le vaste ensemble de pays qui ne parviennent pas à engager ce processus de diversification.

Les PFRDV doivent pouvoir disposer des instruments de politique économique nécessaires à la poursuite d'une stratégie autonome de renforcement de leur production, en particulier au moyen d'une politique de protection et, quand cela leur est possible, par le soutien à la production. La plupart de ces pays n'ont pas disposé des moyens financiers nécessaires au soutien de leur agriculture. Leurs dépenses restent insignifiantes et ils n'ont pas 
été concernés par des engagements de réduction à l'OMC. Pourtant, un soutien dans les domaines du crédit, des transports, de l'irrigation et de l'énergie constitue un élément important d'une stratégie de développement agricole et les PVD doivent pouvoir prendre ces mesures de soutien s'ils en ont les moyens politiques et budgétaires, sans être entravés par les règles commerciales multilatérales. Toutes les mesures relatives au renforcement de la sécurité alimentaire doivent être incluses dans la boîte «verte » ou dans une boîte « développement » incluse dans le « traitement spécial et différencié », traitement qui doit devenir une réalité concrète et ne plus être entravé par les contraintes de l'ajustement structurel.

\section{Les conséquences au Sud de l'extension des droits de propriété intellectuelle sur le vivant}

L'une des contraintes majeures d'une nouvelle révolution verte incluant les préoccupations d'équité et d'environnement réside dans l'accès aux technologies agricoles dans les pays pauvres. Cet accès n'est pas assuré. Le changement technique s'inscrit aujourd'hui dans un système économique libéralisé et globalisé. La compétitivité et le marché règlent les comportements des acteurs étatiques et privés. La protection par brevet devient le moyen de contrôle de l'information et de la compétition industrielle. Un processus de privatisation de la science, des produits mais aussi du savoir lui-même se développe. Dans le domaine des biotechnologies, des réseaux structurent à la fois des pôles de recherche et des entreprises multinationales, les interventions des États industrialisés consistant à soutenir leurs systèmes nationaux d'innovation.

Les pays à déficit vivrier, dont les systèmes publics de recherche, d'encadrement, de formation, de vulgarisation sont d'une grande faiblesse ou quelquefois démantelés, disposent de moins en moins de moyens d'intervention sur leur propre devenir économique et social. Ils risquent de subir « un véritable apartheid scientifique », selon l'expression du président du Groupe consul- 
tatif pour la recherche agricole internationale. Seuls de rares pays (Brésil, Inde...) peuvent disposer d'un système de recherche autonome. La recherche publique peut-elle réduire l'énorme fossé entre les pays industrialisés et les pays du Sud ?

Le renforcement des capacités de production dans les pays du Sud repose sur une meilleure connaissance des systèmes de production, des combinaisons entre systèmes écologiques, pratiques culturales et structures sociales. La recherche publique doit être mise au service des systèmes de production des groupes sociaux les plus pauvres. Elle doit se donner pour objet principal de développer la production dans les zones à faible potentiel où se concentre la pauvreté rurale en ne négligeant pas l'intensification dans les zones à haut potentiel, dans le respect de l'environnement et des ressources naturelles. Lampleur des efforts de recherche et la façon dont ils se répartissent entre cultures et entre régions déterminent le niveau et la répartition des gains de productivité.

Par ailleurs, la généralisation du brevet comme mode d'appropriation privative des ressources génétiques peut avoir des conséquences néfastes sur la sécurité alimentaire des plus pauvres par la réduction de la libre circulation de l'information et de l'accès au savoir.

La convention sur les ressources phytogénétiques de 1983 avait invoqué l'idée de patrimoine commun de l'humanité mais n'avait pas réussi à imposer l'idée de libre accès garanti à des variétés protégées par des certificats d'obtention végétale. La philosophie de ce dispositif basé sur la nécessaire circulation des ressources afin de satisfaire les besoins alimentaires de la planète s'est progressivement heurtée au processus de libéralisation. Dès le milieu des années quatre-vingt, les premiers brevets sur le vivant sont obtenus. Ce qui est protégé n'est plus seulement la variété nouvelle produite et le procédé ayant permis de l'obtenir, mais toute l'information génétique contenue et les applications qu'elle peut permettre.

La convention sur la diversité biologique, en 1992, a inscrit la biodiversité dans le champ du commerce. Elle affirmait la souveraineté des États sur leurs ressources génétiques et liait l'accès aux ressources à la condition que le pays d'origine soit associé équitablement à leurs utilisations. Les pays étaient ainsi conviés à définir des droits de propriété intellectuelle sur ces ressources. Lintégration 
des droits de propriété intellectuelle dans le champ des disciplines du Gatt a été consacrée par l'Organisation mondiale du commerce. Laccord de 1995 sur les « Aspects des droits de propriété intellectuelle liés au commerce » (Adpic) stipule dans son article 27 que les produits des biotechnologies peuvent faire l'objet de brevets. Les technologies qui relèvent du vivant ne peuvent plus être exclues du droit des brevets. Les droits sur les variétés végétales et animales doivent donc être protégés par des brevets ou par des législations sui generis efficaces. Cette protection a donc un impact sur les domaines essentiels que sont les droits des paysans, la défense des savoirs locaux et des innovations et pratiques des communautés locales (article 8J de la convention de 1992), le droit sur les ressources génétiques naturelles, la biosécurité, la qualité et l'innocuité des produits alimentaires.

Le droit de la propriété intellectuelle s'oppose donc au libre transfert des technologies et même, dans leur principe, à la mise en œuvre de recherches autonomes sur la base d'un libre accès aux ressources génétiques, base commune de connaissances de l'humanité. La capacité d'innovation et de production de nouveaux matériaux est, par définition, limitée dans les PFRDV. La plupart de ces pays n'ont pas la capacité de recenser la totalité de leurs ressources et n'ont pas de législation adaptée. Le risque est grand de voir apparaître, aujourd'hui, un phénomène nouveau de dépendance, de voir les paysanneries du Sud confrontées à un processus de privatisation de leurs ressources, de généralisation des brevets et d'impossibilité d'utiliser des ressources auparavant collectives.

On peut donc aisément imaginer que la partie du monde la plus défavorisée se trouve totalement amputée de capacités propres de recherche ainsi que de ses pratiques et savoirs traditionnels. Un risque supplémentaire est la destruction de l'un des aspects de la sécurité alimentaire qu'est la conservation de la biodiversité, résultat naturel des pratiques culturales des paysanneries locales, le matériel végétal servant à la fois à la production et à la conservation des gènes. La gestion traditionnelle du risque conduit des paysanneries locales à combiner différentes variétés en fonction de besoins divers dans le cadre d'une polyculture. Le maintien de ces pratiques est une condition de la réduction de l'insécurité alimentaire. La sécurité alimentaire de chaque société s'oppose à la généralisation du droit de propriété intellectuelle sur le vivant. 


\section{La sécurité alimentaire, le rôle des États et la remise en cause du consensus de Washington}

La croissance de la production et le développement agricole dans les PFRDV passent par la mise en œuvre de véritables stratégies globales de sécurité alimentaire. Leurs moyens sont constitués par des mesures de politique économique (commerce extérieur, prix, production, commercialisation et consommation), des programmes et des projets. Les politiques de régulation des échanges extérieurs et de prix jouent, au sein de ces stratégies, un rôle décisif, car elles traduisent le type du développement poursuivi. Tous les pays doivent pouvoir se protéger, réguler leurs échanges, comme l'a fait l'Europe avec sa Politique agricole commune, afin de préserver son agriculture, son mode d'organisation sociale, sa culture.

Lintégration régionale est un moyen essentiel d'accroître la sécurité alimentaire en Afrique. Elle est depuis longtemps l'objet de nombreux débats mais d'une mise en œuvre limitée. Dans une zone d'intégration, la protection aux frontières est assurée par un tarif extérieur commun. Ce tarif est établi à un niveau tel qu'il assure la compétitivité des céréales locales en limitant la concurrence des importations et stimule la production régionale de produits de base en permettant la croissance de la productivité. Des mesures internes de libéralisation et de dynamisation du secteur privé assurent la stabilisation des marchés intérieurs. Mais l'intégration suppose un certain nombre de conditions économiques. Les investissements d'infrastructures nécessitent un apport important de ressources d'origine publique et privée. Les dépenses publiques doivent assurer la protection aux frontières régionales et la mise en ouvre de politiques de consommation destinées aux couches les plus défavorisées touchées par un niveau des prix à la consommation plus élevé. La libre circulation des produits à l'intérieur de la zone protégée suppose une harmonisation et une coordination régionale, ou bien des politiques économiques communes. Dans ce cadre de coopération agricole, la spécialisation des agricultures régionales sur la base des capacités maximales de charge et des coûts les plus bas par unité produite conduit à une 
répartition nouvelle efficiente des cultures à l'échelle de la zone d'intégration. La mise en œuvre effective de ce schéma reste encore très hypothétique par manque d'une volonté politique affirmée, notamment en Afrique.

Le désengagement des États n'est pas un facteur favorable au processus d'intégration. Le marché à lui seul ne peut permettre d'atteindre la sécurité alimentaire. Il est nécessaire pour les États des PFRDV, en particulier en Afrique, de retrouver leurs grandes fonctions de régulation de l'activité économique, à l'inverse du processus constaté ces vingt dernières années.

Dans les premières approches théoriques sur le développement, la capacité de l'État à corriger les échecs et les imperfections du marché et à orienter les économies vers les objectifs de développement était largement reconnue. Avec le «consensus de Washington ", l'accent est mis sur les échecs de l'intervention de l'État dans la régulation de l'économie. Celui-ci ne trouve plus de place dans l'espace de l'analyse économique et devient étranger à un monde entièrement conçu autour de l'idée d'échanges privés. Les accords privés se substituent à un arbitre extérieur comme mode de régulation du système. De là découle un principe dominant du consensus et donc de l'ajustement : le moins d'État. L'État étant créateur de distorsions, de conflits artificiels dans la sphère des relations marchandes généralisées.

Cependant, l'existence d'un marché régulé ou " gouverné » par l'État n'est plus à démontrer en Asie, et sa nécessité pour les pays les plus pauvres est de plus en plus reconnue.

Les griefs faits à l'État en Afrique sont connus. De l'ambition d'être l'acteur essentiel d'une croissance accélérée, l'État se serait transformé en "État baudruche » à l'origine d'inefficacité et de gaspillage des ressources. Les politiques publiques, en particulier d'industrialisation (par substitution aux importations), n'ont débouché que sur l'absence d'efficacité et de compétitivité. Les ressources provenant de l'agriculture n'ont pas été utilisées pour accroître sa productivité, mais ont été transférées vers la consommation urbaine ou l'investissement industriel.

Ainsi, l'État s'est progressivement transformé d'acteur essentiel et légitime d'une croissance accélérée en prédateur, source d'inefficacité, de corruption et de " mauvaise gouvernance ». Les ana- 
lyses socio-anthropologiques fondent l'État africain moderne sur les pratiques traditionnelles du pouvoir. Ces pratiques traditionnelles du pouvoir (à structure patrimoniale) ont été institutionnalisées après les indépendances et ont abouti à des formes combinées de gestion moderne et traditionnelle. Ces formes incluent des structures juridiques et institutionnelles formelles et le maintien de systèmes d'obligations, de prébendes, de clientélisme qui supposent la captation par des « entrepreneurs politiques » des ressources publiques et leur redistribution selon des réseaux complexes de relations non propices à l'épargne et l'investissement productif.

Dans une période " post ajustement ", le rôle de l'État et le transfert des ressources extérieures constituent deux clés essentielles du développement des plus pauvres et de leur sécurité alimentaire. Un État " fort », selon l'expression introduite par Myrdall, est en mesure de mettre en ouvre des stratégies et politiques autonomes fondées sur une vision à long terme des intérêts globaux du pays en y intégrant les stratégies des acteurs privés. État « fort » et État autoritaire ne sont naturellement pas synonymes. À l'inverse, un État « mou » ne fait que subordonner les politiques qu'il met en œuvre à des intérêts particuliers. Lémergence d'États forts en Asie est considérée aujourd'hui comme ayant constitué une cause essentielle de son développement. L'Afrique continue d'être constituée d'États particulièrement faibles dans leurs capacités d'élaboration d'une vision stratégique à long terme et dans la conception et la mise en œuvre de politiques et stratégies autonomes. Le constat révèle qu'en général, les pays africains à faible revenu continuent de ne pas disposer des institutions et des procédures qui assurent de manière stable et durable l'orientation à long terme du système économique et social dans son ensemble, c'est-à-dire de la coordination des instruments de gestion de court terme avec la nécessaire accumulation du capital matériel et humain à moyen et long terme.

La lutte contre la pauvreté est à l'évidence indissociable de la sécurité alimentaire des ménages. Cette lutte passe par la régulation du partage du revenu national et la réduction des inégalités sociales, et seul un renouvellement profond du rôle de l'État peut l'autoriser. 


\section{Conclusion}

Le renforcement des capacités de production de biens alimentaires et d'accès des individus aux denrées alimentaires dans les zones les plus défavorisées de la planète est une condition nécessaire de la sécurité alimentaire mondiale. La mise en ouvre de véritables stratégies, mobilisant les différents acteurs, recourant à des formes de protection, est indispensable. La capacité de disposer d'une recherche publique autonome, le retour des États dans des fonctions réelles de régulation, une intégration régionale poussée, le développement de la participation des individus à la vie publique constituent quelques-uns des éléments internes nécessaires à cette évolution.

Dans les dernières négociations multilatérales, les PVD ont fait preuve de nouvelles capacités d'organisation et de proposition. La réforme des structures de l'Organisation mondiale du commerce, la prise en compte des intérêts de l'ensemble des pays en voie de développement, et en particulier de ceux des PFRDV, dans les négociations pourraient aboutir à un système multilatéral bénéfique pour tous. Le renforcement de capacités autonomes de ces pays accompagné d'un soutien actif des organisations internationales dans le financement de programmes d'investissements cohérents restent les conditions indispensables à la sécurité alimentaire dans les pays à déficit et par delà à la sécurité alimentaire mondiale. 


\section{Allocutions de clôture}

\section{Jean-François GIRARD}

Président de I'IRD

Paris, 15 octobre 2003

Outre le mérite d'associer trois organismes de recherche, ce colloque s'est emparé d'un problème global complexe, l'alimentation dans le monde, qui touche par définition les hémisphères nord et sud, et dont le traitement relève de la pluridisciplinarité.

Le problème est en effet complexe dans la mesure où les paramètres déterminants sont étroitement imbriqués, qu'ils soient environnementaux, économiques, sociaux ou politiques... Il présente ainsi de fortes similitudes avec les problèmes de santé publique au point qu'il faut se demander si le problème de l'alimentation approchée de façon Nord-Sud, globale n'est pas un problème de santé publique ? Cette dimension "santé » est devenue essentielle, et notamment dans le contexte Nord-Sud, où l'accès à l'aliment est un droit, l'aliment un bien public. C'est aussi un déterminant de santé, aussi bien sur le plan quantitatif, la faim, que sur le plan qualitatif, alors que l'aliment est un déterminant culturel, au Nord comme au Sud.

Mais l'aliment est aussi un déterminant de santé dans les pays émergents, dans lesquels on observe la transition sanitaire ou épidémiologique. Alors que le tribut payé aux maladies transmissibles est encore important, s'ajoutent les maladies non transmissibles - obésité, maladies cardio-vasculaires, cancers posant de redoutables problèmes de choix de priorités. Pour l'aliment comme pour les autres déterminants de santé, les stratégies globales imposées par une chaîne complexe en 5 ou 6 étapes, de la production à l'assiette, doivent s'accompagner de stratégies locales 
où la notion de bien-être et la dimension culturelle auront toute leur place. Enfin, ici aussi, avec l'aliment, la pluralité des acteurs est une caractéristique et au sein de tous ces acteurs, la femme joue un rôle essentiel, comme toujours en santé. En fait, l'aliment comme déterminant de santé est particulièrement complexe.

Comme le montrent les contributions présentées dans cet ouvrage, la question de l'alimentation, comme tous les déterminants de santé, nécessite l'élaboration de politiques publiques s'appuyant sur un équilibre entre l'État, puissance publique, et la société civile et ses organisations non gouvernementales. On ne rappellera jamais assez la nécessité du débat public, sous toutes ses formes.

Enfin concernant l'aliment en tant que déterminant de santé, un paramètre important est également celui de la rapidité de l'évolution de la situation globale et de la prise de conscience. Il y a dix ans, le problème ne se posait pas, on l'ignorait. Il y a à présent urgence et l'appel aux connaissances scientifiques et à la recherche est pressant et insistant.

La question et les réponses qui peuvent être données se situent donc bien à l'interface entre recherche et politique. Les chercheurs et les gestionnaires d'établissement ont une obligation de rendre la connaissance intelligible et accessible au politique afin que ce dernier soit en mesure de s'en emparer pour établir des priorités et faire des choix. Ce n'est pas là la moindre des responsabilités des chercheurs. 


\section{Benoît LESAFFRE}

Directeur général du Cirad ${ }^{1}$

Paris, 15 octobre 2003

Merci à Bertrand Hervieu, merci à l'Inra et au Palais de la Découverte d'avoir organisé cette journée pendant la fête de la science et en associant les établissements que sont l'IRD et le Cirad. Je n'ai pas pu assister à toute la journée et, si j’y avais participé, la richesse des débats comme le dernier auquel nous avons assisté m'empêcherait de tirer aisément des conclusions. Je ferai donc simplement deux remarques, d'abord en tant que citoyen, puis en tant qu'acteur de la recherche.

Ma première remarque est que l'idée de cette fête de la science ou de «la science en fête » est une excellente occasion de rapprocher science et société.

La question que nous avons abordée ici aujourd'hui apparaît relativement simple : le monde peut-il nourrir le monde ? En réalité, cette interrogation renvoie à un très grand nombre d'autres questions dont on voit qu'elles font débat dans notre assemblée, et de façon encore plus amplifiée dans la société. Cette question est d'ailleurs de même nature que celles qui se réfèrent au développement durable qui, lui aussi, est un sujet de grand débat dans la société. Je suis convaincu que, si l'on interrogeait 10 citoyens du Nord et 10 citoyens du Sud, ou des différents Sud, simplement pour définir le développement durable, nous aurions au moins 20 réponses différentes.

S'interroger sur la manière de construire le débat science et société sur le développement durable renvoie à la place donnée aux générations futures. Comment en effet nos enfants perçoivent-ils et s'approprient-ils ces idées complexes que nous abordons aujourd'hui ? Ce sont eux les acteurs de demain. Michel Griffon nous a opportunément rappelé que, en Afrique, multi- 
plier par cinq la production à l'horizon 2050 pour faire face aux besoins, ce sera l'œuvre des jeunes qui naissent aujourd'hui, car ce seront eux qui feront la production de demain. Nous devons ainsi nous interroger sur la façon dont nous donnons « envie de science " à la société et comment nous donnons "envie de société » à la science.

Ma deuxième remarque, comme acteur de la recherche, a trait au positionnement de nos organismes de recherche. Comment définir nos priorités, comment les hiérarchiser, et comment les mettre en ouvre ? Il ne s'agit pas de refaire la hiérarchie des priorités actuelles, mais il me semble indispensable de mieux articuler les niveaux planétaires et locaux dans nos recherches à propos des systèmes alimentaires en voie de mondialisation.

Cette question a été abordée ce matin. On ne peut pas se contenter de dire que « l'on pense globalement et on agit localement » car définir des actions efficaces suppose d'aborder les sujets dans leur complexité aux différentes échelles et de les articuler dans différentes perspectives. Comment par exemple évalue-t-on le changement des habitudes alimentaires et les effets des concentrations urbaines ? En dix ans les situations ont profondément changé partout dans le monde. Comment en tirer des conséquences dans nos domaines de recherche, par exemple pour une exploitation plus judicieuse de la diversité des ressources naturelles et génétiques ?

Le débat entre « artificialisation accrue de la production » et «production moins intensive » est une bonne illustration de ces enjeux. Il est bien plus complexe que ce que cette formulation semble le laisser entendre, puisque l'on doit à la fois augmenter la production et gérer les ressources naturelles de manière à assurer leur renouvellement. Dans ce cadre, l'utilisation des ressources génétiques, leur accès et leur mode de propriété sont stratégiques.

Se pose aussi la place de la demande de qualité dans la consommation des produits alimentaires. Cela renvoie à des questions concernant toute la chaîne de production et de transformation, sur la traçabilité et, peut-être avant tout, sur le comportement et les attentes des consommateurs du Nord et du Sud. Comment aborde-t-on concrètement ce type de sujet, qui interroge à la fois la société et la recherche? 
Aujourd'hui, la question du mode de travail de la recherche est devenue centrale. Gérard Azoulay a utilisé le mot très fort « d'apartheid scientifique » vécu par certains pays du Sud. On peut certes faire beaucoup de recherche dans nos pays industriels; elle est très utile. Mais s'il n'y a pas assez de chercheurs dans les pays en développement concernés par les questions alimentaires et de développement durable, cela ne servira pas à grand-chose. Je suis frappé, lors de mes nombreux contacts avec nos partenaires du Sud, de voir combien est immense la demande de construction de compétences scientifiques et techniques, tant pour agir au sein des pays que pour accompagner et éclairer les politiques publiques. Cela a été rappelé par Jean-François Girard. Ces compétences sont par ailleurs indispensables pour définir les choix internationaux de ces pays qui se sont par exemple exprimés à Cancun d'une manière assez nouvelle.

La présence effective du Cirad sur les terrains du Sud, avec les acteurs scientifiques de ces pays mais également avec l'ensemble des partenaires des systèmes d'innovation, est une de nos réponses essentielles pour aborder les questions de recherche les plus importantes, sur les terrains concrets, mais également pour participer en même temps à la construction des systèmes de recherche et de développement.

Pour terminer, je reviens sur nos « agendas ». Pour ne pas les construire seuls, nous faisons un travail inter-organismes comme vous le voyez ici au niveau national et européen, d'une part, et le Cirad lance une consultation de nos partenaires du Sud dès janvier 2004, d'autre part, afin que notre agenda de recherche ne soit pas simplement le nôtre, mais soit également celui de nos partenaires du Sud. 


\section{Bertrand Hervieu}

Président de l'Inra'

Paris, 15 octobre 2003

Je veux tout d'abord remercier très sincèrement et très chaleureusement Bernard Hubert, qui a bien voulu prendre en charge la préparation de ces échanges et l'organisation de ce colloque ; nous savons tous que ce genre d'évènement ne peut aboutir que si quelqu'un accepte de prendre les choses en main et les faire aboutir quoi qu'il en coûte.

Merci à lui de s'être mis au service de ce projet ; merci à tous les orateurs et à tous les intervenants - certains sont venus d'OutreAtlantique et d'Outre-Méditerranée - au nom de tous, je les remercie tout particulièrement. Nous voulions avoir des regards venus d'ailleurs afin de ne pas être entre seuls Européens ; cela a donc été possible et je m'en réjouis.

Sur le thème du colloque : "Le monde peut-il nourrir le monde ", bien des chercheurs se sont essayés à réfléchir depuis une vingtaine d'années et je suis heureux de voir à quel point nous avons avancé et à quel point nous sommes moins ignorants et plus lucides sur une question à la fois complexe et centrale.

Nous avons compris, au fil des années, au fil des débats, au fil de nos impasses, que pour avancer, il nous fallait changer d'échelle et surtout conjuguer des échelles et des approches diverses. Notre sujet va du plus local au plus global, du plus historique au plus instantané, et je dirais même du plus individuel au plus universel.

Pendant vingt ans, nous avons maintenu une vision convaincante pour nous Occidentaux du développement et de sa relation avec la science et avec le progrès. Nous avons longtemps parlé dans le domaine de l'agriculture et de l'alimentation de ce que nous appelions la chaîne du progrès. Ce débat rappelle aujourd'hui la nécessité radicale de changer de paradigme et de poser les bases 
d'une construction conceptuelle avant même d'évoquer la pratique. Nous avons à éclairer ce que représente le passage de la notion de développement à celle de développement durable et nous devons repenser les interfaces entre la recherche, la connaissance et l'innovation.

Je veux souligner la percée faite par la communauté scientifique grâce à l'IRD, qui le premier a intégré dans sa réflexion les questions de nutrition et de santé, permettant ainsi de sortir d'une approche trop limitée à la production agricole et aux politiques publiques de l'alimentation pour aborder la sécurité alimentaire mondiale.

De la même façon, la souveraineté alimentaire nationale et régionale a été à juste titre re-questionnée au cours de ce colloque. Je me demande pour ma part si la notion d'autonomie ne serait pas plus judicieuse que celle de souveraineté pour nommer le caractère spécifique de la question agricole et alimentaire dans les échanges. Nous ne pouvons plus formuler cette question ainsi que nous la formulions lors du colloque de 1987 de l'Association française de Sciences politiques, consacré aux politiques agricoles, qui avait rappelé à juste titre en quels termes l'agriculture était encore une " affaire d'État ».

La construction des blocs régionaux et les relations qu'entretiennent les autonomies, relatives au regard de l'agriculture, de l'alimentation, de la santé et de l'environnement au sein de ces blocs n'est pas encore pensée.

Enfin, à travers nos débats, les sujets liés à la biodiversité, à la connaissance des matériels génétiques et à leur appropriation ont été abordés avec rigueur. Il est vrai qu'il ne saurait y avoir de transfert de technologies sans appropriation de ces dernières par le plus grand nombre et donc sans culture scientifique " globalement » répandue.

Au terme de cette journée, nous mesurons que nous avons besoin de science pour comprendre et traiter ces questions, mais nous avons aussi compris que nous avons besoin d'une science partagée, d'une science comprise, ce qui suppose que nous abandonnions une vision descendante du transfert de technologies pour entrer dans une ère qui serait celle d'une production commune de la science, et, ce faisant, d'une production commune de la culture scientifique. 
En d'autres termes, la coopération scientifique ne saurait être autre chose qu'une volonté de produire en commun pour partager et diffuser le développement scientifique. Cela dépasse les frontières de nos organismes de recherche, cela dépasse également nos frontières nationales et nous fait percevoir une fois de plus que nous avons besoin de l'Europe dans la construction de cette science. En retour, nous pouvons penser que l'Europe a aussi besoin de cet élan pour être une Europe du $\mathrm{xxI}^{\mathrm{e}}$ siècle. 


\section{Table des mots -clés}

Les mots-clés renvoient à la première page des articles.

Accords de Lomé : 133

Accords Gatt/OMC : 93

Afrique : 93

Agriculture : 11

Agro-alimentaire : 11

Aide alimentaire : 111, 125

Aide d'urgence : 111

«Ajustement structurel »: 125

Appartenance : 25

Aquaculture : 11

«Banquet de l'humanité »: 125

Besoins nutritionnels : 43

Biodiversité : 133, 151

Biofortification : 77

Biosécurité : 11

Biotechnologies : 133

«Boîte verte » : 133

Bretton Woods (système monétaire) : 93

Commerce : 93

Communication : 77

Comportement alimentaire : 25, 43

Conflits : 111

Consensus de Washington : 93

Consommateur : 25

Consommation : 25,93

Convivium : 25

Corps humain : 43

Corps social : 25, 43

Crise alimentaire : 111 
Décolonisation : 93

Déliance : 57

Dépenses d'entretien : 43

Dette : 117

Développement : 133

Développement durable : 11, 65, 151

Double fardeau : 65

Droits : 11

Droits/règles du jeu : 57

État : 93

Europe : 111, 11

Exportations : 133

Faim : 65, 77

« Faim cachée »: 65

Fait alimentaire : 11

Famine : 93, 111

Femmes : 65

Filière : 11, 25

Flexibilité : 125

Foncier : 93

Globalisation : 125, 133

Goût : 25

Gouvernance : 57, 93

Groupe de Cairns : 125

Groupe des 21 : 125

Identité culturelle : 25

Importations : 133

Inégalités : 133

Insécurité : 111

Institutions : 77

International : 77

Jeûne : 43 
Kilocalorie, kcal : 43

Labellisation : 11, 25

Lipides : 43

Maladie cardio-vasculaire : 43

« Maladie non transmissible liée à l'alimentation... » : 65

Malnutrition : 111, 133

Marché : 93, 125, 133

Micro-finance : 77

Modèles : 87

Mondialisation : 65, 93, 125

Mortalité/longévité : 43

Négociations : 125

Nord-Sud : 87, 93, 117, 125, 148

Normes, normalisation : 93

Nutrition : $77,65,43$

Obésité : 43

OGM : 93

PAC, politique agricole commune (UE) : 125

Pauvreté : 65, 111

Paysannerie : 93

Pêche : 11

Pénurie : 111

Physiologie de la nutrition : 43

Politiques (agricoles, alimentaires, ...) : 65, 77, 87, 93, 117

Politiques publiques : 146

Production : 11

Qualification : 11, 25

Qualité des aliments : 25

«Qualité totale »: 57 
Recherche : 125, 11, 77, 133, 146, 148, 151

Ressources naturelles : 77

Ressources naturelles renouvelables : 11, 77

Ressources renouvelables : 11

Révolution verte : 93

Risques naturels : 111

Round du développement : 125

Rural : 11

Santé : 147

Santé publique : 65,77

Savoir-faire : 25

Sécurisation : 11

Sécurité : 11, 77, 133

Sécurité alimentaire : 11

Signes de qualité : 11, 25

Solidarité : 11

Sommet mondial de l'alimentation : 11, 111, 133

Symbolique des aliments : 25, 43

« Syndrome hollandais »: 93

«Systèmes agroalimentaires localisés »: 25

Systèmes alimentaires : 11

Terroir : 11, 25, 93

« Tout sauf les armes »: 133

Transfert : 151

«Transition nutritionnelle »:65, 77, 87

« Triple fardeau »: 87

Vulgarisation : 77 


\section{Liste des sigles}

ACC : Administrative Committee on Coordination (de l'ONU)

ACC/SCN : ACC/SubCommittee on Nutrition de l'ACC

ACP (groupe) : États d'Afrique, des Caraïbes et du Pacifique

Adpic: Aspects des droits de propriété intellectuelle liés au commerce

AIP : Action incitative programmée

Alisa : Alimentation, savoir-faire et innovations agro-alimentaires en Afrique de l'Ouest

AOC : Appellation d'origine contrôlée

ATP : Adénosine triphosphate

BM : Banque mondiale (World Bank, en anglais)

CFA (franc CFA) : Franc de la Communauté financière d'Afrique CGIAR : Consultative Group on International Agricultural Research Ciat : Centre international sur l'agriculture tropicale

CIN : Conférence internationale sur la nutrition

Cirad : Centre international de recherche en coopération pour le développement

Cirad-SAR : Systèmes agro-alimentaires et ruraux (département du Cirad)

CNRS : Centre national de la recherche scientifique

FAO : Food and Agriculture Organization (en français, OAA)

FMI : Fonds monétaire international

Gatt : Accord général sur les tarifs douaniers et le commerce (General Agreement on Tariffs and Trade) 
GIS : Groupement d'intérêt scientifique

Ifpri : International Food Policy Research Institute

IGP : Indication géographique protégée

IMC : Indice de masse corporelle

Inra : Institut national de la recherche agronomique

IRD : Institut de recherche pour le développement (ex-Orstom)

MNTA : Maladies non transmissibles liées à l'alimentation

MPE : Mortalité protéino-énergétique

MSH : Maison des Sciences de l'Homme

NHSA (Inra) : Nutrition humaine et sécurité des aliments (une des directions scientifiques de l'Inra)

OCDE : Organisation de coopération et de développement économiques

OGM : Organisme génétiquement modifié

OMC : Organisation mondiale du commerce

OMS : Organisation mondiale de la Santé

Orstom : cf. IRD

PED : Pays en développement

PFRDV : Pays à faible revenu et à déficit vivrier

PMA : Pays les moins avancés

Pnud : Programme des Nations unies pour le développement

PPTE (initiative) : Pays pauvres très endettés

PVD : Pays en voie de développement

RDC : République démocratique du Congo

SAD (Inra-SAD) : Sciences pour l'action et le développement (département de l'Inra)

SAM : Sécurité alimentaire mondiale

Smiar : Système mondial d'information et d'alerte rapide (FAO)

Syal : Système agro-alimentaire localisé

UE : Union européenne

UMR : Unité mixte de recherche 
Unicef : Fonds des Nations unies pour l'enfance

USA : United States of America

Usaid : US Agency for International Development

WHO : World Health Organization (OMS, en français)

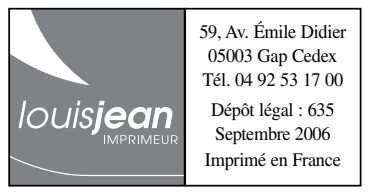


Deux milliards de personnes dans le monde souffrent aujourd'hui de carences alimentaires graves, dont les trois quarts sont des paysans, et plus de 800 millions d'individus sont encore sous-alimentés. Pourtant, l'agriculture mondiale n'a jamais autant produit et la production moyenne suffirait à couvrir les besoins de la planète. Ce contexte, paradoxal et préoccupant, est de plus complexe car les situations de malnutrition ne se superposent plus au simple clivage entre pays riches et pays pauvres.

Pour rendre compte du fait alimentaire dans sa dimension globale et dans toute sa complexité, cet ouvrage collectif ouvre la réflexion à divers champs disciplinaires. Économistes, sociologues, anthropologues, géographes, nutritionnistes et écologues y décrivent l'alimentation comme un fait structurant des sociétés que les crises alimentaires contribuent à déstabiliser, tant au Sud qu'au Nord. Les textes explorent des voies peu empruntées et rarement rassemblées dans un même ouvrage. La mise en œuvre d'une véritable politique alimentaire y apparaît comme un des volets indispensables à la cohérence des politiques agricoles et agro-alimentaires, afin de satisfaire les besoins des quelque neuf milliards d'hommes qui pourraient peupler notre planète en 2050.

Bernard HUBERT est écologue de formation. Après dix années à l'Orstom (devenu IRD) en Afrique de l'Ouest, il a rejoint I'Inra où il a été chef du département de recherche sur les Systèmes agraires et le développement de 1994 à 2003. Chargé des questions de développement durable à I'Inra, il est actuellement directeur scientifique du secteur « Société, Économie, Décision ». Il est également directeur d'études à l'EHESS.

Olivier CLÉMENT est agronome et ingénieur du génie rural, des eaux et des forêts. Il a réalisé la majeure partie de sa carrière au sein d'organismes de recherche sur des thématiques liées aux systèmes aquatiques. Il participe actuellement à la réflexion menée à l'Inra sur le thème du développement durable.

\section{IRD}

213, rue La Fayette 75480 Paris cedex 10 editions@paris.ird.fr www.editions.ird.fr

\section{Diffusion}

IRD

32, av. Henri-Varagnat

93143 Bondy cedex

fax : 0148027909

diffusion@bondy.ird.fr
Quae

Editions Cemagref, Cirad, Ifremer, Inra c/o Inra, RD 10 F 78026 Versailles www.quae.com

\section{Diffusion}

Quæ c/o Inra, RD 10 F 78026 Versailles fax : 0130833449 serviceclients@quae.fr
$17 €$

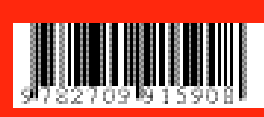

ISBN IRD 2-7099-1590-1

ISBN Quæ 2-7592-0008-6 